Florida International University FIU Digital Commons

\title{
Natural organic matter and colloid-facilitated arsenic transport and transformation in porous soil media
}

Zhangrong Chen

Florida International University

DOI: $10.25148 /$ etd.FI14060185

Follow this and additional works at: https://digitalcommons.fiu.edu/etd

Part of the Chemistry Commons

\section{Recommended Citation}

Chen, Zhangrong, "Natural organic matter and colloid-facilitated arsenic transport and transformation in porous soil media" (2006). FIU Electronic Theses and Dissertations. 2153.

https://digitalcommons.fiu.edu/etd/2153 
Miami, Florida

NATURAL ORGANIC MATTER AND COLLOID-FACILITATED ARSENIC TRANSPORT AND TRANSFORMATION IN POROUS SOIL MEDIA

A dissertation submitted in partial fulfillment of the requirements for the degree of DOCTOR OF PHILOSOPHY

in

CHEMISTRY

by

Zhangrong Chen 
To: Interim Dean Mark Szuchman

College of Arts and Sciences

This dissertation, written by Zhangrong Chen, and entitled Natural Organic Matter and Colloid-Facilitated Arsenic Transport and Transformation in Porous Soil Media, having been approved in respect to style and intellectual content, is referred to you for judgment.

We have read this dissertation and recommend that it be approved.

Helena Solo-Gabriele

Kevin O'Shea

Krish Jayachandran

Piero Gardinali

Yong Cai, Major Professor

Date of Defense: July 14, 2006

The dissertation of Zhangrong Chen is approved.

Interim Dean Mark Szuchman

College of Arts and Sciences

Interim Dean Stephan L. Mintz

University Graduate School

Florida International University, 2006 


\section{DEDICATION}

I dedicate this dissertation to all my mentors, my parents and my husband Haifeng Wang. Without their invaluable knowledge, unconditional love and support in my life, this work would not have been completed. 


\section{ACKNOWLEDGMENTS}

I would like to express appreciation from the bottom of my heart to my committee members: Dr. Solo-Gabriele Helena, Dr. Krish Jayachandran, Dr. Piero Gardinali, and Dr. Kevin O'Shea for their helpful comments and patience.

Special gratitude must be given to my major professor, Dr. Yong Cai. Without his insightful advice, unceasing encouragement and help in many ways, this project could not have been accomplished.

I am also thankful to Mr. George Meichel from Southeast Environmental Research Center (SERC), Dr. Alberto J. Sabucedo, Mr. Myron Georgiadis from The Advanced Mass Spectrometry Facility (AMSF) and Dr. Lena Q. Ma from University of Florida for their help in instrumentation and sample analysis.

I thank all the past and present members of our lab group for their support and cooperation, especially to Dr. Guangliang Liu, Yuxiang Mao, Sheena Powell Szuri, Damaris Hernandez, Lucy Yehiayan and Carlos Zuniga.

Finally, I wish to thank the Department of Chemistry and Biochemistry at Florida International University for providing Graduate Assistantship and NIEHS, NIH for research funding. 
ABSTRACT OF THE DISSERTATION

NATURAL ORGANIC MATTER AND COLLOID-FACILITATED ARSENIC

TRANSPORT AND TRANSFORMATION IN POROUS SOIL MEDIA

by

Zhangrong Chen

Florida International University, 2006

Miami, Florida

Professor Yong Cai, Major Professor

Prediction of arsenic transport and transformation in soil environment requires understanding the transport mechanisms and proper estimation of arsenic partitioning among all three phases in soil/aquifer systems: mobile colloids, mobile soil solution, and immobile soil solids. The primary purpose of this research is to study natural dissolved organic matter (DOM)/colloid-facilitated transport of arsenic and understand the role of soil derived carriers in the transport and transformation of both inorganic and organoarsenicals in soils.

DOM/colloid facilitated arsenic transport and transformation in porous soil media were investigated using a set of experimental approaches including batch experiment, equilibrium membrane dialysis experiment and column experiment. Soil batch experiment was applied to investigate arsenic adsorption on a variety of soils with different characteristics; Equilibrium membrane dialysis was employed to determine the 'free' and 'colloid-bound/complexed' arsenic in water extracts of chosen soils; Column experiments were also set up in the laboratory to simulate arsenic transport and 
transformation through golf course soils in the presence and absence of soil-derived dissolved substances.

The experimental results revealed that organic matter amendments effectively reduced soil arsenic adsorption. The majority of arsenic present in the soil extracts was associated with small substances of molecular weight (MW) between 500 and 3,500 Da. Only a small fraction of arsenic was associated with higher MW substances (MW > 3,500 Da), which was operationally defined as colloidal part in this study. The association of arsenic and DOM in the soil extracts strongly affected arsenic bioavailability, arsenic transport and transformation in soils. The results of column experiments revealed arsenic complicated behavior with various processes occurring in soils studied, including: soil arsenic adsorption, facilitated arsenic transportation by dissolved substances presented in soil extracts and microorganisms involved arsenic species transformation.

Soil organic matter amendments effectively reduce soil arsenic adsorption capability either by scavenging soil arsenic adsorption sites or by interactions between arsenic species and dissolved organic chemicals in soil solution. Close attention must be paid for facilitated arsenic transport by dissolved substances presented in soil solution and microorganisms involved arsenic species transformation in arsenic-contaminated soils. 


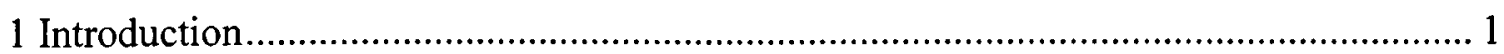

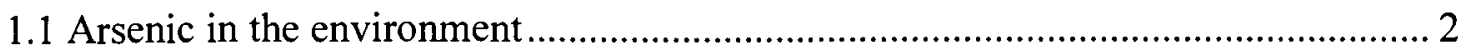

1.2 Arsenic species and species transformation........................................................ 7

1.3 Transport and mobility of arsenic in the soil environment ................................. 17

1.4 Problem statement, hypotheses and objectives of the study …............................. 27

2 Partitioning of Arsenate and MMA in Dissolved, Colloidal, and Soil phases: the Role

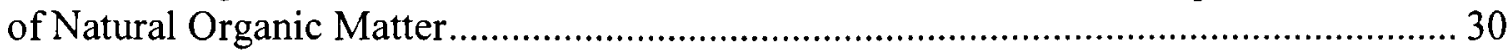

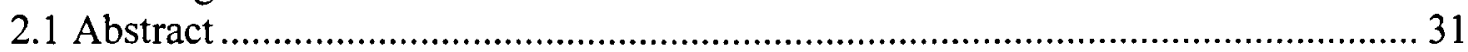

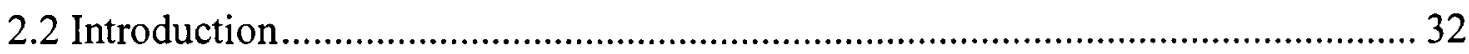

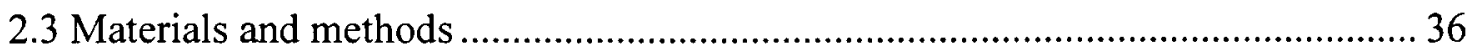

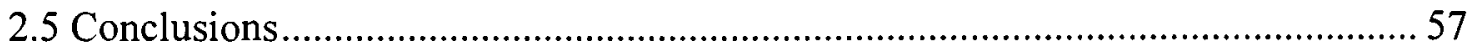

3 Interactions of Arsenic and the Dissolved Substances Derived from Turf Soils........... 58

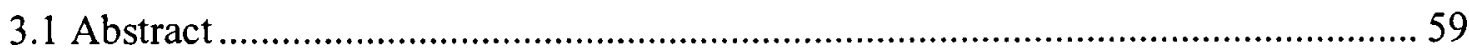

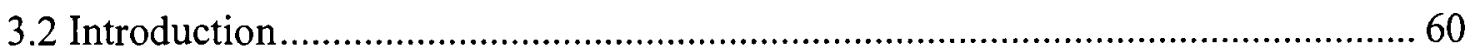

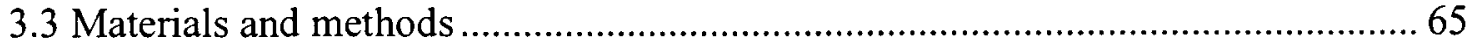

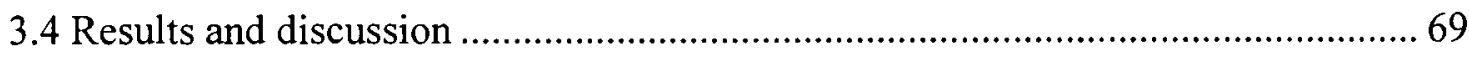

4 Assessment of Arsenic Transport and Speciation in Golf Course Soils Using Column

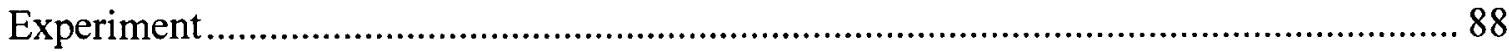

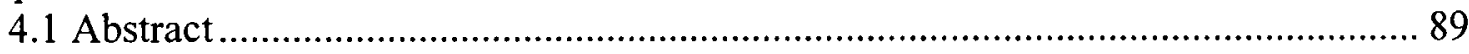

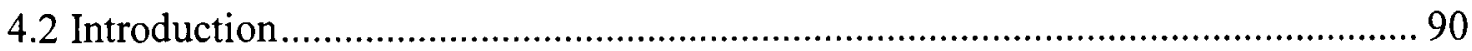

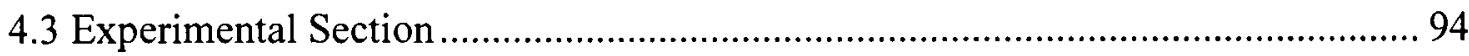

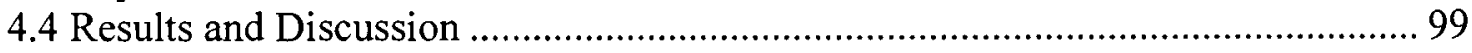

5 General Summary and Future Research Directions.............................................. 119

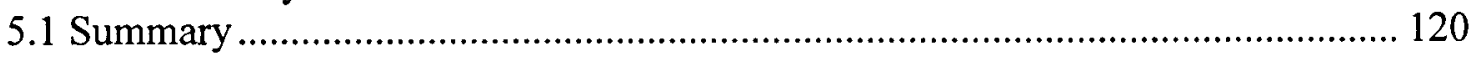

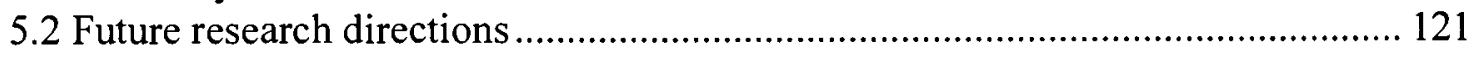

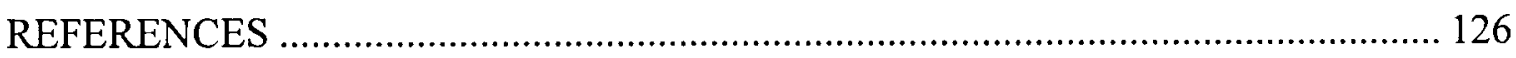

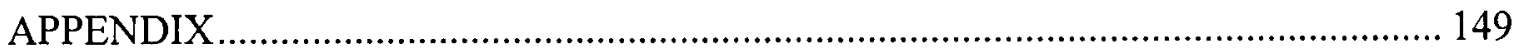

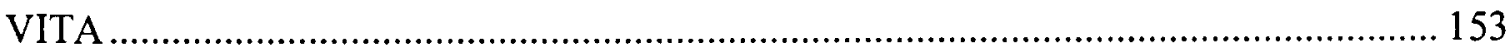




\section{LIST OF TABLES}

TABLE

Table $1.1 \mathrm{pKa}$ values for the various arsenic species 8

Table 1.2 Some common arsenic compounds found in environmental and biological samples.

Table 1.3 Arsine generation reactions and the boiling points of the corresponding products

Table 1.4 Important functional groups present in humic substances. 26

Table 2.1 Selected physical and chemical properties of the studied soils 44

Table 2.2 The isotherm adsorption parameters predicted from the Langmuir equation... 53

Table 2.3 Colloidal associated arsenic and total arsenic recovery from dialysis experiments.

Table $3.1 \mathrm{pH}$ and concentrations of some major and minor elements in soil extracts before equilibrium dialysis

Table 3.2 Estimated arsenic fraction associated with DOM and the apparent distribution coefficients (Kd) of arsenic between dissolved (<500 Da) and DOM associated $(500-3,500 \mathrm{Da})$ in different soil extracts after equilibrium dialysis

Table 3.3 Some apparent distribution coefficient $(\mathrm{Kd})$ of arsenate on different soil materials

Table 3.4 Eh $-\mathrm{pH}$ data before and after membrane dialysis

Table 4.1 Characteristics of the soils used 102 


\section{LIST OF FIGURES}

FIGURE

PAGE

Figure 1.1 Scheme of approach showing speciation of arsenic in environmental and

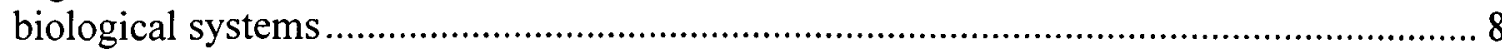
8

Figure 1.2 Eh-pH diagram for aqueous As species in the system $\mathrm{As}-\mathrm{O}_{2}-\mathrm{H}_{2} \mathrm{O}$ at $25^{\circ} \mathrm{C}$ and 1 bar total pressure

Figure 1.3 Microbial transformation of arsenic species (Mukhopadhyay et al., 2002) .... 11

Figure 1.4 Schematic diagram showing arsenic adsorption mechanism on metal oxide (Hematite as a example) in view of coordination chemistry

Figure 1.5 Diagram showing colloid facilitated transport

Figure 2.1 Arsenic species adsorption kinetic study: adsorption behavior (decreased arsenic concentration in solution) as a function of time) for nine types of soils. (a) golf-course soils spiked with $100 \mu \mathrm{g} / \mathrm{L}$ arsenate in solution, (b) golf-course soils spiked with $100 \mu \mathrm{g} / \mathrm{L}$ MMA in solution, (c) soils from other sources spiked $100 \mu \mathrm{g} / \mathrm{L}$ arsenate in solution, (d) soils from other sources spiked with $100 \mu \mathrm{g} / \mathrm{L} \mathrm{MMA}$ in solution.

Figure 2.2 Adsorption isotherms of arsenate $\left(\mathrm{As}^{\mathrm{v}}\right)$ by nine soil substrates and their Langmuir equation fitting lines (solid lines).

Figure 2.3 Adsorption isotherms of MMA by five soil substrates and their Langmuir equation fitting lines (solid lines)

Figure 2.4 Arsenic concentrations inside and outside the dialysis bags ( $3500 \mathrm{MWCO}$ ) for nine soil extracts: a) and c) Arsenate; b) and d) MMA after reaching dialysis equilibrium

Figure 3.1 Experimental setup of the membrane equilibrium dialysis. The dialysis bag filled with soil extract $(15 \mathrm{ml})$ was immersed in a solution spiked with $50 \mu \mathrm{g} / 1$ arsenate before dialysis (a) and after dialysis (b) equilibrium...

Figure 3.2 Dialysis equilibrium time tests for $500 \mathrm{Da}$ (a) and $3500 \mathrm{Da}$ (b) membranes.. 72

Figure 3.3 Arsenic concentrations inside and outside $500 \mathrm{Da}(\mathrm{a})$ and $3500 \mathrm{Da}(\mathrm{b})$ dialysis membranes analyzed by ICP-MS after reaching dialysis equilibrium for different soil extracts. 
Figure 3.4 Concentrations of $\mathrm{Fe}, \mathrm{Al}$, and $\mathrm{Ca}$ inside and outside 500 and $3500 \mathrm{Da}$ membranes after reaching dialysis equilibrium for different soil extracts

Figure 3.5 TOC concentrations inside and outside $500 \mathrm{Da}$ (a) and $3500 \mathrm{Da}$ (b) dialysis membranes after reaching equilibrium 78

Figure 3.6 Arsenic concentrations with speciation information inside and outside 500 $\mathrm{Da}(\mathrm{a})$ and $3500 \mathrm{Da}$ (b) dialysis membranes analyzed by HPLC-HG-AFS after reaching dialysis equilibrium for different soil extracts 84

Figure 3.7 Arsenic speciation for dialysis experiment using NCP, naturally coated sand plus peat $(9: 1 \mathrm{v} / \mathrm{v})$, with the presence of NaN3. AsIII was detected neither inside nor outside solutions 86

Figure 4.1 Breakthrough curves for total arsenic and tracer in UC and NC columns .... 100 Figure 4.2 Effluent $\mathrm{Fe}, \mathrm{Al}$ analysis for $\mathrm{UC}$ and $\mathrm{NC}$ columns ................................... 108

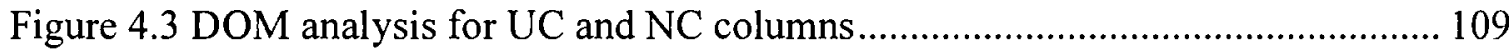

Figure 4.4 Effluent arsenic speciation analysis for UC and NC columns .................... 112

Figure 4.5 Effluent pH for UC and NC columns .................................................... 113

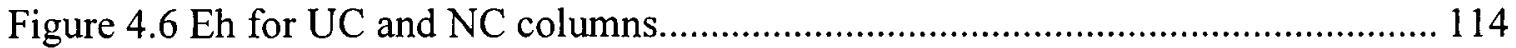

Figure 5.1 Scheme of an approach showing arsenic biogeochemical cycle in soil systems 


\section{ABBREVIATIONS}

$A A S:$ atomic absorption spectrometry

As: arsenic

$A s^{V}$ : arsenate

$A s^{I I I}$ : arsenite

$A F S$ : atomic fluorescence spectrometry

$A R W$ : artificial rain water

CCA: chromated copper arsenate

$C E C$ : cation exchange capacity

$D M A$ : dimethylarsonic acid

DOM: dissolved organic matter

Eh: Redox potential

$H A$ : humic acid

HPLC: high performance liquid chromatography

$H S$ : humic substances

$I C P / M S$ : inductively coupled plasma/mass spectrometry

$M M A$ : monomethylarsinic acid

NOM: natural organic matter

TOC: total organic carbon 
CHAPTER 1

Introduction 


\subsection{Arsenic in the environment}

Arsenic sources and environmental distribution Arsenic (As), a metalloid occurs naturally, being the 20th most abundant element in the earth's crust $(2.5 \mathrm{mg} / \mathrm{kg}), 14$ th in the seawater, and 33rd in the human body and is a component of more than 245 minerals (Mandal and Suzuki, 2002). In natural environment, arsenic is rarely encountered as a free element, more frequently it is found in high concentration in ores containing sulfide, along with copper, nickel, lead, cobalt, or other metals. The As-bearing sulfides and sulfosalts oxidize readily; under surface conditions, oxidation proceeds to arsenic trioxide and to the arsenate stage. In rock, rather uniform distribution of As among the major constituent minerals, except for slight enrichment in the sulfide minerals of igneous rocks; notably enriched As present in sedimentary rocks such as shale, clays, phosphate rocks, and sedimentary iron and manganese oxides. Arsenic is present in all types of soils, and the geologic history of a particular soil determines its As content. The natural As content in virgin soils varies from 0.1 to $40 \mathrm{mg} / \mathrm{kg}$ (Bowen, 1979). Arsenic is found at low concentration in natural water. The concentration of As in unpolluted fresh waters typically ranges from $1-10 \mu \mathrm{g} / \mathrm{L}$, rising to $100-5000 \mu \mathrm{g} / \mathrm{L}$ in areas of sulfide mineralization and mining (Appleton et al., 1996). However, naturally occurring As in groundwater of sedimentary aquifers has recently emerged as a global problem. In the sedimentary aquifers of the Bengal Delta Plain (BDP) in Bangladesh and neighboring West Bengal, India, As concentration range from less than the drinking water standard prescribed by the Bureau of Indian Standards (BIS) $\left(50 \mu \mathrm{g} \mathrm{L}^{-1}\right)$ to as much as $14,000 \mu \mathrm{g}$ $\mathrm{L}^{-1}$ (Karim et al., 1997). Arsenic is mobilized in groundwater by natural processes, which is an issue of major environmental health concern (Khan et al., 2003; Stuben et al., 2003; 
Watanabe et al., 2001; Yokota et al., 2002). The source of As in groundwater is geological in the Ganges basin of West Bengal, India and Bangladesh. Arsenic-rich pyrite has been identified in the sediment samples and both the pyrite oxidation and iron oxyhydroxide-reduction hypotheses are mainly responsible for As poisoning in the Ganges delta of West Bengal and Bangladesh (Chakraborti et al., 2001; Chowdhury et al., 2003; Das et al., 1996). Although problems in the USA are not as severe, moderate to > $50 \mu \mathrm{g} \mathrm{L}^{-1}$ naturally occurring concentrations of As are commonly found in groundwater throughout the western USA (Welch et al., 2000). The high content of As in hot springs is notable; extremely high As concentrations have been reported in some groundwater from areas of thermal activity (Kocar Benjamin et al., 2004; Langner et al., 2001; Yokoyama et al., 1993).

Mining, industrial activities, and to a lesser extent, agricultural practices, are common anthropogenic sources of As compounds. Arsenic compounds are mainly used in agriculture and forestry as pesticides, herbicides, silvicides and wood preservatives; smaller amounts are used in the glass and ceramics industries and as feed additives (Mandal and Suzuki, 2002).

Elevated As levels in surface and groundwater systems can be derived from both anthropogenic and natural sources. Although anthropogenic As contamination from mining operations, fossil/fuel processing, and pesticides/herbicides applications is typically local in extent, contamination can reach levels thousands of times of that from natural sources (Smedley and Kinniburgh, 2002). About $75 \%$ of the total As consumption for more than 100 years in the United States was arsenical pesticides used in agriculture (Onken and Hossner, 1996). Monosodium methanearsonate (MSMA) and disodium 
methanearsonate (DSMA) are frequently used as herbicides for the post-emergent control of grassy weeds in several corps, lawns turf (Monks et al., 1999; Wiese and Hudspeth, 1968). MSMA is one of the three most-used cotton herbicides in U. S. A (Thurman et al., 1998). Arsenical pesticides are applied for turf maintenance on golf courses throughout Florida. Typical MSMA application rates range from 0.05 to $0.22 \mathrm{~g} / \mathrm{m}^{2}$ at golf courses in southeastern Florida (Di Carlo and Fuentes, 2000). After MSMA application, a variety of chemical processes occurring in the heterogeneous soil environment produce several arsenic species (Feng et al., 2005). An elevated arsenic level has been found in the nearby environment and is becoming a serious concern.

Arsenic contamination in water and related health problem Contamination of groundwater with As is a global environmental problem because As can enter groundwater systems from weathering and leaching of As minerals in rocks and soils. The As standard for drinking water established by the World Health Organization (WHO) in 1963 was $50 \mu \mathrm{g} \mathrm{L}^{-1}$, while the guideline set in 1993 was $10 \mu \mathrm{g} \mathrm{L}^{-1}$. In the USA, the maximum contaminant level (MCL) of As in drinking water was $50 \mu \mathrm{g} \mathrm{L}^{-1}$, a level established in 1942 by the U.S. Public Health Service (Code of federal regulation, 1992). Based on the accumulating scientific information and data on the health effects of As, in 2001 EPA (Environmental Protection Agency) issued a new MCL As level for drinking water (EPA, 2001). The new As MCL effective date was February 22, 2002 and water systems must meet this standard by January 2006.

Arsenic contamination in drinking water has created serious health problem in Taiwan, Inner Mongolia of china, Bangladesh, and India; the groundwater As contamination has also been found in other countries, including Canada, Mexico, 
Argentina, Finland, and the U.S.A (Wang and Wai, 2004). The scale of the problem in terms of population exposed to high As concentrations is greatest in the Bengal Basin with more than 40 million people drinking water containing "excessive" As.

Of the various sources of As in the environment, drinking water probably poses the greatest threat to human health. Toxicity and chemical behavior of As compounds are largely influenced by the form and speciation of As. Arsenite ( $\left.\mathrm{As}{ }^{\mathrm{III}}\right)$ is more mobile and more toxic than arsenate $\left(\mathrm{As}^{\mathrm{v}}\right)$. Gaseous arsines are most toxic whereas arsenobetaine and arsenocholine (mainly found in marine organisms) are nontoxic. As a rule, inorganic arsenicals are more toxic than organic arsenicals and the trivalent oxidation state is more toxic than the pentavalent oxidation state (Adriano, 1986; Fowler, 1977). While it is generally accepted that methylation of inorganic As is the principal detoxification pathway in human body, recent studies indicated that $\mathrm{MMA}^{\mathrm{III}}$ and $\mathrm{DMA}^{\mathrm{III}}$ are more cytotoxic, more genotoxic, and more potent inhibitors of the activities of some enzymes than $\mathrm{As}^{\mathrm{III}}$ (Lin et al., 1999; Petrick et al., 2001; Styblo et al., 2000).

In water, arsenic is usually found in the form of arsenate $\mathrm{As}^{\mathrm{V}}$ or arsenite $\mathrm{As}{ }^{\mathrm{III}}$. The most common toxic mode of As is the inactivation of enzyme systems. Arsenic compounds are known to inhibit more than 200 enzymes in humans. The affinity of arsenic for sulfur accounts for the toxicity of arsenite (As ${ }^{\mathrm{III}}$ ) compounds through its interactions with protein thiols in human body. Trivalent As is extremely poisonous because it can bind strongly to sulfur groups in amino acids, such as methionine, cysteine and cystine. Proteins with sulfur containing groups can react with $\mathrm{As}{ }^{\mathrm{III}}$ to form products that will cause biological body malfunction. Arsenate $\mathrm{As}^{\mathrm{V}}$ and phosphate are chemically similar, enzyme normally acting on substrate R-O- $\mathrm{PO}_{3} \mathrm{H}_{2}$ can also act on R-O- $\mathrm{AsO}_{3} \mathrm{H}_{2}$, 
and then $\mathrm{As}^{\mathrm{V}}$ can be disruptive by competing with phosphate. For example, arsenate can uncouple oxidative phosphorylation, generate biological futile cycles (Dixon, 1997). According to Lin et al. (Lin et al., 1999) MMA ${ }^{\text {III }}$ is over 100 times more potent than As ${ }^{\text {III }}$ as an in vitro inhibitor of thioredoxin reductase. So, formation of $\mathrm{MMA}^{\mathrm{III}}$ appears to represent toxification of both $\mathrm{As}^{\mathrm{V}}$ and $\mathrm{As} \mathrm{s}^{\mathrm{III}}$. Also, in vitro studies have shown that $\mathrm{MMA}^{\mathrm{III}}$ and DMA ${ }^{\mathrm{III}}$, like As ${ }^{\mathrm{III}}$, can form GSH complexes, and that these are at least as toxic as $\mathrm{As}^{\mathrm{III}}$. Another in vitro study (Styblo et al., 2000) showed that MMA ${ }^{\mathrm{III}}$ was more cytotoxic to human cells (hepatocytes, epidermal keratinocytes, and bronchial epithelial cells), compared to $\mathrm{As}^{\mathrm{III}}$ and $\mathrm{As}^{\mathrm{V}}$. The authors concluded that high methylation capacity did not protect these cells from the acute toxicity of trivalent arsenicals. A research study assessing the induction of DNA damage by $\left(\mathrm{MMA}^{\mathrm{III}}\right.$ and $\left.\mathrm{DMA}^{\mathrm{III}}\right)$ in human peripheral lymphocytes found that $\mathrm{MMA}^{\mathrm{III}}$ and $\mathrm{DMA}^{\mathrm{III}}$ were 77 and 386 times more potent than $A s^{I I I}$, respectively, they were considered to be direct-acting forms of As that were genotoxic (Petrick et al., 2001).

Human body As source can be from groundwater, air and food chain but major As source for human body is drinking water. Arsenic, being a normal component of human body is transported by the blood to different organs in the body. It causes a variety of adverse health effects to humans after acute and chronic exposures: (1) Dermal changes (pigmentation, hyperkeratoses, and ulceration); (2) Respiratory, pulmonary, cardiovascular, gastrointestinal, hematological, hepatic, renal, dermal, neurological, developmental, reproductive, immunologic, genotoxic, mutagenetic, and carcinogenic effects (Abernathy et al., 1999; Garcia-Vargas and Cebrian, 1996). Studies are needed for further improving arsenic risk assessment at low exposure levels. 


\subsection{Arsenic species and species transformation}

The importance of elemental speciation derives directly from the fact that the chemical form of an element governs many of its features. The determination of the identity and quantity of elements remains important. However, measurement of total metal content alone provides insufficient information for many applications, and in some cases leads to erroneous conclusions. For example: the total As concentration in many types of seafood is dominated by arsenobetaine, which is not toxic. In contrast, inorganic As is highly toxic, and to a degree that depends on its oxidation state. Generally, it can be stated that the chemical, physical, and morphological state of elements in a sample has a direct influence on their toxicity, bioavailability, bioactivity, transport, uptake, biogeological distribution, and environmental impact.

Arsenic constitutes an interesting case for speciation studies. Speciation analysis always includes two steps: separation and detection. Not only should the separation techniques be considered closely in order to maintain the integrity of the species, but also the detection techniques should allow all species detectable. For example, in aquatic environments, As can exist in soluble forms, adsorbed onto solid particles, complexed by humic colloids, etc., the coexistence and transformation of various As species in the water-sediment/soil interface being feasible (Feng et al., 2005; Zobrist et al., 2000). It is always based on sample information and interest of research to choose suitable speciation analysis methods (Francesconi Kevin and Kuehnelt, 2004), speciation can based both physical and chemical interests (Fig 1.1). 


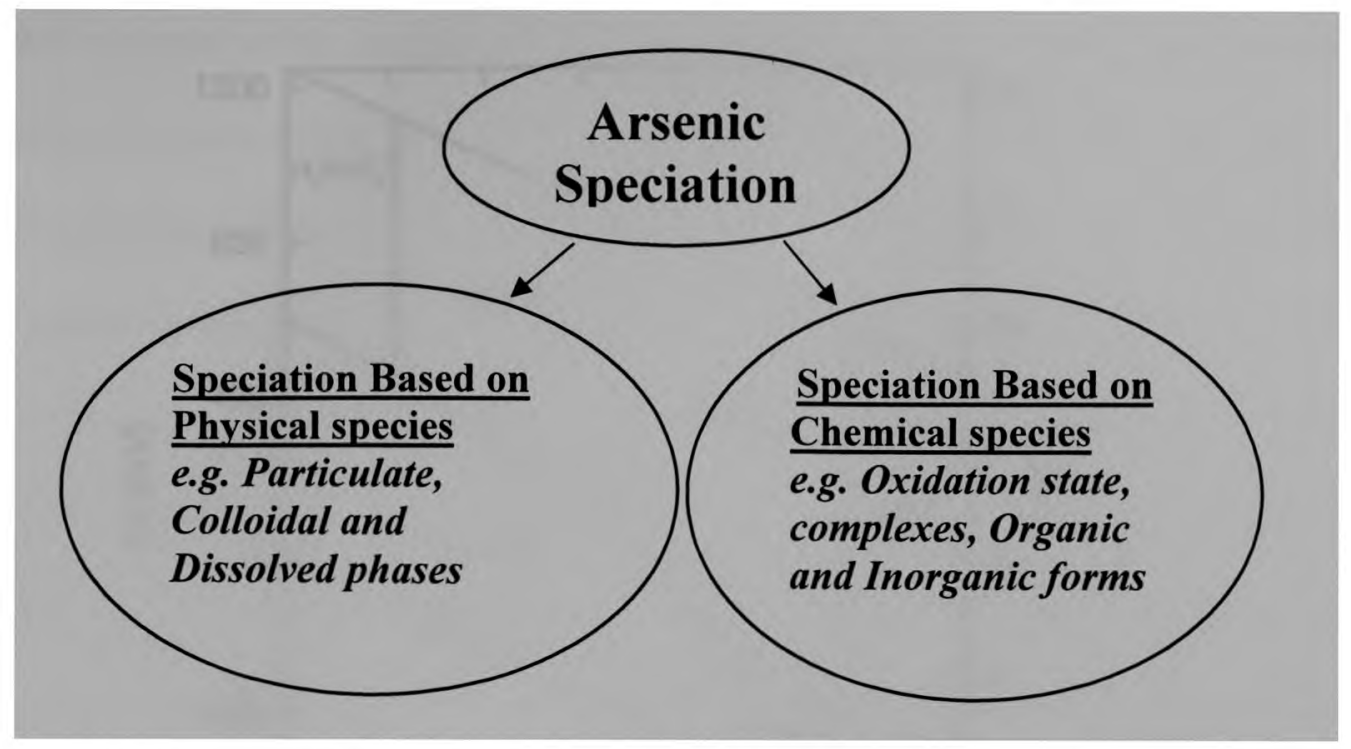

Figure 1.1 Scheme of approach showing speciation of arsenic in environmental and biological systems

Redox potential (Eh) and $\mathrm{pH}$ are two of the most important factors controlling As speciation. Theoretically, under oxidizing conditions, $\mathrm{H}_{2} \mathrm{AsO}_{4}{ }^{-}$is dominant at low $\mathrm{pH}(\mathrm{pH}$ $<6.9$ ), while at higher $\mathrm{pH}, \mathrm{HAsO}_{4}{ }^{2-}$ becomes dominant. Under reducing conditions at $\mathrm{pH}$ $<9.2$, the uncharged arsenite species $\mathrm{H}_{3} \mathrm{AsO}_{3}{ }^{0}$ predominates (Brookins, 1988) (Fig 1.2.). Some $\mathrm{pKa}$ values of the various species of arsenic are summarized in Table 1.1(Lafferty and Loeppert, 2005).

Table 1.1 pKa values for the various arsenic species

\begin{tabular}{cccc}
\hline As species & $\mathbf{p K}_{\mathbf{a} 1}$ & $\mathbf{p K} \mathbf{a} 2$ & $\mathbf{p K}_{\mathbf{a} 3}$ \\
\hline $\mathrm{H}_{3} \mathrm{AsO}_{4}\left(25^{\circ} \mathrm{C}\right)$ & 2.20 & 6.97 & 11.53 \\
$\mathrm{H}_{2} \mathrm{AsO}_{3}\left(\mathrm{CH}_{3}\right)\left(26^{\circ} \mathrm{C}\right)$ & 4.19 & 8.77 & - \\
$\mathrm{HAsO}_{2}\left(\mathrm{CH}_{3}\right)_{2}\left(26^{\circ} \mathrm{C}\right)$ & 6.14 & - & - \\
$\mathrm{H}_{3} \mathrm{AsO}_{3}\left(25^{\circ} \mathrm{C}\right)$ & 9.22 & 12.13 & 13.4 \\
\hline
\end{tabular}




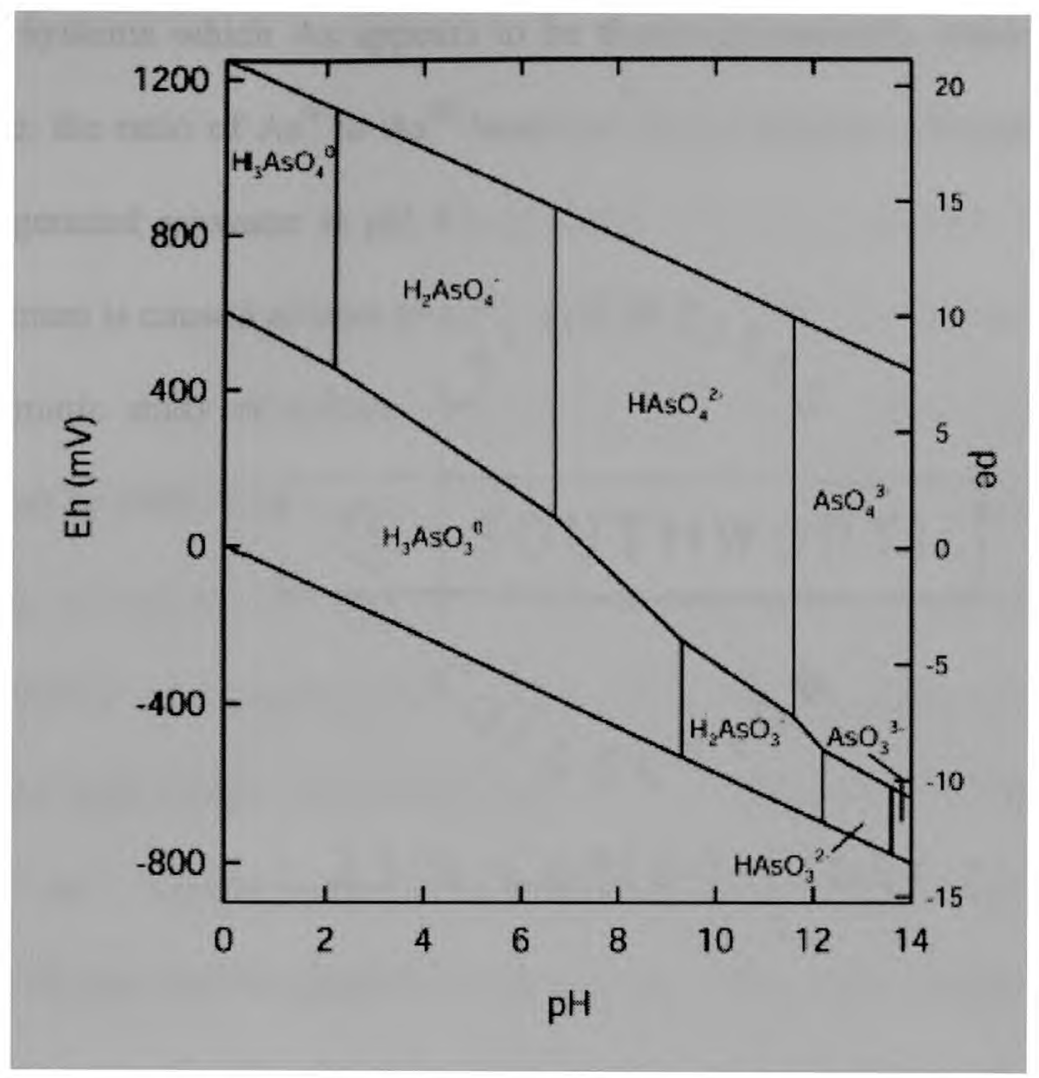

Figure 1.2 Eh-pH diagram for aqueous As species in the system $\mathrm{As}-\mathrm{O}_{2}-\mathrm{H}_{2} \mathrm{O}$ at $25^{\circ} \mathrm{C}$ and 1 bar total pressure

Microorganisms are attributable to many reactions that result in changes in speciation of arsenic; $\mathrm{As}^{\mathrm{III}}$ can be oxidized to $\mathrm{As}^{\mathrm{V}}$, or $\mathrm{As}^{\mathrm{V}}$ can be reduced to $\mathrm{As}^{\mathrm{III}}$ (Jackson et al., 2003; Mukhopadhyay et al., 2002; Oremland et al., 2005; Oremland et al., 2004). These inorganic arsenic forms can also be biomethylated by certain microorganisms to gaseous arsines or to methylated species such as monomethyl arsonic acid (MMA) and dimethyl arsinic acid (DMA), while other microbes can demethylate organic forms to inorganic species (Mukhopadhyay et al., 2002; Sohrin et al., 1997) (Fig 1.3). In the natural environment, the rates of both $\mathrm{As}^{\mathrm{III}}$ oxidation and $\mathrm{As}^{\mathrm{V}}$ reduction reactions are controlled by micro-organisms and can be orders of magnitude greater than under abiotic conditions (Johnson, 1972). The major chemical form in environmental 
aquatic systems which As appears to be thermodynamically stable is arsenate ion. For example, the ratio of $\mathrm{As}^{\mathrm{V}}$ to $\mathrm{As}{ }^{\mathrm{III}}$ based on thermodynamic calculation should be $10^{26}: 1$ for oxygenated seawater at $\mathrm{pH} 8.1$, in reality, it is $0.1: 1$ to $10: 1$. This unexpected high $\mathrm{As}^{\mathrm{III}}$ content is caused at least in part by biological reduction in seawater (Johnson, 1972). A systematic study of arsenic species in related well waters in southwest Taiwan was conducted in 1994 (Chen et al., 1994). The main As species found in well waters were inorganic As species $A s^{\mathrm{V}}$ and $\mathrm{As}{ }^{\mathrm{III}}$, with an average ratio of $\mathrm{As} \mathrm{v}^{\mathrm{V}} / \mathrm{As}^{\mathrm{III}}$ of about 2.6. The As speciation was performed on well water samples from an area around Alaska containing high levels of As (Harrington et al., 1978) and 3 to $39 \%$ contained As ${ }^{\mathrm{III}}$ and rest were $\mathrm{As}^{\mathrm{V}}$. Another study for As in tube well water samples from the affected districts of West Bengal and Bangladesh indicated most of the water samples contained a mixture of arsenite and arsenate with ratio of $\mathrm{As}^{\mathrm{V}} / \mathrm{As}^{\mathrm{III}}$ ranged from 1.4 to 3.3 without methylated arsenic being detected (Samanta et al., 1999).

Some of the common arsenic compounds found in speciation analysis are summarized in Table 1.2. In natural waters and soils, arsenic is mostly found in inorganic forms as trivalent arsenate $\left(\mathrm{As}^{\mathrm{III}}\right)$ or pentavalent arsente $\left(\mathrm{As}^{\mathrm{V}}\right)$. The methylated As species such as $\mathrm{MMA}^{\mathrm{III}}, \mathrm{MMA}^{\mathrm{v}}, \mathrm{DMA}^{\mathrm{III}}$ and $\mathrm{DMA}^{\mathrm{v}}$ in which inorganic As compounds being methylated by microorganisms or biological detoxification pathway can be found in environmental water and soil but mainly be found in biological tissues or metabolites (McSheehy et al., 2003; Shibata and Morita, 2000). Inorganic forms of As can be found in small quantities in living organisms, but generally organoarsenicals species dominate. The presence of organoarsenicals in marine life was confirmed in 1977 when arsenobetaine (AB) was identified in lobster. Since then, a large number of organoarsenic 
species (methylated As compounds, arsenocholine and arsenosugars) have been idebtified in marine tissues (Leermakers et al., 2006).

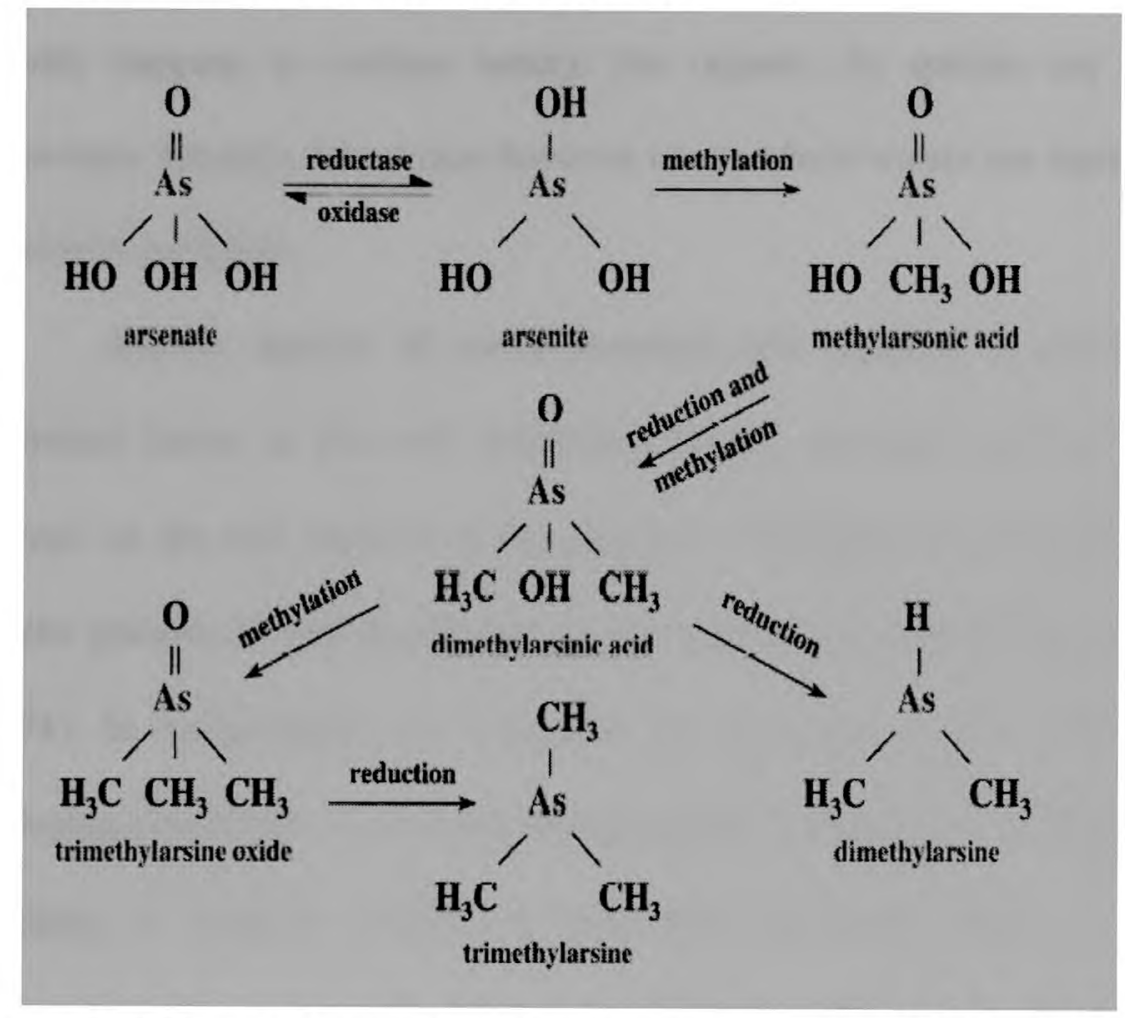

Figure 1.3 Microbial transformation of arsenic species (Mukhopadhyay et al., 2002)

Arsenic species in environmental waters Arsenic has 4 oxidation states in aquatic systems, $-3,0,+3$ and +5 with the two main inorganic species found in water being $\mathrm{As}^{\mathrm{III}}$ and $\mathrm{As}^{\mathrm{V}}$ (Cullen and Reimer, 1989; Fodor, 2001; Stollenwerk, 2003). Thermodynamic studies predict that arsenite is stable under reduced conditions and arsenate is stable under oxidized conditions. However, both species can be found regardless of the redox conditions, suggesting that kinetic or microbial processes are important roles on speciation (Smedley and Kinniburgh, 2002; Stollenwerk, 2003). In the $\mathrm{pH}$ range of 4 to 10 , the predominant $\mathrm{As}{ }^{\mathrm{III}}$ compound is neutral in charge, while the $\mathrm{As}^{\mathrm{V}}$ species are negatively charged (Fig.1.2). Arsenate is found much less mobile under 
intermediate $\mathrm{pH}$ conditions. Inorganic As is exposed to chemical or microbiologically mediated redox and methylation processes to produce organic As forms, the process mostly happens in surface waters, but organic As species are rarely quantitatively important. Organic forms may however occur where waters are significantly impacted by industrial pollution.

Arsenic species in environmental soils Arsenic is found in many different chemical forms in the soil: sulphides, oxides, arsenites and arsenates. The forms of arsenic in the soil depend on the amount of phosphorus, aluminium, iron and organic matter present, as well as $\mathrm{pH}$, and the redox potential (Bhumbla and Keefer, 1994; Huang, 1994). In oxygenated soil, inorganic As is present in the pentavalent form. Under reducing conditions, it is in the trivalent form. Leaching of arsenate is slow, because of binding to hydrous oxides of iron and aluminum. There is ample evidence of biomethylation in the soil and of the release of methylarsines into the air and high levels of methylated arsenic compound have been detected in greenhouse air (Planer-Friedrich, 2004). However, airborne arsenic is mainly inorganic. Methylated arsenic compounds occur naturally in the environment as the result of biological activity, usually only the organic species monomethylarsonic acid (MMA) and dimethylarsinic acid (DMA) are found in detectable concentrations in soils besides abundant inorganic $\mathrm{As}^{\mathrm{V}}$ and $\mathrm{As}{ }^{\mathrm{III}}$ species (Takamatsu et al., 1982; Tlustos et al., 2002). In very few cases trimethylarsine oxide (TMAO) and arsenobetaine (AB) have been detected as minor compounds in soil extracts (Geiszinger et al., 2002). 
Table 1.2 Some common arsenic compounds found in environmental and biological samples

Environmental

Name

Abbreviation Chemical formula

matrices

Inorganic compounds

Arsenite (arsenous acid) $\quad \mathrm{As}^{\mathrm{III}}$

$\mathrm{As}(\mathrm{OH})_{3}$

Water, soil,

tissue

Arsenate (arsenic acid)
rganic compounds

$\mathrm{As}^{\mathrm{V}}$

Water, soil,

\section{Organic compounds}

Urine, Marine

Monomethylarsonous acid MMA $^{\mathrm{III}}$

$\mathrm{CH}_{3} \mathrm{As}(\mathrm{OH})_{2}$

tissue

Urine, Marine

Monomethylarsonic acid

$\mathrm{MMA}^{\mathrm{V}}$

$\mathrm{CH}_{3} \mathrm{AsO}(\mathrm{OH})_{2}$

tissue

Urine, Marine

Dimethylarsinous acid

$\mathrm{DMA}^{\text {III }}$

$\left(\mathrm{CH}_{3}\right)_{2} \mathrm{AsOH}$

tissue

Urine, Marine

Dimethylarsinic acid

$\mathrm{DMA}^{\mathrm{v}}$

$\left(\mathrm{CH}_{3}\right)_{2} \mathrm{AsO}(\mathrm{OH})$

tissue

Arsenobetaine

AsB

$\left(\mathrm{CH}_{3}\right)_{3} \mathrm{As}^{+} \mathrm{CH}_{2} \mathrm{COO}^{-}$

Marine tissue

Arsenocholine

AsC

$\left(\mathrm{CH}_{3}\right)_{3} \mathrm{As}^{+} \mathrm{CH}_{2} \mathrm{CH}_{2} \mathrm{O}^{-}$

Marine tissue

Trimethylarsine oxide

TMAO

$\left.\mathrm{CH}_{3}\right)_{3} \mathrm{AsO}$

Air

Tetramethylarsonium ion

$\mathrm{Me}_{4} \mathrm{As}^{+}$

$\left(\mathrm{CH}_{3}\right)_{4} \mathrm{As}^{+}$

Air

Arsenic-containing ribosides

Arseno sugars

Various structures

Marine tissue 
Arsenic species in biological tissues Some marine organisms have been shown to transform inorganic As into more complex organic compounds, such as arsenobetaine, arsenocholine, and arsoniumphospholipids (Fattorini et al., 2004; Francesconi and Edmonds, 1997). About 25 different As compounds have been identified in biological samples, mainly in marine ecosystems (Michel, 1987) (Figure 1.4). Arsenic is abundant in seafood at concentrations as high as several hundred microgram per gram (Le et al., 2004). It seems that the major As species in fish, crustaceans and molluscs have the tetraalkylarsonium structure $\left(\mathrm{R}_{4} \mathrm{As}^{+}\right)$and the species in marine algae and bivalves have the trialkylarsine oxide structure $\left(\mathrm{R}_{3} \mathrm{AsO}\right)$. Arsenobetaine (AsB, trimethylarsonioacetate) is the most abundant As species in marine fauna, whereas macro-algae contain a class of dimethylarsinoyl ribosides, known under the trivial name of arsenosugars. This class of compounds is generally believed to be innocuous to humans, but humans are able to convert arsenosugars to dimethyl arsinic acid (DMA) (Le et al., 1994), while some studies indicate that DMA has the potential to be a human carcinogen (Wanibuchi et al., 2004).

Arsenic speciation methodology Since most environmental As species are generally present in soluble forms, liquid-separation techniques, in the first place HPLC but also CE, are the most frequently used for separating As species. HPLC allows easy coupling with element-specific detectors, requiring only a simple interface. The chromatographic separation depends on $\mathrm{pH}$. At neutral $\mathrm{pH}$, arsenate $\left(\mathrm{As}^{\mathrm{V}}, \mathrm{pKa} 1=2.3\right)$, MMA (pKa $=3.6)$ and DMA (pKa $=6.2)$ are present as anions; $\mathrm{AsC}^{+}$, trimethylarsine oxide (TMAO, $\mathrm{pKa}=3.6$ ) and TeMA ion as cations; $\mathrm{AsB}(\mathrm{pKa}=2.18)$ as zwitterion; arsenite $\left(\mathrm{As}^{\mathrm{III}}, \mathrm{pKal}=9.3\right)$ as an uncharged species. As a result, both anion exchange (for 
separating $A s^{\mathrm{V}}, \mathrm{As}^{\mathrm{III}}, \mathrm{MMA}$ and $\mathrm{DMA}$ ) and cation exchange (for separating $\mathrm{AB}, \mathrm{AC}$, TMAO and TeMA) are commonly used for a complete separation of these compounds.

Techniques for measuring As species in environmental and industrial waters have been well developed. Hyphenated methods coupling HPLC to hydride generation followed by atomic fluorescence spectrometry detection (HPLC-HG-AFS) are state-ofthe-art techniques for As speciation. Most of the As species exist in environmental samples is ionic form (arsenous acid, $\mathrm{As}(\mathrm{OH})_{3}$ is an exception), and are analyzed accordingly, usually by ion exchange chromatography or ion pairing chromatography. Hydride generation ( $\mathrm{HG}$ ) is a general term describing the conversion of an element or elemental species to a volatile analyte (usually a hydride). For As speciation analysis, the hydride generation method is commonly used for the determination of $\mathrm{As}^{\mathrm{III}} / \mathrm{As}^{\mathrm{V}}$, MMA/MMA ${ }^{\mathrm{III}}$, and DMA/DMA ${ }^{\mathrm{III}}$ after conversion to their respective hydrides (or, more specifically, their respective arsines), namely arsine $\left(\mathrm{AsH}_{3}\right.$, b.p. $\left.-55^{\circ} \mathrm{C}\right)$, methylarsine $\left(\mathrm{CH}_{3} \mathrm{AsH}_{2}\right.$, b.p. $\left.2{ }^{\circ} \mathrm{C}\right)$, or dimethylarsine $\left(\left(\mathrm{CH}_{3}\right)_{2} \mathrm{AsH}\right.$, b.p. $\left.36^{\circ} \mathrm{C}\right)($ Table 1.3$)$. HG-AFS detection yields detection limits around $1 \sim 2 \mu \mathrm{g} / \mathrm{L}$, and problems with chemical interferences during the HG are eliminated by the preceding separation. This method was used for this dissertation research work.

HPLC-HG-AFS is only suitable for hydride active arsenicals, and hence restricted mainly to water samples and urine samples; with AFS as detector the method has detection limits almost comparable with those obtained from HPLC-ICP-MS. HPLCICP-MS, another very useful technique for elemental speciation, provides good separation of arsenic compounds together with excellent detector sensitivity thereby allowing investigation of natural samples with minimal sample preparation. Spectral 
interferences (e.g. ${ }^{40} \mathrm{Ar}{ }^{35} \mathrm{Cl}$ vs ${ }^{75} \mathrm{As}$ ) can occur but these can be readily overcome by chromatography, or by use of reaction/collision cell technology or high resolution mass analyzers. The technique is generally restricted to mobile phases with low organic content and hence has not yet been applied to the determination of non-polar arsenic species (e.g. arsenolipids); assignment of arsenicals is by chromatographic comparison with standards (retention time matching), and thus the method depends on the availability of standard compounds; provides no structural information and hence is greatly restricted in its ability to identify novel arsenic compounds. The technique is generally more expensive than HPLC-HG-AFS. A new player, namely molecular mass spectrometry, also contributed to As speciation analysis in the late 1990s. The potential of the method was realized and molecular mass spectrometric techniques are becoming increasingly important in As speciation analysis (Francesconi Kevin and Kuehnelt, 2004).

Table 1.3 Arsine generation reactions and the boiling points of the corresponding products

\begin{tabular}{|c|c|c|}
\hline \multicolumn{3}{|c|}{$\begin{array}{c}\left(\mathrm{CH}_{3}\right)_{\mathrm{n}} \mathrm{AsO}(\mathrm{OH})_{3-\mathrm{n}}+\mathrm{H}^{+}+\mathrm{BH}_{4}{ }^{-} \rightarrow\left(\mathrm{CH}_{3}\right)_{\mathrm{n}} \mathrm{As}(\mathrm{OH})_{3-\mathrm{n}}+\mathrm{H}_{2} \mathrm{O}+\mathrm{BH}_{3} \\
(\mathrm{CH} 3)_{\mathrm{n}} \mathrm{As}(\mathrm{OH})_{3-\mathrm{n}}+(3-\mathrm{n}) \mathrm{H}^{+}+(3-\mathrm{n}) \mathrm{BH}_{4}^{-} \rightarrow(\mathrm{CH})_{\mathrm{n}} \mathrm{AsH}_{3-\mathrm{n}}+(3-\mathrm{n}) \mathrm{H}_{2} \mathrm{O}+(3-\mathrm{n}) \mathrm{BH}_{3}\end{array}$} \\
\hline As Compound & Reaction product & Boiling point $\left({ }^{\circ} \mathrm{C}\right)$ \\
\hline $\mathrm{As}^{\mathrm{III}} / \mathrm{As} \mathrm{V}^{\mathrm{V}}$ & $\mathrm{AsH}_{3}$ & -55 \\
\hline $\mathrm{MMA} \mathrm{MMA}^{\mathrm{III}}$ & $\mathrm{CH}_{3} \mathrm{AsH}_{2}$ & 2 \\
\hline $\mathrm{DMA}^{\mathrm{DMA}}{ }^{\mathrm{III}}$ & $\left(\mathrm{CH}_{3}\right)_{2} \mathrm{AsH}$ & 36 \\
\hline TMAO & $\left(\mathrm{CH}_{3}\right)_{3} \mathrm{As}$ & 70 \\
\hline
\end{tabular}




\subsection{Transport and mobility of arsenic in the soil environment}

Arsenic adsorption in soils Adsorption, whether by physical or chemical processes, involves the mass transfer of a soluble species (adsorbate) from solution to the surface of a solid phase (adsorbent). When the adsorbent is a porous media, the transport of adsorbate to adsorbent will occur through four basic steps (Prasad, 1994): 1) Bulk solution transport - The adsorbate is first transported from the bulk solution to the hydrodynamic boundary layer surrounding the adsorbent. Depending on the velocity of the bulk solution, this transport will occur either by diffusion or turbulent mixing. 2) External (film) resistance to transport - The adsorbate must then pass through the hydrodynamic boundary layer to the surface of the adsorbent. Transport through the boundary layer is due to molecular diffusion, and the distance the adsorbate must travel, or the thickness of the boundary layer, will depend on the velocity of the bulk solution. The size of the boundary layer will affect the rate of transport. 3) Internal (pore) transport - This step occurs after the adsorbate has passed through the boundary layer and must be transported through the pores to adsorption sites. This intraparticle transport may occur by molecular diffusion through the solution in the pores (pore diffusion) or by diffusion along the adsorbent surface (surface diffusion) after adsorption takes place. 4) Adsorption - The final step is the attachment of the adsorbate onto the adsorbent surface at available sites. This step is very rapid; therefore one of the preceding diffusion steps will control the rate of mass transfer.

The presence of the pollutants in the soil is not as much of a problem as the fact that these pollutants are mobile and could thus affect public health. That is why knowledge of mobility, bioavailability, and transfer mechanisms (inherent to speciation 
and the nature of minerals) is as indispensable as the identification of the pollutants. Arsenic chemistry in soils has been well studied with numerous publications in the literature concerning the high sorptive capacity of soils for As. Arsenic has been known to have a high affinity for oxide surfaces, which is affected by several biogeochemical factors such as soil texture, organic matter, nature and constituents of minerals, $\mathrm{pH}$, redox potential and competing ions (Adriano, 1986; McArthur et al., 2004). Adsorption reactions at the solid-water interface is the predominate mechanism controlling transport of As in many soil and groundwater systems (Stollenwerk, 2003). Soil properties will have a major effect on metal mobility, hydrous oxides of $\mathrm{Fe}, \mathrm{Al}$, and $\mathrm{Mn}$, and clay minerals are commonly associated with aquifer solids and have been shown to be significant adsorbents of As (Inskeep et al., 2002). The extent of As adsorption is also influenced by the chemistry of the aqueous phase including $\mathrm{pH}$, As speciation, and the presence and concentration of natural organic matter (NOM) and competing ions. Arsenic adsorption onto metal oxide surfaces is dominated by electrostatic attraction initially. The surface of a metal oxide consists of metal atoms surrounded by oxygen atoms. Hydrogen atoms from surrounding water will attach themselves to the outlying oxygen atoms. The surface oxygen atoms, hydroxyl groups, and water molecules act as exchangeable ligands. The interface is thus characterized by different types of surface hydroxyl groups and metallic centers (Schindler and Stumm, 1987), which give the surface both ligand- and metal-like properties. The interaction of oxide surfaces with solute hydrogen and hydroxide ions, metal ions, and ligands can be better understood in terms of coordination chemistry and surface complexation (Schindler and Stumm, 1987) (Figure 1.5). 


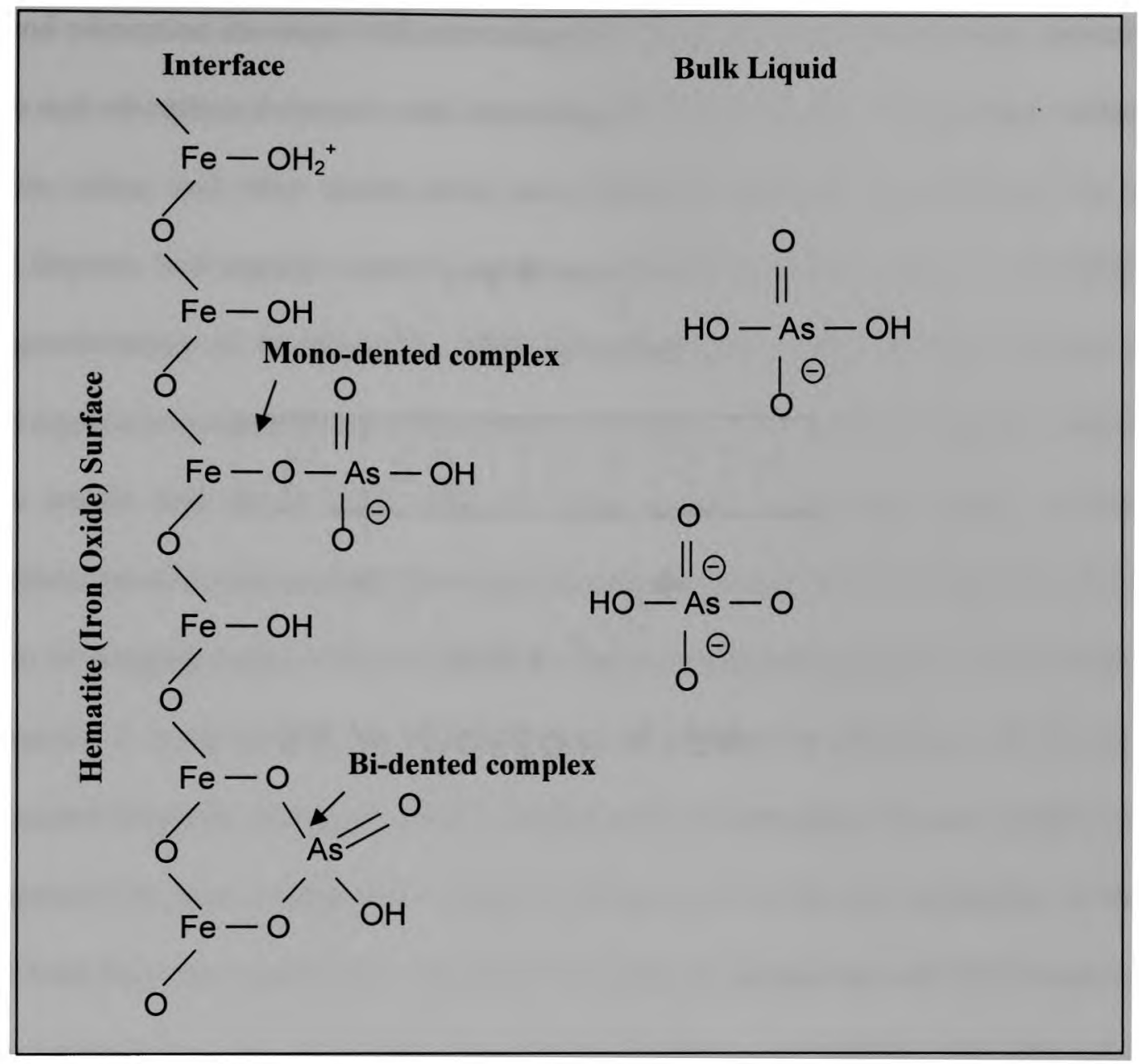

Figure 1.4 Schematic diagram showing arsenic adsorption mechanism on metal oxide (Hematite as a example) in view of coordination chemistry

The adsorption of metals and anions can be treated as competitive complex formation and competitive ligand exchange, respectively, with great dependence on $\mathrm{pH}$. The adsorption of arsenic species on iron hydroxide may occur by anion adsorption mechanism that is accompanied by the uptake of protons or alternatively by the release of hydroxide ions (Benjamin and Leckie, 1981). The specific adsorptions as well as electrostatic interactions are important mechanisms for As adsorption on iron hydroxide (Pierce and Moore, 1982). Under moderately reducing conditions, trivalent arsenite is 
stable and adsorption increases with increasing $\mathrm{pH}$. In an oxidized environment, arsenate is stable and adsorption decreases with increasing $\mathrm{pH}$. The presence of phosphate, sulfate, carbonate, silica, and other anions have been shown to decrease adsorption of As to varying degrees. Soil organic matter is another potentially important factor in controlling the biogeochemistry of As (Ko et al., 2004; McArthur et al., 2004). Mineral surfaces in soil and aquatic environments are often coated, to a large extent, with soil organic matter, such as humic and fulvic acids. One of those studies found that despite anionic competition, arsenite and arsenate form aqueous complexes with humic acids (HA) in the presence of bridging metals. When negatively charged functional groups in HA compete with arsenic, it could desorb As from hematite and inhibit the adsorption of As onto humic-coated hematite (Ko et al., 2004). Taking reduced adsorption on iron-oxides into consideration HA may facilitate the enhanced transport of As into the subsurface, in the form of both free and organically complexed As species in aquatic and soil environments. Another interesting work has been done in terms of NOM on As mobility, McArthur et al. (McArthur et al., 2004) found that As is supplied by reductive dissolution of $\mathrm{FeOOH}$ and release of the sorbed As to solution and the process is driven by NOM in peaty strata both within the aquifer sands and in the overlying confining unit in the Bengal Basin.

As arsenic is more highly methylated its adsorption affinity generally decreases (Lafferty and Loeppert, 2005). Greater mobility of As could also be important in soil systems that have methylated As (MSMA, DSMA) applied in the form of pesticides or herbicides. If soil systems with conditions favorable for As methylation, the As could become more mobile. Turpeinen et al. (Turpeinen et al., 1999) observed that increased microbial activity in soil caused increased methylation and thus more leaching of As. As 
methylation proceeds from the inorganic forms of As to the mono- and di-methyl forms of As, the general trend is for adsorption potential to decrease. The adsorption of methyl As likely plays a significant role in behavior of the total As in soil systems especially in those areas that organoarsenicals are applied as pesticides or herbicides. The reduced adsorption affinity of methyl As species could cause increased levels of As to move into ground and surface water when these species are present. Increased As mobility due to the presence of methyl As in soil systems could also impact As bioavailability.

Facilitated arsenic transport Arsenic is mainly transported in the environment by water. Dissolved substances or colloidal particles may bind trace metals, allowing the pollutants to be transported with these much more mobile "carriers" (McCarthy and Zachara, 1989). This process is termed "facilitated transport". Colloids in sediment pore waters usually consist of a complex mixture of particles with organic, inorganic, and biological origin. A single entity in the colloidal size range can exhibit a certain heterogeneity, being itself an agglomerate or consisting from clay minerals or secondary precipitates with organic (humic substances) or inorganic coatings. Colloids range in size from $1 \pm 2 \mathrm{~nm}$ for organic macromolecules to a few micrometers $(\mu \mathrm{m})$ for clay and oxide minerals (Yariv and Cross, 1979). They can make up a significant proportion of suspended sediments and are important in that they: effectively bind pollutants; do not readily settle out of surface waters; and are mobile in ground-waters. Consequently they can facilitate the transport of pollutants. The engineered application of carriers that can facilitate the transport of heavy metals may have potential application in the remediation of contaminated sites. In addition, since many carriers exit naturally in soil and 
groundwater, knowledge of the effect of these particles and dissolved molecules on metal mobility can greatly help risk assessment.

There are at least two criteria to consider when a candidate carrier enhances the mobilization of heavy metal contaminants: a) the carrier must have high affinity for the pollutant; b) the carrier must be dispersed and mobile in the soil environment. When colloidal particles are present in the subsurface system, it should be modified a threephase porous medium with two solid phases, that is, mobile colloidal particles and stationary solid matrix. Accurate predictions using this facilitated transport mechanism require an understanding and proper estimation of chemical partitioning among all three phases: mobile colloids, mobile soil solution, and immobile soil solids.

Magee et al. (Magee et al., 1991) developed a three-phase model to estimate the retardation of sorbed pollutants in the presence of a carrier that is also allowed to sorb to stationary soil media. This model can be applied to metal pollutants under conditions in which the adsorption of metal to the porous media obeys a linear isotherm (or is governed by a single distribution coefficient). Given these assumptions, the retardation coefficient for the metal is given by:

$$
R^{*}=\frac{1+K_{d}^{o m}[\text { Carrier }]+K_{d}^{s} \rho_{b} / n}{1+\frac{K_{d}^{o m}[\text { Carrier }]}{1+K_{o m}^{s} \rho_{b} / n}}
$$

where [Carrier] is the concentration of the carriers, $\rho_{b}$ is the bulk density of the porous medium, $n$ is the porosity, $K$ s are the distribution or binding coefficients, and the subscripts and superscripts $d, s$, and $o m$ designate the dissolved trace metal ions, the solid phase, and the organic ligand, respectively. The retardation factor $\left(R^{*}\right)$ is defined as the 
ratio of the average transport velocity of pore water to that of a pollutant. Using this model, the transport of trace metals can be estimated with the knowledge of the binding constant of metal to carriers ( $\left.K_{d}^{o m}\right)$, metal to soil $\left(K_{d}^{s}\right)$, and carrier to soil $\left(K_{o m}^{s}\right)$. An ideal carrier for use in soil remediation should have a low carrier-to soil-surface binding constant $\left(K_{o m}^{s}\right)$ and a high trace metal-to-carrier binding constant $\left(K_{d}^{o m}\right)$, since this combination results in a smaller retardation coefficient for the pollutant in the presence of the carrier (Chen et al., 1995).

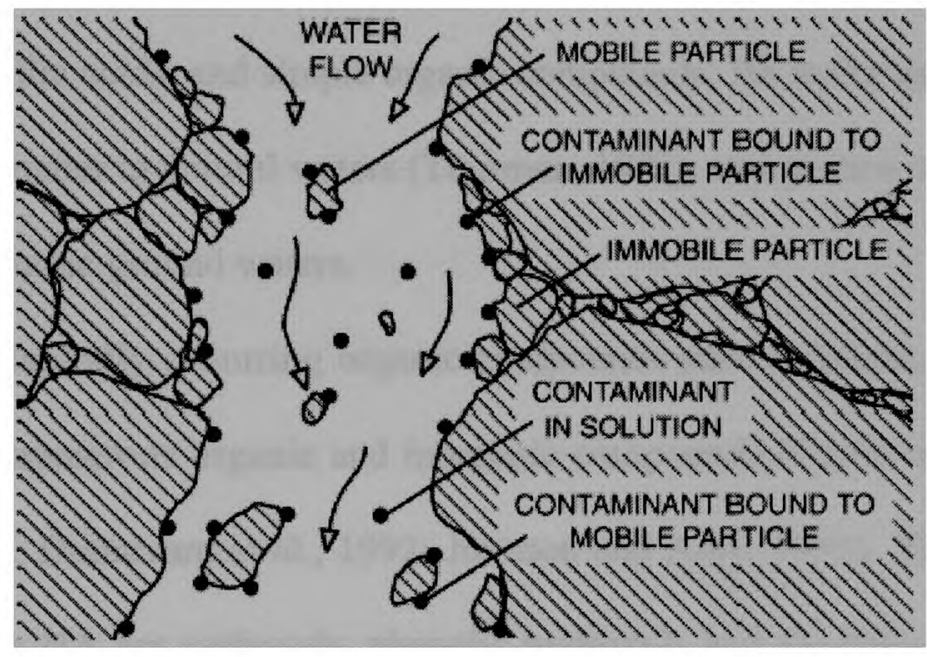

Figure 1.5 Diagram showing colloid facilitated transport

Note: Contaminants $(\bullet)$ are either dissolved in the aqueous phase or adsorbed on the surface of the solid phase. While one normally assumes that the solid phase is immobile, colloids can be released from the matrix, and act as contaminant carriers. Reprinted from reference (Grolimund and Borkovec, 2005; Grolimund et al., 1996).

Another possible mechanism for "facilitated transport" of pollutants may involve NOM (Laegdsmand et al., 2005; Schmitt et al., 2003; Williams et al., 2002, 2006). 
Organic matter in soil comes from several sources including plants, animals and microorganisms as well as the decomposition products from these sources. Other sources include airborne dusts, and applied chemicals. In soils the wide array of organic materials exists in different particle sizes with different degrees of decomposition and this translated into organics with differing solubilities and functional grouping. Soil organics may be separate discrete phases or they may be intimately associated with mineral surfaces. NOM in ground waters mainly consists of partially decomposed plant material and most is found as dissolved organic matter such as humic substances (HS), hydrophillic acids, and simple organic compounds. HS make up $50-80 \%$ of the dissolved organic matter in natural waters (Thurman, 1985), and ground waters rich in NOM can be termed humic ground waters.

Naturally occurring organic compounds such as humic acid (HA) can serve as a sink for numerous organic and inorganic compounds (Carter and Suffet, 1982; Chiou et al., 1986; Dunnivant et al., 1992; Johnson and Amy, 1995). The predominant functional groups in HA are carboxyls, phenolic hydroxyls and alcoholic hydroxyls (de Wit et al., 1993) (Table 1.4). Many of these groups are acidic and are deprotonated at the $\mathrm{pH}$ of most natural waters ( $\mathrm{pH} \mathrm{6-8).} \mathrm{The} \mathrm{resulting} \mathrm{anionic} \mathrm{charge} \mathrm{on} \mathrm{the} \mathrm{molecules} \mathrm{accounts} \mathrm{for}$ many HA characteristics, including aqueous solubility, binding capacity for metals and buffer capacity. The presence of HA in subsurface water is believed to enhance the transport of associated contaminants in the subsurface environment (McCarthy and Zachara, 1989). In addition, the adsorbed HA can change the physicochemical properties of the soil surface whose behavior (e.g., electrophoretic mobility, colloidal stability and transport) may be dominated by the adsorbed HA (Kretzschmar et al., 1997; Kretzschmar 
and Sticher, 1997). The major mechanisms by which HA adsorbs onto mineral surfaces have been proposed to involve: (i) anion exchange (electrostatic interaction), (ii) ligand exchange surface complexing, (iii) hydrophobic interaction, (iv) entropic effects, (v) hydrogen bonding and (vi) cation bridging. A detailed description of these mechanisms has been presented by Sposito (Sposito, 1984).

It is generally accepted that metal transport in natural aquatic systems strongly depends on the metal binding form. Besides interaction with colloidal particles and soil materials, complex formation is one of the most important reactions of metal ions in aquatic systems. Apart from well-defined inorganic and organic ligands, the heterogeneous mixture of refractory organic substances from microbial degradation and microbial synthesis processes, which will be referred to as NOM, is an important complexing agent for metal ions (Schmitt et al., 2003). In most cases, NOM is found to facilitate metal transport in aqueous systems.

Dissolved organic ligands competing with the soil matrix for metal binding can also accelerate metal transport (Artinger et al., 1998). A number of investigations have demonstrated that significant correlation between organic carbon content and As distribution suggests organic matter plays a significant role in controlling As transport. A positive and significant correlation of As with dissolved organic carbon (DOC) concentration reflects that sedimentary organic matter and peat soils are one of the important materials relating to high concentration of As in sediments of the Bengal delta (Anawar et al., 2003; McArthur et al., 2004). In the As affected delta area of Taiwan, the aquifer sediments were rich in organic matter, and waters tapped from organic black sediments of the lagoons in the endemic area were full of As and methane gas (Tseng et 
al., 1968). Kalbitz and Wennrich (Kalbitz and Wennrich, 1998) found that DOC concentration correlated very well with As concentration in aqueous extracts from soil.

Table 1.4 Important functional groups present in humic substances

\begin{tabular}{|c|c|c|c|}
\hline Amino & R-NH & Imine & $\mathrm{R}-\mathrm{CH}=\mathrm{NH}$ \\
\hline \multirow[t]{2}{*}{ Amide } & \multirow{2}{*}{$\stackrel{\stackrel{\mathrm{O}}{\|}-\stackrel{\mathrm{C}}{\mathrm{C}}-\mathrm{NH}_{2}}{ }$} & Ester & R-C-O-R' \\
\hline & & Ether & R-CH2-O-CH2-R' \\
\hline Amine & $\mathrm{R}-\mathrm{CH}_{2} \mathrm{NH}_{2}$ & Alcoholic $\mathrm{OH}$ & $\mathrm{R}-\mathrm{OH}$ \\
\hline Aldehyde & $\mathrm{R}-\mathrm{CHO}$ & Phenolic $\mathrm{OH}$ & \\
\hline Carbonyl & $\stackrel{\text { O }}{{ }^{\prime \prime}}$ & Imidazole & \\
\hline Carboxyl & $\stackrel{\mathrm{O}}{\stackrel{\mathrm{R}}{\|}-\mathrm{C}-\mathrm{OH}}$ & Quinone & \\
\hline Enol & $\mathrm{R}-\mathrm{CH}=\mathrm{CH}-\mathrm{OH}$ & Hydroquinone & \\
\hline Ketone & $\stackrel{\stackrel{O}{\|}}{R-C-R^{\prime}}$ & & \\
\hline Keto Acid & $\mathrm{R}-\mathrm{CO}-\mathrm{COOH}$ & Catechol & \\
\hline Imino & $=\mathrm{NH}$ & & $\mathrm{OH}$ \\
\hline
\end{tabular}


As to our knowledge, there is little information about colloid/DOM facilitated As transport in soil environment. Several research studies have found that natural organic matter or dissolved organic carbon have strong effect on As adsorption. Dobran and Zagury found that an increase in dissolved organic carbon content promoted both $\mathrm{As}^{\mathrm{V}}$ and $\mathrm{As}{ }^{\mathrm{III}}$ solubilization and high content of dissolved organic compounds prevented As adsorption in CCA-contaminated soils (Dobran and Zagury, 2006). Another recent study indicated that DOM can dramatically replace As from sorbent soil surface sites (Ghosh et al., 2006). These results suggested that high potential facilitated As transport by colloid/ DOM in soil-aquifer system.

\subsection{Problem statement, hypotheses and objectives of the study}

Arsenic-containing chemicals are used on a massive scale as pesticides in agriculture. In the United States, large quantities of sodium salts of monomethylarsonic acid (MMA) are utilized as herbicides in cotton production (Bednar et al., 2002). The monosodium salt of MMA is among the top pesticides utilized in the United States with approximately 1.2 million $\mathrm{kg}$ of arsenic applied annually to 3.8 million acres (Thelin and Gianessi, 2000). In addition, approximately $35,000 \mathrm{~kg}$ of As from dimethylarsinic acid (DMA) is applied annually as defoliant (Bednar et al., 2002). These organoarsenical pesticides have been measured in the environment. In cotton-producing areas, MMA and DMA are detected in surface water, groundwater, and rivers (Bednar et al., 2002). These pesticides were also detected in soil 1-1.5 years after their application to experimental field plots (Akkari et al., 1986; Woolson et al., 1982).

MMA is also frequently used as an herbicide for the post-emergent control of grassy weeds in turf grasses at golf courses in southeastern Florida. Typical application 
rates range from 0.2 to $0.9 \mathrm{~kg}$ of MSMA/acre, significant migration of MMA and $\mathrm{As}^{\mathrm{V}}$ out of the vadose zone and into the water table around golf course areas was found within one month from only 1 application of MMA (Di Carlo and Fuentes, 2000). MMA applied to golf course greens was also detected in percolate water (Feng et al., 2005).

Once arsenic-containing substances such as MSMA and DSMA are released into the environment, they are subject to transport and transformations in the environment. These transport and transformation are largely controlled by soil adsorption/desorption processes. The unbound forms of these arsenicals undergo a cascade of abiotic and/or biotic transformation including oxidation/reduction and methylation/demethylation (Cullen and Reimer, 1989). In South Florida, soils are typically low in organic matter and dominated by sand. In addition, depth to groundwater is usually less than five feet. Golf course greens are usually built from imported sand to maximize drainage, organic matter amendment such as the treatments consisting of Sphagnum peat moss are considered as one of most common soil amendments (Bigelow, 2000) to increase soil water content, soil organic matter and total porosity. The factors that control fate of As especially those organoarsenicals in environment after application is critical for risk assessment.

The goal of this study was to understand the factors controlling arsenic distribution in soil-water system and the role of colloid/DOM in arsenic transport and transformation in natural porous soil media. The specific objectives of the research are to: 1) Investigate the effects of soil characteristics on As adsorption, particularly the influence of soil organic matter amendment As distribution and transformation in soilwater system; 2) Estimate the relative retardation capability of As in soils used in south Florida golf courses by studying the partition of both inorganic and organic arsenic 
compounds between real dissolved, colloidal, and immobile (soil) phases. Determine the extent to which transport of As may be altered by soil-derived colloid/DOM materials; 3) Examine As species transformation in the environmental conditions and the factors controlling these processes.

To fulfill these objectives, DOM/colloid facilitated As transport and transformation in porous soil media were investigated using a set of experimental approach including soil batch experiment, equilibrium membrane dialysis experiment and column experiment. Soil batch experiment was applied to investigate As adsorption on a variety of soils with different characteristics; Equilibrium membrane dialysis method was employed to determine the 'free' and 'colloid-bound/complexed' As in water extracts of chosen soils; Column experiments were also set up in the laboratory to simulate As transport and transformation through golf course soils in the presence and absence of soil-derived dissolved substances under saturated conditions.

The study was guided by the following hypotheses: 1) Transport of As through soils is significantly related to soil properties and facilitated by the presence of colloid/DOM carriers. The degree of the enhancement of mobility is dependent on identity of the arsenic species and carriers; 2) Arsenic transformation during it transports in soils is controlled by key physical-chemical factors (i.e. redox, $\mathrm{pH}$, organic matter, As association and microorganisms). Changes in As speciation significantly alter As interactions and subsequently As mobility. 
CHAPTER 2

Partitioning of Arsenate and MMA in Dissolved, Colloidal, and Soil phases: the Role of Natural Organic Matter 


\subsection{Abstract}

Mobility and bioavailability of arsenic in the environment are essentially controlled by the adsorption behavior of arsenic species onto soils and the interactions between arsenic and the dissolved materials. Recent studies have suggested that natural organic matter may play a significant role in arsenic mobility than previously recognized. In order to better assess the environmental impact of widespread application of organoarsenicals as herbicides, two set of experiments for both inorganic arsenate $\left(\mathrm{As}^{\mathrm{V}}\right)$ and monomethylarsinic acid (MMA) were conducted in this study. The adsorption/desorption kinetics and the sorption coefficients of As on nine soils, including five golf-course soil substrates and four other commercially available garden soils or natural soil with high organic matter content, were characterized using equilibrium batch sorption isotherms. The heterogeneous colloid-binding characteristics of arsenic were evaluated using equilibrium dialysis technique. The results indicated that the presence of a variety of organic matter effectively reduced soil arsenic adsorption capability. The dissolved organic chemicals derived from organic matter rich soils either scavenged soil adsorption sites or interacted with arsenic, consequently making the associated arsenic in soil solution not available for adsorption. Except for one naturally collected soil (with extremely high $\mathrm{Fe}$ and $\mathrm{Al}$ content), all of them displayed relatively low arsenic retention level. When organic amendments are applied on arsenic contaminated soil, close attention must be paid for the amendment effects on soil surfaces and subsequent arsenic behavior in the soil system. The equilibrium dialysis results indicated that only a small fraction of arsenic presented in the molecular weight cut-off (MWCO) fraction larger 
than $3500 \mathrm{Da}$ in the soil extract. A three-component equilibrium model was proposed to describe the partitioning of arsenic species in the water, colloidal, and soil system.

\subsection{Introduction}

Elevated concentrations of arsenic (As) in waters and soils pose a significant threat to human health (Tchounwou et al., 2004). The hazard imposed by As present in soils is dependent on their ability to migrate into water systems and their availability for biological uptake. The degree to which a contaminant may dissociate from soil solids and become mobile or bio-available is therefore a determining risk factor. Many biogeochemical processes, such as biotic/abiotic adsorption, precipitation, complexation, microbe activity, oxidation/reduction (redox), and methylation/demethylation are involved in As solid-phase partitioning and speciation and therefore controlling its mobility and toxicity (Masscheleyn et al., 1991a; Oremland and Stolz, 2003; Smedley and Kinniburgh, 2002). Arsenic adsorption on clay, oxides of Al, Fe and Mn, and organic matter is generally thought to be the most important process that immobilizes this metalloid (El Khatib and Balba, 2004; Livesey and Huang, 1980; Lombi et al., 1999; Pierce and Moore, 1982; Sadiq, 1997; Stollenwerk, 2003). However, the interactions of As with dissolved substances in soil solution have been found to significantly affect the movement of As in soil and ground water. The association between As and dissolved substances in soil solution may increase its potential mobility during groundwater percolation. A number of studies have been carried out on inorganic arsenate $\left(\mathrm{As}^{\mathrm{V}}\right)$ and arsenite $\left(\mathrm{As}^{\mathrm{III}}\right)$ adsorption on individual soil minerals such as Fe (Antelo et al., 2005; Gerth, 2005; Hsia et al., 1994; Lenoble et al., 2002), Al (Davis and Misra, 1997; Lin and Wu, 2001), Mn oxides (Ouvrard et al., 2002) and phyllosilicate clay minerals (Manning 
and Goldberg, 1996a). There are also some studies of As adsorption on real intact soils (Jiang et al., 2005b; Violante et al., 2002). Soils are heterogeneous complexes of organic matter, metal oxides, clay minerals and microorganisms, with diverse structures. The study about As adsorption and desorption behaviors on actual soil samples will provide more realistic estimation for risk assessment of the As associated environmental problems. Furthermore, while considerable research has been conducted with inorganic As and soil or soil minerals, there has been considerably less research on the interactions of organoarsenicals with soil constituents (Bowell, 1994; Cox and Ghosh, 1994; Lafferty and Loeppert, 2005; Xu et al., 1991). There is a lack of understanding in soil characteristics and the processes that dictate the transport and transformation of As in organoarsenicals applied field. This hampers a precise risk assessment associated with the application of organoarsenicals as herbicides and therefore the appropriate policy making.

Partitioning of As in soil-water systems can be divided into three operationally defined geochemical fractions: soil substrate adsorbed, colloid associated, and truly dissolved. The truly dissolved part can be further specified into "free" As or small molecule-bound As complexes (Lin et al., 2004; Mukhopadhyay and Sanyal, 2004). The importance of understanding the effects of these partitioning on the biogeochemical cycling of contaminants has been recognized (Corapcioglu and Jiang, 1993; Laegdsmand et al., 2005). Due to the complexity of As chemistry, the contribution of these processes in governing As mobility and bioavailability in a given soil-water system remains to be unequivocally resolved.

In natural systems, the presence of dissolved organic matter (DOM) may compete with As species for adsorption site on soil surfaces, or interact with As 
contaminant in soil solution and further cause facilitated transport of contaminants in soils (de Jonge et al., 2004). The adsorption of $\mathrm{As}^{\mathrm{V}}$ on goethite $(\alpha-\mathrm{FeOOH})$ was investigated in the presence of either peat humic acid or Suwannee River Fulvic Acid, the results indicated that both humic acid and fulvic acid decreased $\mathrm{As}^{\mathrm{V}}$ adsorption $27 \%$ and $17 \%$ respectively (Grafe et al., 2001). Another study indicated that peat moss, humins and humic acid, extracted from sphagnum peat moss, significantly decreased the As sorption to sorghum biomass (Cano-Aguilera et al., 2005). Low soil organic matter content and limited soil water holding capacity are the major natural constraints of dry land cropping on sandy soils. Organic matter amendment can increase soil nutrient level, water holding capacity and total porosity. In South Florida, depth to groundwater is usually less than five feet. Golf course greens are usually built from imported sand to maximize drainage, golf course soil treatments consisting of Sphagnum peat moss are considered as one of most common amendments (Bigelow, 2000).

Arsenic-containing chemicals are used on a massive scale as pesticides in agriculture. In the United States, large quantities of sodium salts of monomethylarsonic acid (MMA) are utilized as herbicides in cotton production (Bednar et al., 2002). The monosodium salt of MMA is among the top pesticides utilized in the United States with approximately 1.2 million $\mathrm{kg}$ of As applied annually to 3.8 million acres (Thelin and Gianessi, 2000). In addition, approximately $35,000 \mathrm{~kg}$ of As from dimethylarsinic acid (DMA) is applied annually as defoliant (Bednar et al., 2002). Monosodium methanearsonate (MSMA) and disodium methanearsonate (DSMA) are also frequently used as herbicides for the post-emergent control of grassy weeds in several corps, lawns turf (Monks et al., 1999; Wiese and Hudspeth, 1968). MSMA is one of the three most- 
used cotton herbicides in U. S. A (Thurman et al., 1998). In cotton-producing areas, MMA and DMA are detected in surface water, groundwater, and rivers (Bednar et al., 2002). These pesticides were also detected in soil 1-1.5 years after their application to experimental field plots (Akkari et al., 1986; Woolson et al., 1982). MSMA is frequently used as an herbicide at golf courses in Florida. Typical application rates range from 0.2 to $0.9 \mathrm{~kg}$ of MSMA/acre, significant migration of MMA and $\mathrm{As}^{\mathrm{V}}$ out of the vadose zone and into the water table around golf course areas was found within one month from only 1 application of MMA (Di Carlo and Fuentes, 2000). A variety of arsenic species was also detected in percolate water after MSMA applied to golf course greens (Feng et al., 2005).

Once arsenic-containing substances such as MSMA and DSMA are applied in the field, they are subject to transport and transformations in the environment. These transport and transformation are largely controlled by soil adsorption/desorption processes. The unbound forms of these arsenicals undergo a cascade of biotic transformation that include oxidation, reduction, methylation and demethylation (Cullen and Reimer, 1989). As arsenic is more highly methylated its adsorption affinity generally decreases (Lafferty and Loeppert, 2005). Greater mobility of As could also be important in soil systems that have methylated arsenic (MSMA, DSMA) applied in the form of pesticides or herbicides. The adsorption of methyl As likely plays a significant role in behavior of the total As in soil systems especially in those areas where organoarsenicals are applied as pesticides or herbicides. The reduced adsorption affinity of methyl As species could cause increased levels of As to move into ground and surface water when these species are present. 
In this study, a variety of soil samples including four well characterized golf substrates and several organic rich soils were selected to investigate the role of organic matter in the partitioning behaviors of As in different fractions. The objectives of this research were (i) to quantify the kinetic characteristics of adsorption of $A s^{\mathrm{V}}$ and MMA in these nine soils and assess the effects of organic matter, especially Sphagnum peat moss amendment on As adsorption and soil itself using batch experiment (ii) to evaluate the association between As and naturally occurring heterogeneous colloids/DOM using equilibrium dialysis method.

\subsection{Materials and methods}

\subsubsection{Chemical and Materials}

All chemicals used in the experiments were analytical or trace metal grade. As ${ }^{\mathrm{V}}$ and MMA individual stock solutions $(1000 \mathrm{mg} / \mathrm{L})$ were prepared by dissolving the appropriate amounts of sodium hydrogen arsenate heptahydrate (A.C.S. Reagent, $98^{+} \%$, Aldrich) and monosodium acid methane arsonate (99.5\%, Chem Service Inc, West Chester, PA) in distilled deionized (DDI) water. Standards for metal analysis were of ICP-MS grade $\left(1000 \mathrm{mg} / \mathrm{L}\right.$ in $5 \% \mathrm{HNO}_{3}$. GFS Chemicals, Columbus, $\left.\mathrm{OH}\right)$. Spectra/Por $\mathrm{CE}$ (Cellulose Ester) membrane and $1.2 \mu \mathrm{m}$ Millipore GF/C glass fiber membrane filter were purchased from Fisher Scientific (Pittsburgh, PA). To prevent metal contamination, all glassware was acid cleaned prior to the experiments.

\subsubsection{Soil selection and characterization}

We decided to primarily focus on several soil components that have been widely used in Florida golf courses. These soil substrates have been well characterized and used in previous field and laboratory studies. These substrates with or without organic matter 
amendment included: Uncoated sand (plain sand) - UC; Naturally coated sand (coated with hydroxy-interlayered vermiculite and Kaolinite) - NC; Canadian Sphagnum peat Moss - P; Uncoated sand plus peat $(9: 1 \mathrm{v} / \mathrm{v})$ - UCP; Naturally coated sand plus peat $(9: 1$ $\mathrm{v} / \mathrm{v}$ ) - NCP. The uncoated sand used was common quartz sand, light gray or colorless, and did not have clay-sized coatings. Naturally coated sands, collected from Lake County, Florida, had a reddish-brown hue due to oxidized $\mathrm{Fe}$ and $\mathrm{Al}$ in the clay-sized fraction of the coating. It consisted of quartz and clay fractions including hydroxyinterlayered vermiculite $\quad\left(\left(\mathrm{Mg}, \mathrm{Fe}^{++}, \mathrm{Al}\right)_{3}(\mathrm{Al}, \mathrm{Si})_{4} \mathrm{O}_{10}(\mathrm{OH})_{2} \cdot 4\left(\mathrm{H}_{2} \mathrm{O}\right)\right), \quad$ kaolinite $\left(\mathrm{Al}_{2} \mathrm{Si}_{2} \mathrm{O}_{5}(\mathrm{OH})_{4}\right)$, geothite $(\mathrm{FeO}(\mathrm{OH}))$ and gibbsite $\left(\mathrm{Al}(\mathrm{OH})_{3}\right)$. In order to compare the effects of organic matter from different sources on As adsorption, three garden soils were purchased from a local store. These include all purpose organic compost derived from cow manure compost - OCP, peat humus organic growing medium - PHU (Greenleaf products, INC. FL); and potting soil plus Osmocote - POT (The Scotts Company, OH). In addition, a natural soil with high organic content was collected from Everglades National Park.

Soil $\mathrm{pH}$ was measured using the method of $\mathrm{CaCl}_{2}$ extraction by mixing $10 \mathrm{~g}$ soil and 20 $\mathrm{ml}$ 0.01 $\mathrm{M} \mathrm{CaCl}_{2}$ solution (Al-Busaidi et al., 2005). For total metal analysis, soil samples were digested using open vessel by trace metal nitric acid (Irizarry et al., 2001). The As in solutions and soil digests were analyzed using inductively coupled plasma mass spectrometry (ICP-MS) (HP4500 PLUS, Hewlett-Packard Co., Wilmington, DE, USA). Soil total organic matter (TOC) was determined as the loss of weight of soil on ignition at $550{ }^{\circ} \mathrm{C}$ for 5 hours (Svendsen et al., 1993). Dissolved organic carbon (DOC) was measured by acidifying to $\mathrm{pH}<2$ with $3 \mathrm{~N} \mathrm{HCl}$, purging the sample with $\mathrm{CO}_{2}$-free air, 
and analyzing for total carbon using a hot platinum catalyst direct injection analyzer (Shimadzu TOC 5000).

\subsubsection{Kinetic and Isotherm experiments}

The classic adsorption process was characterized by the final equilibrium of the solute between the two phases (dissolved and solid) and the time required to reach equilibrium. The adsorption isotherm was obtained using the constant-temperature equilibrium relationship between the mass of the arsenic per unit mass of soil and the equilibrium concentration of arsenic in solution of less than $1.2 \mu \mathrm{m}$ (Langmuir, 1997). Batch experiments were performed by combining background solution, soil, and pure solute, agitating, and recording the final solute equilibrium concentrations in each phase. Soil As adsorption kinetic and isotherm studies were carried out in an artificial rain water (ARW) (Velthorst, 1993) aqueous medium at $25^{\circ} \mathrm{C}$. The experiments were performed by adding $50 \mathrm{ml}$ of ARW with different concentrations $(0-5000 \mu \mathrm{g} / \mathrm{L})$ of As species in a $60 \mathrm{ml}$ HDPE amber wide-mouth bottle (Fisher Scientific, Pittsburgh, PA) containing $10 \mathrm{~g}$ of soil. The resulting soil samples were put on an Orbital Shaker (Model DS-500, VWR International, West Chester, PA) and shaken continuously at a speed of 300 rotations per minute (rpm) for a pre-set time period. The mixture was then filtrated using $1.2 \mu \mathrm{m} \mathrm{GF/C}$ glass fiber membrane filter (Fisher) before analyses. All adsorption isotherm experiments were conducted in triplicate.

The experiment for soil adsorption equilibrium time (soil adsorption kinetic study) was conducted by adding $50 \mathrm{ml}$ ARW spiked with $100 \mu \mathrm{g} / \mathrm{L}$ of either $\mathrm{As}^{\mathrm{V}}{ }^{\mathrm{or}}$ MMA to 10 g soil and the resulted mixture was continuously shaken on an orbital shaker at a speed of $300 \mathrm{rpm}$. An aliquot sample $(0.5 \mathrm{ml})$ was withdrawn from the supernatant and filtered 
with a $1.2 \mu \mathrm{m}$ membrane filter at each sampling interval (starting from $1 \mathrm{hr}$ till $24 \mathrm{hr}$ ) for As analysis. After sampling, the slurry returned to the shaker and shaking continued. Adsorption isotherms were determined for both $\mathrm{As}^{\mathrm{V}}$ and MMA for nine soils at $25^{\circ} \mathrm{C}$ using pre-determined adsorption equilibrium time. Different $\mathrm{As}^{\mathrm{V}}$ and MMA solutions with initial concentrations $\mathrm{C}_{0}$ (from $10 \mu \mathrm{g} / \mathrm{L}$ to $5 \mathrm{mg} / \mathrm{L}$ ) were prepared in $\mathrm{ARW}$. Then experiments were initiated by mixing $10 \mathrm{~g}$ of soil with $50 \mathrm{ml} \mathrm{As}^{\mathrm{V}}$ or MMA solution. Each trial was performed in triplicate. The average and coefficient of variation in the amount of $\mathrm{As}^{\mathrm{V}}$ or MMA adsorbed was reported. Arsenic and other ARW extractable metal elements content of the filtered soil extract (filtered through $1.2 \mu \mathrm{m} \mathrm{GF} / \mathrm{C}$ glass fiber membrane filter) was determined by ICP-MS. The ICP-MS was equipped with an ASX500 auto sampler (Cetac Technologies Inc., Omaha, NE, USA). Aluminum and iron analysis was conducted using atomic absorption spectrometer (AAS) (Model AAnalyst 600, PerkinElmer Instruments, Shelton, CT).

\subsubsection{Adsorption equations and data analysis}

The analysis of the isotherm data is important in order to develop an equation which could accurately represent the results and could be used for the purposes of experimental design. Various adsorption-isotherm equations, in particular the Freundlich and Langmuir equations, have been used to evaluate the adsorption of metals or metalloids by different soils. Of these two equations, the widely used Langmuir isotherm has found successful application to many real sorption processes and often provides the better fit to metal and metalloid adsorption data, and enables the calculation of the maximum adsorption capacity and the adsorption equilibrium constant related to bonding energy. Careful attention must be paid when the Langmuir equation is used because one 
basic assumption underlying the Langmuir equation is that all the soil adsorption sites are uniform. Although it seems unlikely that all adsorption sites on soil surfaces have the same binding energy for a particular metal or metalloid, a reasonability good fitting could still be obtained especially at low adsorbate concentrations (Gupta et al., 1988; Mehta and Khandelwal, 1980). In this study, spiked As concentration was relatively low, therefore, the Langmuir one-surface model was used to describe the adsorption of As ${ }^{\mathrm{V}}$ and MMA on the soils. The one-site Langmuir isotherm model (Langmuir, 1918) is expressed as in the form:

$$
C_{a d}=\frac{K C_{e q} M}{1+K C_{e q}}
$$

where $C_{a d}$ is the adsorbed As (adsorbate per unit mass of adsorbent), $\mu \mathrm{g} / \mathrm{kg} ; C_{e q}$ is the pseudo-equilibrium concentration of $\mathrm{As}, \mu \mathrm{g} / \mathrm{L} ; M$ is the maximum capacity of arsenic adsorption, $\mu \mathrm{g} / \mathrm{kg} ; K$ is the binding strength constant related to bonding energy, $\mathrm{L} / \mathrm{kg}$. Fitting of adsorption isotherms and the calculation of the parameters in Equation (1) were undertaken by Software Origin 6.0 using Non-linear regression (Langmuir EXT1) fitting curve.

\subsubsection{Equilibrium dialysis experiments}

Dialysis is the movement of molecules by diffusion from high concentration to low concentration through a semi-permeable membrane. Only those molecules that are small enough to fit through the membrane pores are able move through the membrane and reach equilibrium with the entire volume of solution in the system. Once equilibrium is reached, there is no further net movement of the substance because molecules will be moving through the pores into and out of the dialysis membrane at the same rate. By 
contrast, large molecules that cannot pass through the membrane pores will remain on the same side of the membrane as they were when dialysis was initiated.

In order to evaluate the interactions between As and colloids, which is operationally defined as fraction with $\mathrm{MW}$ from 3,500 Da to $1.2 \mu \mathrm{m}$, equilibrium dialysis was conducted using the solution resulted from the isotherm experiment (containing about $200 \mu \mathrm{g} / \mathrm{L} \mathrm{As}$ ) after adsorption equilibrium was reached. Dialysis membrane tubing (Spectra/Por CE, Fisher Scientific) with molecular weight cut-off (MWCO) of $3500 \mathrm{Da}$ was soaked in DDI water for $30 \mathrm{~min}$, and then rinsed thoroughly with DDI water. This procedure removes the sodium azide that was used as membrane preservative. For dialysis experiment, $15 \mathrm{ml}$ selected dialysis solution (filtered through $1.2 \mu \mathrm{m} \mathrm{GF} / \mathrm{C}$ glass fiber membrane filter) referred to as inside solution was put inside dialysis bag, then this sealed bag was immersed in $400 \mathrm{ml} \mathrm{ARW}$ solution referred to as outside solution. Solid $\mathrm{KCl}$ was added to the outside solutions until the ionic strength as measured by a conductivity meter (Model 441, Corning Inc. New York) matched that of the inside solution. The volume ratio of outside/inside solution was set at 26: 1 (Truitt and Weber, 1981). During the dialysis process, the closed containers were continuously stirred with a magnetic stirrer at $25^{\circ} \mathrm{C}$ for five days. The experiment was conducted in triplicate. Preliminary experiments were conducted to determine the time needed to reach equilibrium for both $\mathrm{As}^{\mathrm{V}}$ and MMA over the membrane. Based on the results of the pilot dialysis experiments for both $\mathrm{As}^{\mathrm{V}}$ and MMA standards, the experimental equilibrium dialysis time was set for 5 days for 3500 Da membrane. At the end of dialysis process, both solutions inside and outside dialysis bag were analyzed by ICP-MS for As concentration. In order to study associated As size distribution in soil/water equilibrium 
system, As - containing solutions resulted from isotherm experiment were chosen as inside solution for dialysis experiments. Arsenic concentration in those solutions was selected as close as possible (ranged from 180 to $220 \mu \mathrm{g} / \mathrm{L}$ ). For better data interpretation, all initial As concentration in selected dialysis solutions were normalized to $200 \mu \mathrm{g} / \mathrm{L}$ and corresponding dialysis results for As concentration inside/outside dialysis bag were also multiplied by same coefficient after dialysis equilibrium.

\subsection{Results and discussion}

\subsubsection{Soil characteristics}

Some physicochemical characteristics of the nine soils are summarized in Table 2.1. The soils studied had organic carbon contents ranging from 0.01 to $53.2 \%$ and $\mathrm{pH}$ ranged from 3.37 to 7.14. As expected, the TOC and DOC contents were significant higher in the garden soils, Everglades soil, and peat soil than in the rest four golf-course soils. Cation exchange capacity (CEC) varied from soil to soil, with peat having the highest CEC value and being followed by garden and Everglades soils. The golf course soil components, except peat exhibited the lowest CEC. Results for the analysis of the nitric acid extractable fraction indicated that the Everglades and garden soils contained higher $\mathrm{Fe}, \mathrm{Al}$, and $\mathrm{Mn}$ than the rest of golf soil components. $\mathrm{NC}$ had higher $\mathrm{Fe}, \mathrm{Al}$ and Mn compared with UC with or without the addition of peat. Fe, Al, and Mn contents in the ARW-extractable solution showed different patterns. As expected, much lower concentrations in $\mathrm{Fe}, \mathrm{Al}$, and $\mathrm{Mn}$ were found for most soils tested. It should be pointed out that the ARW-extractable $\mathrm{Fe}, \mathrm{Al}$, and $\mathrm{Mn}$ was substantially increased for $\mathrm{UC}$ and $\mathrm{NC}$ with the addition of $10 \%(\mathrm{~V} / \mathrm{V})$ peat (UCP and $\mathrm{NCP}$ ) compared to $\mathrm{UC}$ and $\mathrm{NC}$ alone. This is particularly true for Fe and $\mathrm{Al}$. Since the ARW-extractable $\mathrm{Fe}, \mathrm{Al}$, and $\mathrm{Mn}$ were 
relatively low in peat, their presence in the $10 \%(\mathrm{v} / \mathrm{v})$ peat could not directly contribute to the sharp increase of these elements in UCP and NCP. These results demonstrate that the addition of peat to $\mathrm{UC}$ and $\mathrm{NC}$ greatly enhanced $\mathrm{Fe}, \mathrm{Al}$ and $\mathrm{Mn}$ dissolution from the soils. This finding is in good agreement with the results obtained in our previous study (Chen et al., 2006). It is worth to note that the addition of $10 \%$ peat did not seem to significantly influent the concentrations of $\mathrm{HNO}_{3}$-extractable $\mathrm{Fe}, \mathrm{Al}$, and $\mathrm{Mn}$ in UCP and NCP soils. The clear increases in Mn in UCP and NCP were likely resulted from the high concentration of $\mathrm{Mn}$ in peat in the $\mathrm{HNO}_{3}$-extractable solution. Arsenic in the ARWextractable solutions for the garden and Everglades soils ranged from 26.3 to $88.4 \mu \mathrm{g} / \mathrm{kg}$ and not detectable for all golf soil components $(<0.1 \mu \mathrm{g} / \mathrm{kg})$. For the $\mathrm{HNO}_{3}$-extractable, As was found to be the highest in the Everglades and garden soils and followed by golf soil components, except for peat where As was not detectable. Arsenic concentrations in garden and Everglades soils were typical for agricultural soils in Florida (Ma et al., 1997).

\subsubsection{Adsorption kinetic study}

Results for both arsenate and MMA adsorption kinetics for all soils are in agreement with biphasic As adsorption behavior observed on several soil minerals (Arai and Sparks, 2002; Fuller et al., 1993; Raven et al., 1998) as well as whole soils (Barrachina et al., 1996; Elkhatib et al., 1984) over different time scales (Figure 2.1). There was an initial rapid adsorption phase, in which the soil retains most of the solute. In a second phase, the kinetic is much slower, with a smaller amount of the As adsorbed, evolving toward an equilibrium point that can not be reached within a reasonable experimental time. The $24-\mathrm{h}$ period in which the pseudo-equilibrium state was obtained was a key factor, providing an experimentally feasible time frame for our isotherm study. 
Table 2.1 Selected physical and chemical properties of the studied soils

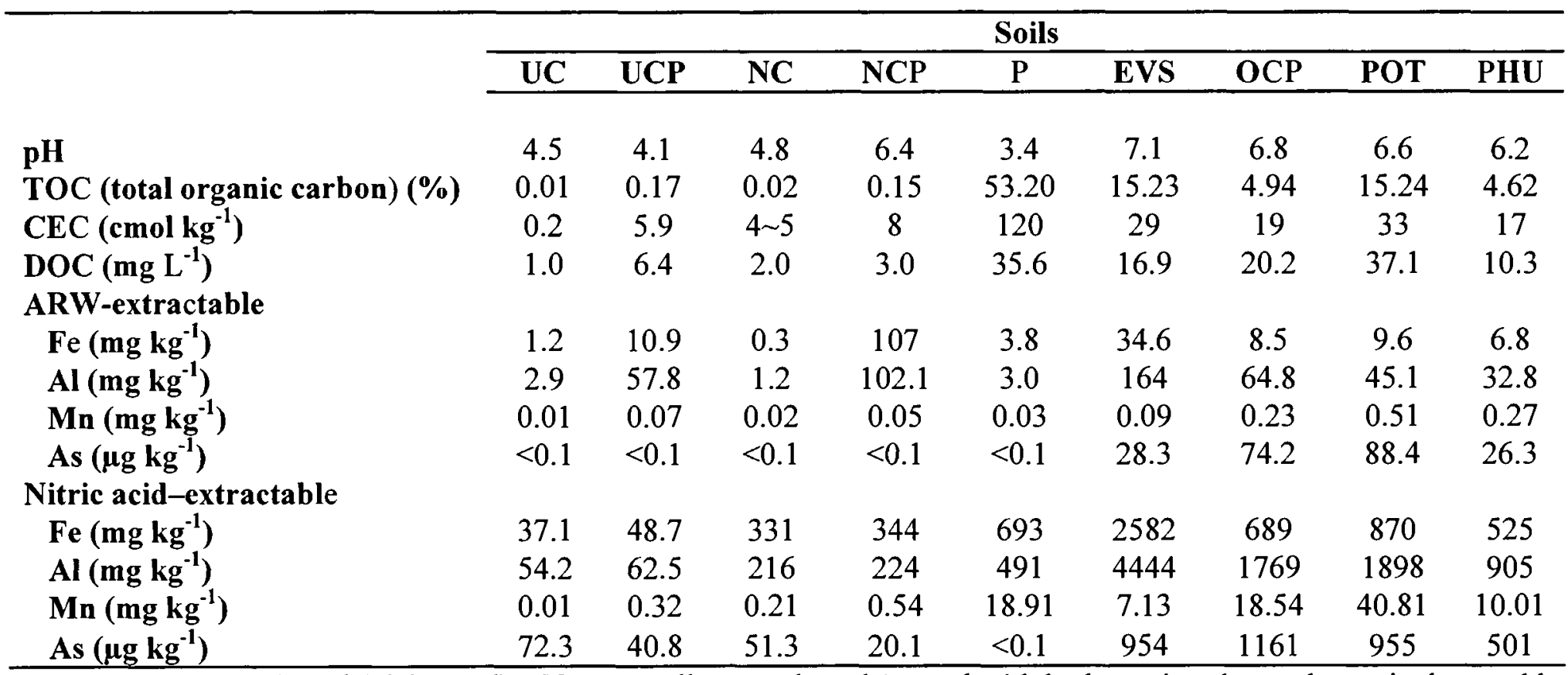

Note: UC - uncoated sand (plain sand); NC - naturally coated sand (coated with hydroxy-interlayered vermiculate and kaolinite); P - Canadian Sphagnum peat moss; UCP - uncoated sand plus peat $(9: 1 \mathrm{v} / \mathrm{v})$; NCP - naturally coated sand plus peat $(9: 1 \mathrm{v} / \mathrm{v})$; OCP All purpose organic compost derived from cow manure compost (Greenleaf products, INC. FL); PHU - Peat humus organic growing medium (Greenleaf products, INC. FL); POT - Potting soil plus Osmocote (The Scotts Company, OH); EVS - Everglades soil (Collected from Everglades National Park, FL). 
The soil As adsorption kinetic study results indicate that As adsorption was initially $(0-2 \mathrm{hr})$ rapid because of the greater availability of the soil surface area at the start then followed by a slow continuum uptake, and the adsorption processes almost reached the steady state after $4 \mathrm{~h}$ for golf course soils. The garden and Everglades soils took a little longer time (5h) especially EVS for MMA $(12 \mathrm{~h})$ than that for golf course soils to reach As adsorption equilibrium. The reaction time of $24 \mathrm{~h}$ was chosen because the extent of adsorption after that slowed down significantly for all types of soil. Equilibrium experiments carried out in relatively short reaction times (usually 24 h) have been used widely for quantifying the extent of As adsorption in soils (Jacobs et al., 1970; Smith et al., 1999).

Naturally coated sand (NC) and uncoated sand (UC) can adsorb most spiked As species $(\sim 90 \%)$ (Figure $2.1 \mathrm{a}$ and $2.1 \mathrm{~b}$ ). Addition of $10 \%(\mathrm{~V} / \mathrm{V})$ of peat to these sands greatly reduced their As adsorption capabilities and hence majority of the spiked As were remained in solution. Similar adsorption patterns were observed for both $\mathrm{As}^{\mathrm{V}}$ and MMA. It is well established that $\mathrm{Fe}$ and $\mathrm{Al}$ oxides and hydroxides have a high affinity to As. Several studies have demonstrated that As adsorption on soils is correlated with $\mathrm{Al}$ and Fe oxides contents in soils (De Brouwere et al., 2004; Goldberg, 2002; Livesey and Huang, 1980). However, simple correlation made between As adsorption and Fe/Al contents in soil solid phase may be misleading. The characteristics of the dissolved substances derived from soil could substantially alter the As adsorption behavior. In this study, although the addition of $10 \%(\mathrm{~V} / \mathrm{V})$ peat in UC and NC slightly increased the Fe/Al contents in these soils (Table 1), sharper decreases in As adsorption were observed (Figure $2.1 \mathrm{a}$ and $2.1 \mathrm{~b}$ ). This was likely attributed to the presence of dissolved organic 
matter derived from peat and the release of $\mathrm{Fe}$ and $\mathrm{Al}$ from soil surfaces, both causing decrease in As adsorption on the soil surfaces. Peat alone has similar As adsorption level as UCP and NCP (Figure 2.1a and 2.1b).

The garden soils (OCP, PHU, and POT) showed much lower As adsorption compared to the golf soil components UC and NC (Figure 2.1c and 2.1d), even though the contents of $\mathrm{Fe}, \mathrm{Al}$ and $\mathrm{Mn}$ in the garden soils were higher than in that $\mathrm{UC}$ and $\mathrm{NC}$ (Table 2.1). It seems that the higher organic matter in the garden soils contributed the decrease in As adsorption. With regard to the Everglades soil (EVS), about $98 \%$ of $\mathrm{As}^{\mathrm{V}}$ and $82 \%$ of MMA were adsorbed after 24 hours. The Everglades soil was high in organic matter and extremely high in $\mathrm{Fe}$ and $\mathrm{Al}$ compared to the garden soils. The strong As adsorption on the Everglades soil may be due to the sufficient active sites on the surface, which generated from the Fe/Al oxides. Compared with the golf course soils, As adsorption on most of the garden and Everglades soils seems slow. In heterogeneous soil systems, non-equilibrium conditions of arsenic adsorption may be due to the heterogeneity of soil sorption sites. Some of these sorption sites may cause slow precipitation of As at the mineral surface, that is, three-dimensional growth of a particular As solid surface; some of these sorption sites may cause slow diffusion to sites within the soil matrix, that is, slowly accessible sites with variable degrees of affinities to As (Zhang and Selim, 2005). The golf course soil components have relatively simpler composition and therefore the soil sorption sites are probably more homogeneous than the garden and Everglades soils. This could be the reason for fast As equilibrium establishment for the golf course soil components. 

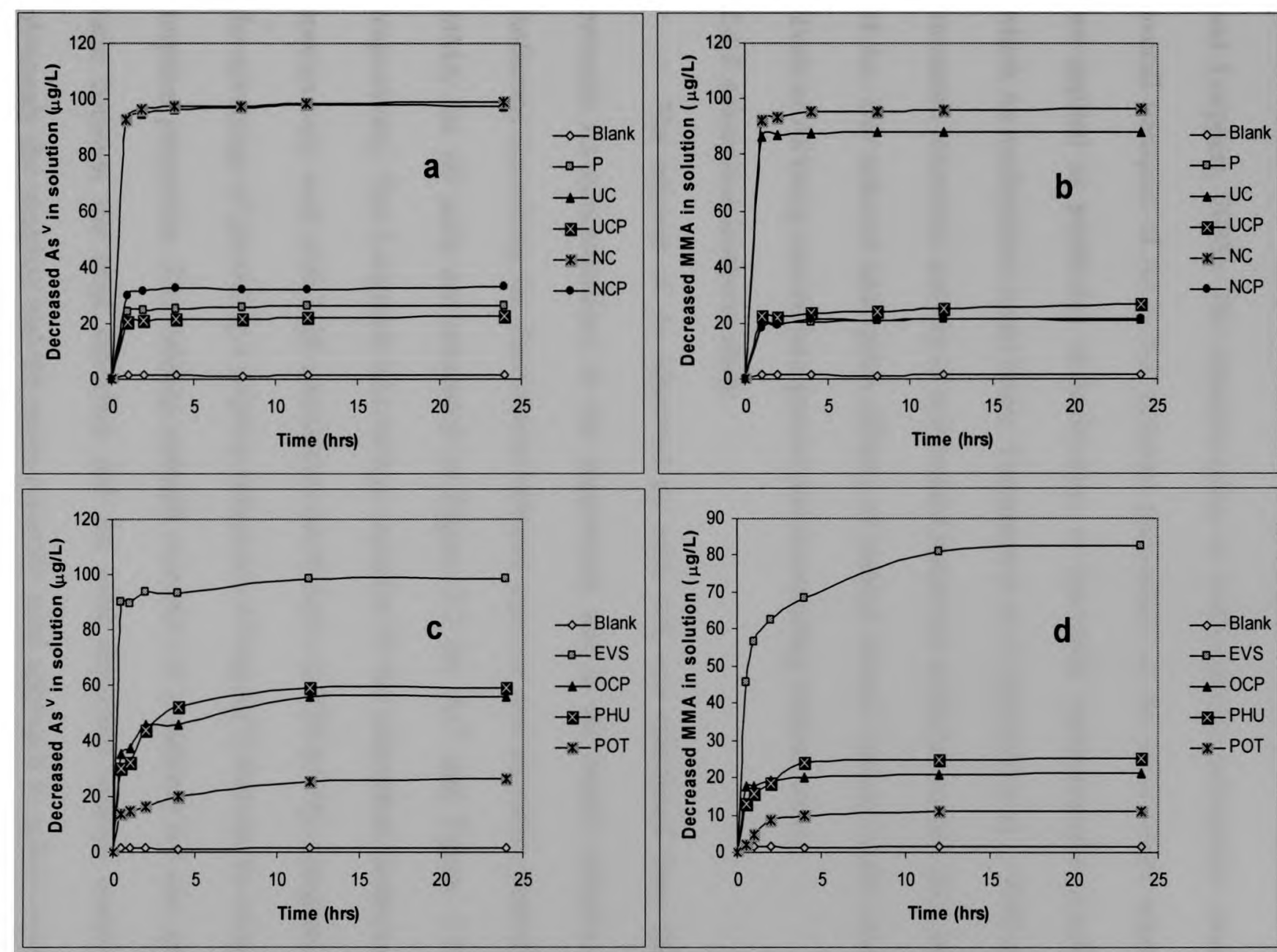

Figure 2.1 Arsenic species adsorption kinetic study: adsorption behavior (decreased arsenic concentration in solution) as a function of time) for nine types of soils. (a) golf-course soils spiked with $100 \mu \mathrm{g} / \mathrm{L}$ arsenate in solution, (b) golf-course soils spiked with $100 \mu \mathrm{g} / \mathrm{L}$ MMA in solution, (c) soils from other sources spiked $100 \mu \mathrm{g} / \mathrm{L}$ arsenate in solution, (d) soils from other sources spiked with $100 \mu \mathrm{g} / \mathrm{L}$ MMA in solution 
Generally speaking, most of the nine types of soils showed lower adsorption capability for MMA than for $\mathrm{As}^{\mathrm{v}}$. This is in agreement with the previous observation that as arsenic is more highly methylated its adsorption affinity generally decreases (Lafferty and Loeppert, 2005). The characteristics of methylarsenic adsorption could affect the overall transport of As in soil systems, particularly in the areas where organoarsenicals are applied as pesticides or herbicides, or favorable environmental conditions under which As methylation could occur. Turpeinen et al. (Turpeinen et al., 1999) observed that increased microbial activity in soil caused increased methylation and thus more leaching of As. The reduced adsorption affinity of methyl arsenic species could cause increased levels of As being moved into ground and surrounding surface waters.

\subsubsection{Adsorption isotherm study}

The amount of As adsorbed by each soil was calculated from the difference between As concentrations in the supernatant and in the initial solution. Adsorption isotherms describing the distribution between aqueous and adsorbed phases for $\mathrm{As}^{\mathrm{V}}$ and MMA for all soils are presented in Figure 2.2 for $\mathrm{As}^{\mathrm{V}}$ and Figure 2.3 for MMA, respectively. The Langmuir one-surface equation fit the adsorption isotherms of arsenic species very well with high correlation coefficients (0.979-0.993). Langmuir model has the advantage of providing a sorption maximum $M\left(\mathrm{mg} \mathrm{kg}^{-1}\right)$ that can be correlated to soil sorption properties. The binding strength constant $(K)$, defined for one species as the ratio between the total adsorbed and the total dissolved species concentrations, is obviously the simplest and the more currently used approach in solute transport model. The constants $M$ and $K$ were obtained by curve fitting (equation 1). Best-fit parameters 
are given in Table 2.2 for the soils tested. Large $K$ suggests strong adsorption and low soil mobility, while small $K$ suggests the opposite.

The results demonstrated that the adsorption quantity of arsenate or MMA was highly relevant to soil characteristics and both As species uptake increased with increasing initial As concentrations spiked. Note that the differences in concentration scales used for different soils in Figures 2.2 and 2.3. With minor organic matter presence in the soils (UC and $\mathrm{NC}$ ), As adsorption seems determined by the $\mathrm{Fe}$ and $\mathrm{Al}$ contents. Slight difference in $\log \mathrm{K}$ between $\mathrm{UC}$ and $\mathrm{NC}$ for both $\mathrm{As}^{\mathrm{V}}$ and MMA indicates that similar adsorbing sites were probably involved in these two types of soils (Table 2.2). Therefore, the much higher values in $M$ for NC compared to UC were attributed to the higher concentrations of $\mathrm{Fe}$ and $\mathrm{Al}$ in $\mathrm{NC}$. Some points on the isotherm curves displayed negative As adsorption at low As spiking levels for most of soils especially for garden soils (PHU, OCP and POT). It was due to accountable original As contents in these soils. Low level As spiked ARW solution actually could leach significant As from soil themselves after reaching adsorption equilibrium (Table 2.2). OCP and POT soil themselves released relatively high As in ARW solution. POT soil exhibited extremely low As adsorption, basically no adsorption for spiked organic As species MMA (Figure 2.2 and Figure 2.3). Low arsenic adsorption by POT was likely caused by the presence of fertilizer Osmocote (Merrifield garden center, VA) in this soil; Osmocote contains high percentage of phosphate (standard 14\%) and fertilizer phosphate is very competitive anion on arsenic adsorption (Melamed et al., 1995).

The relationships between Langmuir maxima $(M)$ and contents of $\mathrm{Fe}$ or $\mathrm{Al}$ oxides have also been reported by other researchers. For example, Jacobs et al. (Jacobs et 
al., 1970) found that $A s^{\vee}$ adsorption increased with the increasing content of Fe oxide. Livesey and Huang (Livesey and Huang, 1980) reported that the Langmuir maxima for arsenate adsorptions on five soils are linearly related to the amount of ammonium oxalate extractable $\mathrm{Al}$ and, to a lesser extent, to the content of ammonium oxalate-extractable $\mathrm{Fe}$. Zhang and Selim (Zhang and Selim, 2005) found that Langmuir maxima exhibited a linear relationship with the total amount of citrate-bicarbonate-dithionite (CBD)extracted $\mathrm{Fe}$ and $\mathrm{Al}$ oxides. None of these researches has mentioned that organic matter amendment effect. The NC and UC soils had higher adsorption capacity of As than the NCP and UCP soils due to the peat amendment in NCP and UCP. With $10 \%(\mathrm{~V} / \mathrm{V})$ peat added to UC and NC soil sands, Langmuir maxima ( $M$ ) and adsorption coefficient $K$ for both $\mathrm{As}^{\mathrm{V}}$ and MMA substantially decreased. The adsorption coefficients $K$ of arsenate and MMA for both UCP and NCP soils were 1 to 2 orders of magnitude lower than for pure UC and NC. The K values for EVS soil fell between those UC and UCP, and between UC and NCP for both $\mathrm{As}^{\mathrm{V}}$ and MMA, suggesting the presence of absorbing sites in EVS with moderate binding strength. The three garden soils displayed relatively weak As adsorption capability even with relative high $\mathrm{Fe}$ and $\mathrm{Al}$ contents comparing to UC and NC soils (Table 2.1 and Table 2.2).

$\mathrm{Fe}$ or $\mathrm{Al}$ oxides were considered as one of the main factors determining the soil adsorption capacity for As (De Brouwere et al., 2004; Goldberg, 2002; Livesey and Huang, 1980). Based on our research findings, we conclude that it is only true when organic matter present in soil low. 


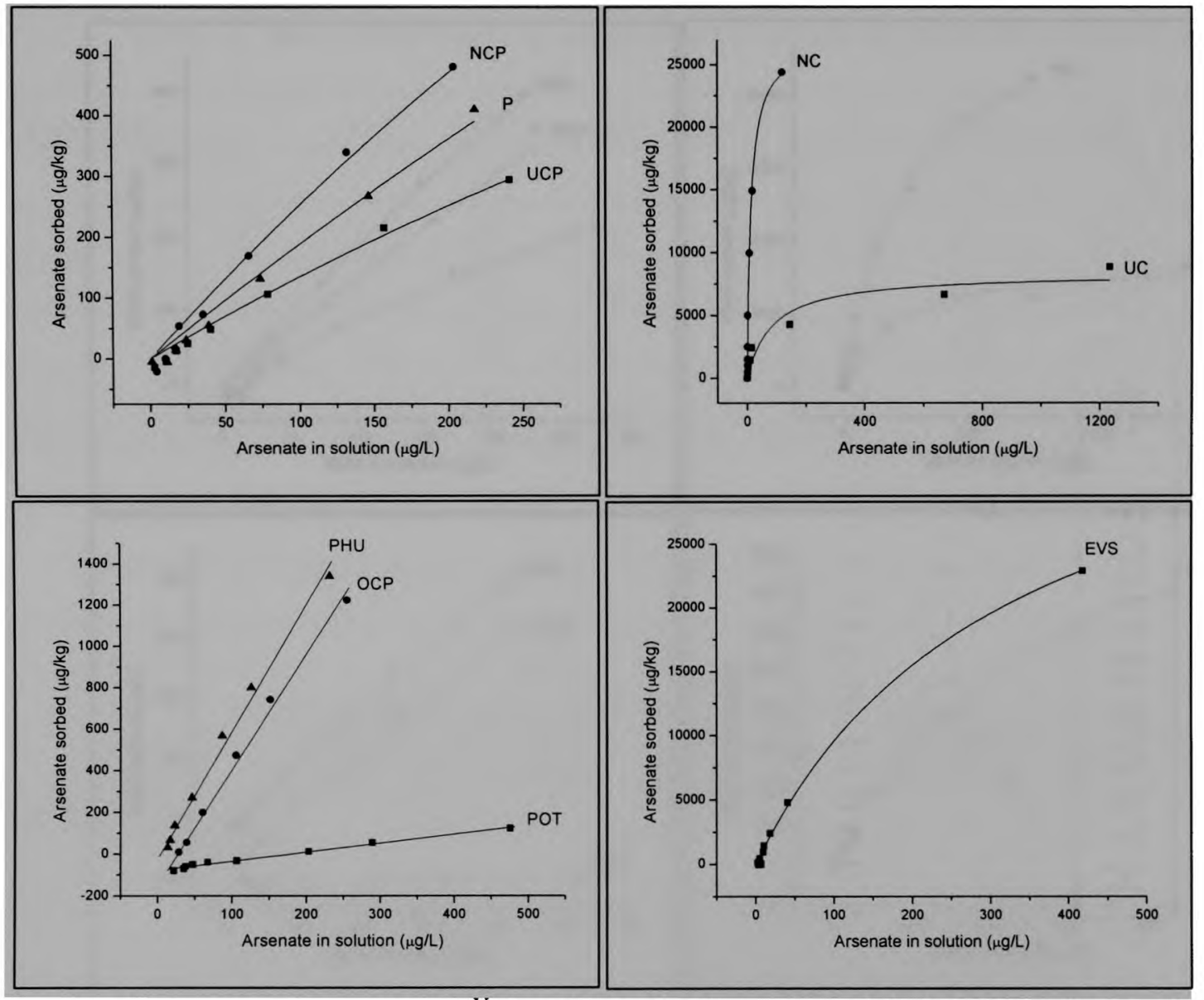

Figure 2.2 Adsorption isotherms of arsenate $\left(\mathrm{As}^{\mathrm{V}}\right)$ by nine soil substrates and their Langmuir equation fitting lines (solid lines) Note: Five golf - course soil types: UC - uncoated sand (plain sand); NC - naturally coated sand (coated with hydroxy-interlayered vermiculate and kaolinite); P - Canadian Sphagnum peat moss; UCP - uncoated sand plus peat (9:1 v/v); NCP - naturally coated sand plus peat $(9: 1 \mathrm{v} / \mathrm{v})$. Four soils from other sources: OCP - All purpose organic compost derived from cow manure compost (Greenleaf products, INC. FL); PHU - Peat humus organic growing medium (Greenleaf products, INC. FL); POT - Potting soil plus Osmocote (The Scotts Company, OH); EVS - Everglades soil (Collected from Everglades National Park, FL). 


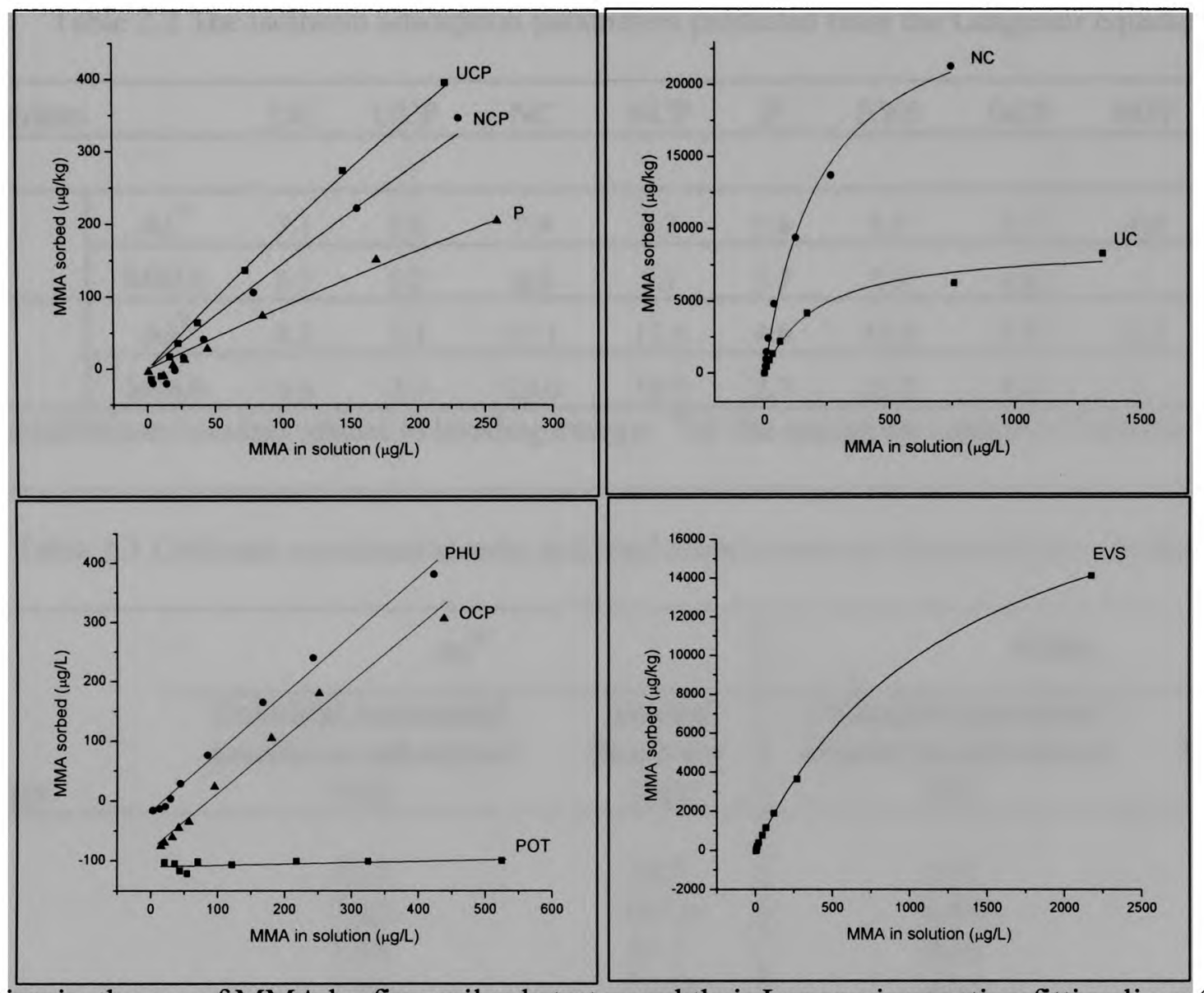

Figure 2.3 Adsorption isotherms of MMA by five soil substrates and their Langmuir equation fitting lines (solid lines)

Note: Five golf - course soil types: UC - uncoated sand (plain sand); NC - naturally coated sand (coated with hydroxy-interlayered vermiculate and kaolinite); P - Canadian Sphagnum peat moss; UCP - uncoated sand plus peat ( $9: 1 \mathrm{v} / \mathrm{v})$; NCP - naturally coated sand plus peat $(9: 1 \mathrm{v} / \mathrm{v})$. Four soils from other sources: OCP - All purpose organic compost derived from cow manure compost (Greenleaf products, INC. FL); PHU - Peat humus organic growing medium (Greenleaf products, INC. FL); POT - Potting soil plus Osmocote (The Scotts Company, OH); EVS - Everglades soil (Collected from Everglades National Park, FL). 
Table 2.2 The isotherm adsorption parameters predicted from the Langmuir equation

\begin{tabular}{|c|c|c|c|c|c|c|c|c|c|c|}
\hline \multicolumn{2}{|c|}{ Soil substrates } & $\mathrm{UC}$ & UCP & $\mathrm{NC}$ & NCP & $\mathbf{P}$ & EVS & $\mathrm{OCP}$ & POT & PHU \\
\hline \multirow{2}{*}{$\log K^{a}(L / k g)$} & $\mathrm{As}^{\mathrm{V}}$ & 7.1 & 5.6 & 7.9 & 5.3 & 5.6 & 6.5 & 5.7 & 4.6 & 6.1 \\
\hline & MMA & 6.7 & 5.2 & 6.6 & 5.1 & 5.7 & 5.9 & 4.6 & - & 5.2 \\
\hline \multirow{2}{*}{$\mathrm{M}^{\mathrm{b}}(\mathrm{mg} / \mathrm{kg})$} & $\mathrm{As}^{\mathrm{V}}$ & 8.3 & 3.4 & 27.1 & 11.6 & 4.6 & 41.0 & 9.9 & 3.5 & 5.7 \\
\hline & MMA & 6.6 & 3.3 & 23.0 & 10.9 & 2.7 & 23.2 & 8.3 & - & 6.4 \\
\hline
\end{tabular}

${ }^{\mathrm{a}} \mathrm{K}$ : the adsorption equilibrium constant related to bonding energy; ${ }^{\mathrm{b}} \mathrm{M}$ : the maximum capacity of arsenic adsorption.

Table 2.3 Colloidal associated arsenic and total arsenic recovery from dialysis experiments

\begin{tabular}{ccc|cc}
\hline & \multicolumn{2}{c|}{ As $^{\mathbf{v}}$} & \multicolumn{2}{c}{ MMA } \\
\cline { 2 - 5 } Soil substrates & $\begin{array}{c}\text { Colloidal Associated } \\
\text { Arsenic in soil extract } \\
(\%)\end{array}$ & $\begin{array}{c}\text { Arsenic } \\
\text { Recovery } \\
(\%)\end{array}$ & $\begin{array}{c}\text { Colloidal Associated } \\
\text { Arsenic in soil extract } \\
(\%)\end{array}$ & $\begin{array}{c}\text { Arsenic } \\
\text { Recovery } \\
(\%)\end{array}$ \\
\hline UC & 0.67 & 98.7 & 0.07 & 105.7 \\
UCP & 1.42 & 101.6 & 0.89 & 93.3 \\
NC & 1.18 & 87.7 & 0.12 & 95.1 \\
NCP & 7.07 & 113.9 & 4.64 & 102.5 \\
P & - & 112.1 & - & 91.0 \\
EVS & 0.33 & 90.1 & 0.20 & 91.5 \\
OCP & 0.51 & 84.9 & 0.05 & 87.8 \\
POT & 0.46 & 86.6 & - & 92.1 \\
PHU & 0.56 & 73.6 & 0.35 & 75.8 \\
\hline
\end{tabular}



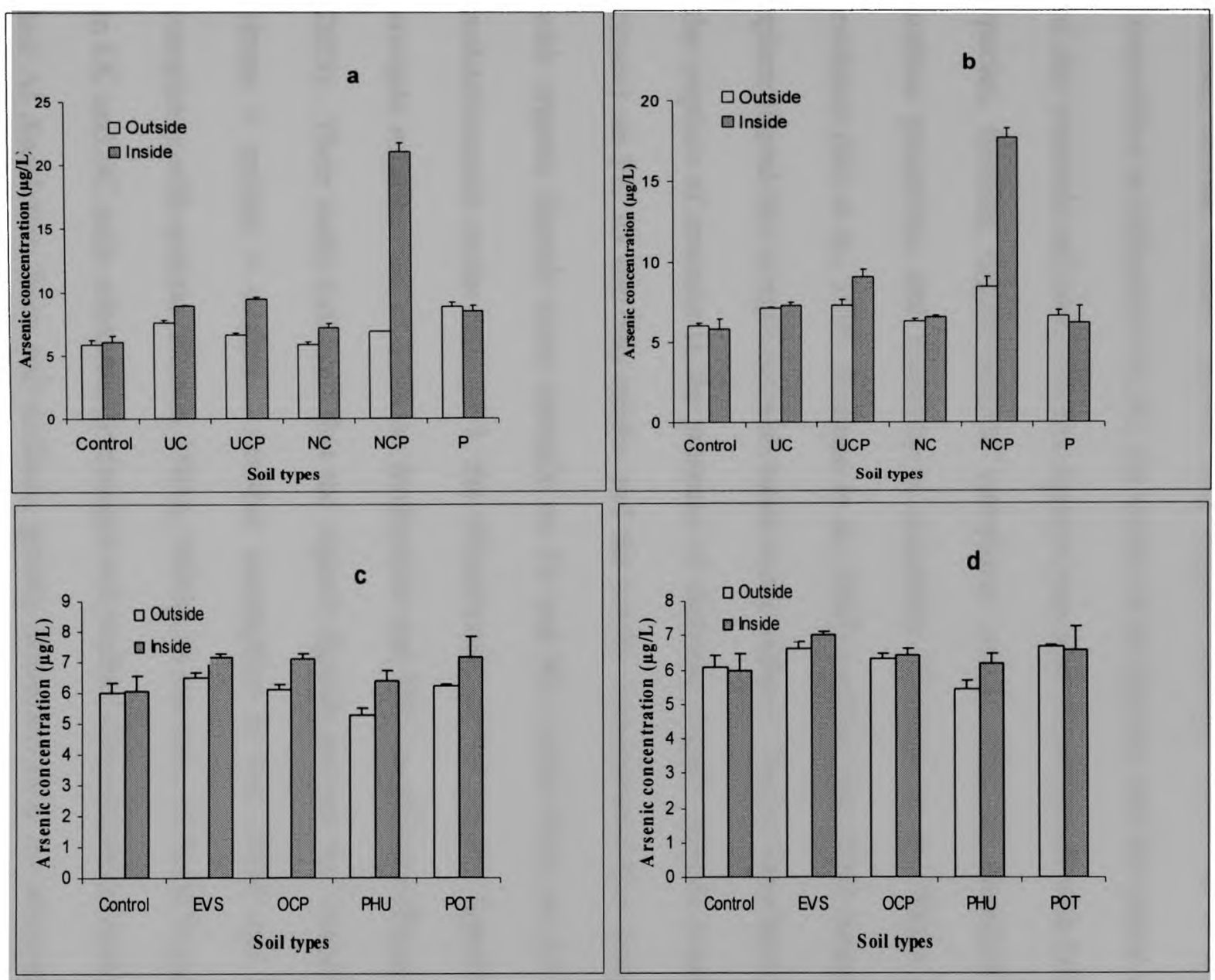

Figure 2.4 Arsenic concentrations inside and outside the dialysis bags (3500 MWCO) for nine soil extracts: a) and c) Arsenate; b) and d) MMA after reaching dialysis equilibrium 
When organic ligands such as strongly chelating organic acids generated from organic matter as well as humic and fulvic acids are previously adsorbed on variable charge minerals or soils, the competitive adsorption of As and organic ligands (e.g., oxalate, tartrate, malate, citrate) may happen (Bowell, 1994; Xu et al., 1988). This competition is influenced by $\mathrm{pH}$, the nature of the ligands, and the nature of the surfaces of clay minerals and soils. Organic ligands may also co-precipitate with $\mathrm{OH}-\mathrm{Al}$ or $\mathrm{OH}-\mathrm{Fe}$ species, forming organo-mineral complexes which differ in chemical composition, surface properties, and reactivity to adsorbent (Violante et al., 2002). Spectroscopic evidence (Gu et al., 1995; Redman et al., 2002) verified that DOM forms strong innersphere ligand-like complexes with metal oxide surfaces. Studies have been carried out on the sorption of arsenate in the presence of chelating organic ligands (oxalate, malate or citrate) on $\mathrm{Fe}, \mathrm{Al}$ and $\mathrm{Mn}$ oxides and the results demonstrated that arsenate competes with organic ligands more strongly on $\mathrm{Fe}$ and $\mathrm{Mn}$ oxides than on $\mathrm{Al}$ oxides. At a malate/arsenate molar ratio of 1 , the effectiveness of the organic ligands in inhibiting arsenate sorption was of $5.5 \%$ on ferrihydrite and $38 \%$ on gibbsite (Pigna and Violante, 2003). Their study indicated that the organic ligands prevent $\mathrm{As}^{\mathrm{V}}$ sorption as follows: citrate $>$ malate $>$ oxalate. Another assumption is that DOM can form aqueous complexes with arsenic (Bloom, 1981a, 1981b). In our case, $10 \%(\mathrm{~V} / \mathrm{V})$ peat amendment in UC and NC soils substantially changed soil surface characteristics (notice that great $\mathrm{Fe}$ and $\mathrm{Al}$ dissolution from soil surface), greatly decreased their As adsorption capability. Other organic matter rich soils also displayed relatively weak As adsorption given the fact that relative $\mathrm{Fe}$ and $\mathrm{Al}$ contents in these soils. Depending on the degree of decomposition, DOM from organic matter amendment may contain a variety of organic 
ligands: such as humic substances, phenol-carbonic acids, amino acids, aldehydes, phenols, sugars, quinones, sterols, terpenes (Black et al., 1954), etc. The interactions between these organic ligands, soil surface $\mathrm{Fe}, \mathrm{Al}$ oxides and adsorbent arsenic ultimately controlled arsenic distribution and mobility in soil systems.

In summary, the presence of organic matter effectively decreases As adsorption capability of soils. Two possible reasons for the observed decrease: 1) DOM interacts with As species and form complexes and subsequently making As not available for soil adsorption; 2) the organic ligands possibly compete with As and scavenge soil As adsorption sites. Strong Fe and Al dissolution occurred from UCP and NCP soils in ARW solution due to $10 \%(\mathrm{~V} / \mathrm{V})$ peat amendment to $\mathrm{UC}$ and $\mathrm{NC}$, suggesting that substances derived from peat moss interact with surfaces in UC and NC soils.

\subsubsection{Dialysis of $A s^{V}$ and $M M A$}

The purpose of this experiment was to evaluate the binding possibility of both $\mathrm{As}^{\mathrm{V}}$ and MMA with colloids and DOM derived from the soils used. In this case, associated As species with MW higher than 3,500 Da were operationally defined as "colloid associated As". Arsenic recoveries of all dialysis experiments were between $85 \sim 114 \%$ (Table 2.3) except for PHU soil extract which was about 75\%. The normalized dialysis results for both $\mathrm{As}^{\mathrm{V}}$ and MMA (Figure 2.4) showed that a very small fraction of As was bound to colloids (> $3500 \mathrm{Da}$ ) in all soil ARW soil extracts (around or less than 1\%). The NCP soil extracts showed approximately 7 and $5 \%$ of the total As associated with the colloidal materials for $\mathrm{As}^{\mathrm{V}}$ and MMA respectively. In our previous dialysis experiments in which As was spiked in outside solution and pure soil extract was put inside dialysis bag (Chen et al., 2006), less than $2 \%$ of total spiked arsenate were associated with MW > 
3,500 Da fraction of dissolved substances in the soil extracts for all tested soils (UC, NC, UCP, NCP and P). This study further confirmed that colloid associated As was not significant in the soil-water systems studied.

\subsection{Conclusions}

$\mathrm{Fe} / \mathrm{Al}$ oxides content and organic matter concentration are all important factors determining As adsorption, hence the mobility in natural soils. $\mathrm{Fe}$ and $\mathrm{Al}$ oxides are positively related to As adsorption only at relatively low concentration organic matter. The content of organic matter in soil will effectively reduced soil As adsorption capability. Care must be exercised for organic matter soil amendment in As contaminated soils. DOM may create the competitive soil-water interfacial environment for the As adsorption. It is likely that the dissolved/surface-bound organic matter become competitive ligands for As, possibly resulting in the enhanced mobility of As. Colloid facilitated transport processes may contribute to the rapid transport of As in subsurface environment, but our results illustrate only a very small fraction of As was associated with colloidal material (> $3500 \mathrm{Da}$ ) in soil ARW extracts. Based on our previous (Chen et al., 2006) and current dialysis results, arsenic was most likely bonded to DOM with MW less than $3500 \mathrm{Da}$. The associations between As and these small substances greatly effect As adsorption on soils, and enhance the facilitated-transport for As in the environments. 
CHAPTER 3

Interactions of Arsenic and the Dissolved Substances Derived from Turf Soil 


\subsection{Abstract}

Monosodium methanearsonate (MSMA) is frequently used as an herbicide for the control of weeds in turf grasses at golf courses in Florida. There are concerns about arsenic (As) contamination of local shallow groundwater from the application of MSMA. It has been suggested that mobility of As in the environment is primarily controlled by adsorption onto surfaces of metal oxides in soil, particularly iron, aluminum, and manganese. However, the dissolved materials derived from soil or soil amendment may interfere with this adsorption. These dissolved materials influence soil As adsorption capability through their interactions with soil surfaces as well as the formation of complexed or colloid-bound As in the soil/water system. The distinction between 'free' As and colloid-bound/complexed As in soil solution is important for understanding the mobility and bioavailability of As in the environment. In this study, equilibrium membrane (500 and 3,500 Da) dialysis method was employed to determine the 'free' and 'bound' As in water extracts of five types of golf-course soils containing coated and uncoated sands in various proportions with peat. All samples were evaluated for arsenic species (arsenite, $\mathrm{As}{ }^{\mathrm{III}}$ and arsenate, $\mathrm{As} \mathrm{s}^{\mathrm{V}}$ ), dissolved organic matter, and additional constituents (iron, aluminum, and calcium). The impacts of microbial growth were evaluated by conducting experiments with and without the addition of sodium azide for one particular soil type. The results indicated that: (1) the presence of peat in the soils plays a significant role in the distribution of As in the dissolved phase of soil solution; (2) the majority As present in the soil extracts from soils containing peat were associated with substances of molecular weight (MW) between 500 and 3,500 Da and with only a small fraction of As being associated with higher MW substances (MW > 3,500 Da); (3) 
the dissolved substances derived from the naturally coated sand and uncoated sand did not show strong binding capability with As; and (4) the association of As and dissolved organic matter (DOM) in the soil solution strongly affected As bioavailability, thus determining As transformation via microorganism-mediated processes; and (5) the presence of peat enhanced greatly the release of iron, aluminum, and calcium from soil. Amendment of sand with peat is a common practice in Florida golf courses. However, the addition of peat will alter the properties of the soils, which in turn could affect strongly As transport and transformation. The results of this study are useful in understanding the factors controlling As trapping and transport within porous soil media and in developing comprehensive plans for managing and re-mediating those As contaminated environments, such as golf courses.

\subsection{Introduction}

Health problems associated with exposure to toxic As species have drawn attention world-wide (Tchounwou et al., 2004) and the use of arsenical pesticides may contribute to the arsenic burden of the environment thereby increasing the likelihood of human exposures. It was found that about $96 \%$ of Florida golf courses spray herbicides containing the active ingredient monosodium methylarsonate (MSMA) 2-3 times every year at an application rate of $\sim 0.224 \mathrm{~g} / \mathrm{m}^{2}$ (Chen, 2003). Due to the local shallow groundwater, significant migration of MSMA and arsenate out of the vadose zone and into the water table has been found after MSMA application (Di Carlo and Fuentes, 2000). A survey conducted on Florida golf courses by the Dade County Department of Environmental Resources Management (DERM) and Florida Department of Agriculture and Consumer Services (FDACS) revealed that the groundwater contamination by As 
was widespread beneath the five golf courses studied (Wiegand, 1999). A laboratory study on As mobility in the soils collected from some selected golf courses (Cai et al., 2002) demonstrated that As present in these soils was relatively mobile or mobilizable, suggesting potential for As leaching. Recently, a field study was conducted to evaluate the influences of substrate composition on As retention and species conversion after application of MSMA (Feng et al., 2005). The results indicated that the substrate composition significantly influenced As mobility and As species transformation in the percolate water. Arsenic species transformation occurred in soil, resulting in cooccurrence of four As species, arsenite $\left(\mathrm{As}^{\mathrm{III}}\right)$, arsenate $\left(\mathrm{As}^{\mathrm{V}}\right)$, monomethylarsonic acid (MMA) and dimethylarsinic acid (DMA) in percolate water. Results from the studies using soils collected from the South Florida golf courses provide useful information in the evaluation of As transport within porous soil media, particularly for golf courses built following the U.S. Golf Course Association (USGA) specifications.

Arsenic movement through soil is mainly related to the fluid dynamics and to its sorption on the solid phase, the latter being in turn controlled by the composition of both solid and liquid phases. Arsenic retention and transport in soil is primarily related to the content of $\mathrm{Fe}$ and $\mathrm{Al}$ oxides (Fuller et al., 1993; Wilkie and Hering, 1996), redox potential (Deuel and Swoboda, 1972; Hess and Blanchar, 1976; Webb, 1966), pH, the type and content of clay in the soil (Dickens and Hiltbold, 1967; Elkhatib et al., 1984), microbial communities (Jackson et al., 2003; Mukhopadhyay et al., 2002; Oremland et al., 2005; Oremland et al., 2004; Sohrin et al., 1997), and to a lesser extent upon exchangeable $\mathrm{Ca}$ and oxyanion competition (Manning and Goldberg, 1996b). Numerous studies have already been conducted on As adsorption onto oxy-hydroxides (Dzombak, 
1990; Gupta and Chen, 1978; Lafferty and Loeppert, 2005; Oscarson et al., 1983; Tossell, 1997; Wilkie and Hering, 1996) and clay minerals (Goldberg, 2002; Goldberg and Glaubig, 1988; Griffin et al., 1977; Manning and Goldberg, 1997). However, only a few of those considered the interactions of As with organic matter (Alberic et al., 2000; CanoAguilera et al., 2005; Grafe et al., 2001; Redman et al., 2002; Thanabalasingam and Pickering, 1986; Warwick et al., 2005) and/or organic-mineral complexes (Saada et al., 2003; Takahashi et al., 1999; Xu et al., 1988), although this has often been revealed as one of the determining factors in cycling of metallic and metalloid pollutants. Moreover, the possibility of As adsorption on organic matter in soil has often been reported (Bhumbla and Keefer, 1994; Chen et al., 1994; Lund and Fobian, 1991; Mok and Wai, 1994; Viraraghavan et al., 1992). Dissolved arsenate $\left(\mathrm{As}^{\mathrm{V}}\right)$ is found primarily in an anionic form, with $\mathrm{H}_{2} \mathrm{AsO}_{4}{ }^{-}$predominating in the $\mathrm{pH}$ range of 2-6, and $\mathrm{HAsO}_{4}{ }^{2-}$ predominating in the $\mathrm{pH}$ range of $6-11$ (Brookins, 1986). Therefore, it is likely that the mechanism of initial adsorption is a result of electrostatic attraction between anionic $\mathrm{As}^{\mathrm{V}}$ and positively charged metal oxide surfaces such as $\gamma-\mathrm{Al}_{2} \mathrm{O}_{3}, \beta-\mathrm{FeOOH}$, positively charged DOM molecules or negatively charged DOM through a formation of cation bridges (by, e.g., $\mathrm{Ca}^{2+}, \mathrm{Mg}^{2+}$, and $\mathrm{Fe}^{3+}$ ) (Fischer and Buttchereit, 2002; Jansen et al., 2003).

The interactions of metals with naturally occurring colloids or DOM play an important role in determining the fate of metals in soils. It is widely accepted that a large proportion of vital or toxic chemicals is associated with inorganic colloids and complexed with DOM in aquatic systems (Jackson et al., 2005; Shafer et al., 2004). Studies of these associations based on molecular size distribution in soil and sediment pore waters have 
attracted much attention in recent years since the facilitated-transport are found to be an important factor controlling the fate and bioavailability of these toxic chemicals (de Jonge et al., 2004). Arsenic distributes between the two phases in the soil-water system, liquid soil solution and solid soil substrate. In the liquid solution, As species may exist in "free" form and/or in association with the dissolved organic matters (DOM) or colloids derived from the soil. The mechanisms of As association with these substances may include molecule-surface interactions, electrostatic interactions (i.e., ion exchange, coulombic attraction), ligand exchange and surface complexation, covalent bonding, and Van der Waals forces. The association strength between As and DOM/colloids is different among these interactions. However, very little work has been done on the association of As with colloids and DOM and the facilitated transport of As in soil. Not only does the association of As with colloid and DOM in solution phase influence the mobility of As through the soil system, it also affects its bioavailability and toxicity (Zhou and Wong, 2003). With regard to the As in Florida golf courses, it is expected that the interactions between As and colloidal materials would play an important role in As fate and transport in the soils based on the fact that the soils used in the Florida golf courses are usually composed of sand and are often amended with organic matter (peat) to improve nutrient and water retention. The large amount of colloidal materials derived from frequent watering could move rapidly through the soils layer. The potential As movement companying with the colloids could has potential impact to the surrounding environment.

Several techniques exist for characterizing the size distribution of associated trace pollutants in aquatic environment. These include dialysis, size-exclusion chromatography 
and ultrafiltration (Cai, 1999). Ultrafiltration is a relatively inexpensive, nondestructive and reagent-free technique, and is frequently used to process large volume samples (Logan and Wagenseller, 2000). In size exclusion chromatography, the solutes are separated in chromatographic columns based on their molecular size. Significant errors could be introduced because of the potential chemical interactions among the column packing, the eluent and the organic components. Dissociation could occur during size exclusion chromatographic separation (Amy et al., 1987; Logan and Wagenseller, 2000). Equilibrium dialysis is a nondestructive means of separating molecules across a semipermeable membrane. A membrane is a selective barrier between two phases: the retentate phase and the permeate phase. The retention of the solutes depends on the size and shapes (linear or spherical, flexible or rigid) configuration of the solutes relative to the pore sizes of the membrane. The separation basically is achieved according to molecular size. The driving force is the concentration differential between the solutions on each side of the membrane. The technique based on the separation of the smaller "free" molecules from the larger complexes by means of a dialysis membrane has been used successfully in several studies of the binding of metals to DOM in natural systems (Buschmann and Sigg, 2004; Haitzer et al., 2002; Jansen et al., 2003; Truitt and Weber, 1981). Very few studies, however, have dealt with metalloid As (Lin et al., 2004).

The purpose of this study was to investigate As distribution in soil solutions and association with dissolved substances derived from several well characterized soils used in Florida golf courses. Since large amount of inorganic arsenate has been observed in a few weeks after MSMA application in a filed study (Feng et al., 2005), we decided to focus inorganic arsenate $\left(A s^{v}\right)$ in this study. Efforts were made to assess the size 
distribution of associated As and to evaluate the effects of naturally-occurring heterogeneous inorganic Fe-, Al- and Ca-containing colloids and DOM on As transport and transformation in the soil-water systems studied. The As speciation in soil solutions was determined by two different operative procedures: an ion-exchange based procedure carried out using high performance liquid chromatography-hydride generation-atomic fluorescence spectrometry (HPLC-HG-AFS) and a molecular weight based procedure carried out using equilibrium dialysis with membranes at different molecular weight cut off (MWCO).

\subsection{Materials and methods}

Chemicals and Materials Individual $\mathrm{As}^{\mathrm{III}}$ and $\mathrm{As}^{\mathrm{V}}$ stock solutions $(1000 \mathrm{mg} / \mathrm{L})$ were prepared by dissolving appropriate amounts of sodium metaarsenite ( $98 \%$, Aldrich) and sodium hydrogen arsenate heptahydrate (98\%, Aldrich) in distilled deionized (DDI) water. Standard solutions used for other metal analyses were ICP-MS grade standards (1000 mg/L in 5\% $\mathrm{HNO}_{3}$ ) purchased from GFS Chemicals, Inc. (Columbus, OH). Spectra/Por CE (Cellulose Ester) membranes and $0.45 \mu \mathrm{m}$ Millipore membrane filter were purchased from Fisher Scientific (Pittsburgh, PA). To prevent metal contamination, all glassware was acid-cleaned prior to the experiments. All other chemicals used in the experiments were analytical or trace metal grade.

Instrumentation Soil extractions were conducted using an Orbital Shaker (Model DS-500, VWR International, West Chester, PA). Total elemental analysis was performed using inductively coupled plasma mass spectrometer (ICP-MS) (Hewlett Packed, model HP4500 PLUS, Wilmington, DE, USA). Arsenic speciation was conducted using HPLCHG-AFS. Separation of the individual As species was performed using a 
SpectraSYSTEM P4000 Thermo Separation Products (Thermo Separation Products, San Jose, CA). This HPLC system was coupled to a PS Analytical Millenium System with Fluorescence detector (PS Analytical, UK). Mobile phase (1.5 mM phosphate, $\mathrm{pH} 5.8$ ) was pumped isocratically at $1 \mathrm{ml} / \mathrm{min}$ through a Hamilton PRP-X100 polymeric guard and analytical anion exchange columns (Hamilton Company, NV, USA). Al and Fe analysis was conducted using an atomic absorption spectrometer (Model AAnalyst 600, PerkinElmer Instruments, Shelton, CT). Dissolved organic carbon (DOC) was measured by acidifying to $\mathrm{pH}<2$ with $3 \mathrm{~N} \mathrm{HCl}$, purging the sample with $\mathrm{CO}_{2}$-free air, and analyzing for total carbon using a hot platinum catalyst direct injection analyzer (Shimadzu TOC 5000).

Soil selection and preparation of soil extracts Five different types of soils, including uncoated sand (plain sand) - UC; naturally coated sand (coated with hydroxyinterlayered vermiculate and kaolinite) - NC; Canadian Sphagnum peat moss - P; uncoated sand plus Canadian Sphagnum peat moss peat at $10 \%(\mathrm{~V} / \mathrm{V})-\mathrm{UCP}$; naturally coated sand plus Canadian Sphagnum peat moss peat at 10\% (V/V) - NCP. The uncoated sands and naturally coated sands are the normal substrates for golf courses putting greens. The uncoated sand used was common quartz sand, light gray or colorless, and did not have clay-sized coatings. Naturally coated sand, collected from Lake County, Florida, had a reddish-brown hue due to oxidized $\mathrm{Fe}$ and $\mathrm{Al}$ in the clay-sized fraction of the coating. It consisted of quartz and clay fractions including hydroxy-interlayered vermiculate $\left(\left(\mathrm{Mg}, \mathrm{Fe}^{++}, \mathrm{Al}\right)_{3}(\mathrm{Al}, \mathrm{Si})_{4} \mathrm{O}_{10}(\mathrm{OH})_{2} \cdot 4\left(\mathrm{H}_{2} \mathrm{O}\right)\right), \quad$ kaolinite $\quad\left(\mathrm{Al}_{2} \mathrm{Si}_{2} \mathrm{O}_{5}(\mathrm{OH})_{4}\right)$, geothite $(\mathrm{FeO}(\mathrm{OH}))$ and gibbsite $\left(\mathrm{Al}(\mathrm{OH})_{3}\right)$. The cation exchange capacities of uncoated 
sands, naturally coated sands and Canadian Sphagnum peat moss were 0.1, 4-5 and 110$130 \mathrm{cmol} / \mathrm{kg}$, respectively (Snyder, 2003).

Soil extracts were prepared by adding $100 \mathrm{ml}$ distilled deionized water (DDI water) to $20 \mathrm{~g}$ soil. The resulted suspension was shaken on the orbital shaker at $300 \mathrm{rpm}$ for $24 \mathrm{hrs}$. The samples were then centrifuged at $2800 \mathrm{~g}$ for 10 minutes. The supernatant was filtered through a $0.45 \mu \mathrm{m}$ Millipore membrane. Prior to the dialysis experiments, As was analyzed in the five soil extracts and was found to be below the detection limits of both methods: ICP-MS $(0.02 \mu \mathrm{g} / \mathrm{L}$ for total As) and HPLC-HG-AFS (2 and $1 \mu \mathrm{g} / \mathrm{L}$ for $A s^{V}$ and $A s^{I I I}$, respectively). The soil extracts were immediately used for the dialysis experiments.

Equilibrium dialysis experiments Before experiments, the dialysis membrane bags (Spectra/Por CE, Fisher Scientific) with molecular weight cut-off (MWCO) of 500 or $3500 \mathrm{Da}$ were soaked in DDI water for $30 \mathrm{~min}$, and then rinsed thoroughly with DDI water. This procedure removes the sodium azide that was used as membrane preservative. Pyrex glass beakers $(600 \mathrm{ml})$ were filled with $400 \mathrm{ml}$ of $50 \mu \mathrm{g} / \mathrm{L} \mathrm{As}{ }^{\mathrm{V}}$ solution referred thereafter to as outside solution. In this outside solution a dialysis tube filled with $15 \mathrm{ml}$ soil extract (or with conductivity-adjusted water alone for control experiment) referred thereafter to as the inside solution, was immersed. Solid $\mathrm{KCl}$ was added to the outside solutions until the ionic strength as measured by a conductivity meter (Model 441, Corning Inc. New York) matched that of the inside solution. The volume ratios of the outside/inside solutions was set to 26: 1 (Truitt and Weber, 1981). Then the beakers were sealed with Parafilm to avoid water evaporation during the course of the experiments and the outside solutions were continuously stirred at room temperature $\left(20^{\circ} \mathrm{C}\right)$ using 
magnetic stirring bars. All experiments were conducted in duplicate. Free As ions could penetrate dialysis membrane and become associated with the dissolved substances present in the soil extract, and some of the associated As species will stay inside the dialysis bag depending on the membrane pore sizes. Free As and those bound As less than the MWCO will reach equilibrium after a certain period of time (Figure 3.1). Arsenic recovery for all dialysis experiments was between 85 to $105 \%$.
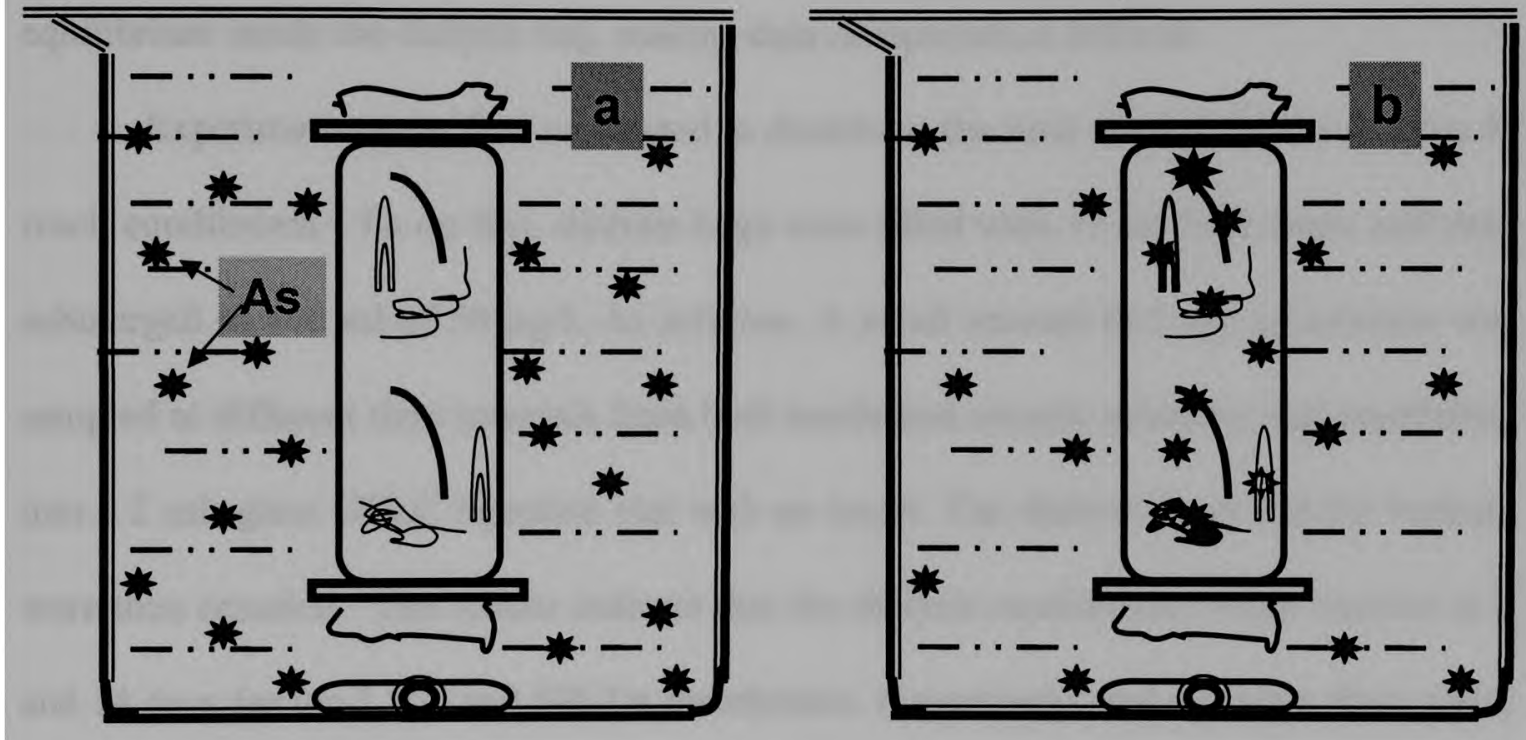

Figure 3.1 Experimental setup of the membrane equilibrium dialysis. The dialysis bag filled with soil extract $(15 \mathrm{ml})$ was immersed in a solution spiked with $50 \mu \mathrm{g} / \mathrm{l} \mathrm{ppb}$ arsenate before dialysis (a) and after dialysis (b) equilibrium

There were several reasons why $\mathrm{As}^{\mathrm{V}}$ was spiked in the outside solution instead of the inside soil extract solution. Arsenic concentration inside the dialysis bag is expected to increase after equilibrium dialysis and the increase in As concentration is caused solely by the association of As with the dissolved materials (e.g. DOM and/or colloids). This arrangement eliminates potential problems for data interpretation, that is, higher As 
concentration in inside dialysis bag may cause by insufficient dialysis time if $\mathrm{As}^{\mathrm{V}}$ is originally spiked in inside dialysis bag. In addition, dramatic changes in As concentration in outside solution would not occur after dialysis equilibrium due to the large volume ratio (outside to inside solutions) (26:1) selected. This would reduce the possibility of disturbing As association equilibrium inside the dialysis bag. If As is spiked inside the dialysis bag, however, the sharp decrease in free As concentration because of the distribution to outside solution could substantially influence the As association equilibrium inside the dialysis bag, making data interpretation difficult.

Experiments were first conducted to determine the time needed for the dialysis to reach equilibrium. To do this, dialysis bags were filled with $15 \mathrm{ml}$ DDI water and then submerged in $400 \mathrm{ml}$ of $50 \mu \mathrm{g} / \mathrm{L}$ As solution. A small amount $(0.2 \mathrm{ml})$ of solution was sampled at different time intervals from both inside and outside solutions and transferred into a $2 \mathrm{~mL}$ glass HPLC injection vial with an insert. The dialysis bags and the beakers were then resealed. The results indicate that the dialysis equilibriums were reached at 7 and 14 days for the 3,500 and 500 Da membranes, respectively, and therefore these times were selected as equilibration periods for all dialysis experiments.

In order to investigate the role played by microbe-involved processes in As species transformation and distribution, further dialysis experiments using one soil type (type $\mathrm{NCP}$ ) was conducted with the addition of sodium azide $\left(\mathrm{NaN}_{3}\right) \cdot \mathrm{NaN}_{3}(0.02 \%)$ was used to inhibit microbe growth (Carter and Suffet, 1982).

\subsection{Results and discussion}

Equilibration time Preliminary experiments were conducted to determine the time needed for the dialysis to reach equilibrium. As expected, As concentration inside the dialysis 
bag was increased progressively, while As in outside solution slightly decreased (Figures $3.2 \mathrm{a}$ and $3.2 \mathrm{~b}$ ). The dialysis equilibriums were reached at 7 and 14 days for 3,500 and 500 Da membranes, respectively. Dialysis was therefore carried out for 7 and 14 day for 3,500 and 500 Da membranes, respectively for the following experiments.

Arsenic distribution Results from the control experiment (without soil extract inside the bags) indicated that As could freely pass both 500 and 3,500 Da membranes and reach equilibrium after the selected dialysis time (Figures $3.3 \mathrm{a}$ and $3.3 \mathrm{~b}$ ). When soil extracts were added inside the dialysis bags, significant differences in As concentrations inside and outside the 500 Da membrane were observed for most of the soil extracts (Figure 1a). Arsenic tended to concentrate inside the $500 \mathrm{Da}$ bag whenever peat was present in the soils (NCP, UCP, and P), with the highest corresponding to the extract of pure peat. For soils without the presence of peat, different As partitioning patterns were observed, with a small amount of As concentrated inside the bag for the uncoated sand (UC) and no difference in As concentrations cross the membrane for the naturally coated sand (NC). When the 3,500 Da membrane was used, slight differences in As concentrations inside and outside the bag were observed for soils with the presence of peat (NCP, UCP, and P), whereas no differences were found for uncoated and naturally coated sands (UC and NC) (Figure 3.3b).

These results indicated that (1) the presence of peat in the soils plays a significant role in the distribution of As in the dissolved phase of soil solution; (2) the majority As present in the extract of soils with peat were associated with substances with MW between 500 and 3,500 $\mathrm{Da}$ and with only a small fraction of As being associated with higher $\mathrm{MW}$ substances ( $\mathrm{MW}>3,500 \mathrm{Da}$ ); and (3) the dissolved substances derived from 
the naturally-coated sand and uncoated sand did not show strong binding capability with As although As was associated to the substances with MW from 500 to $3500 \mathrm{Da}$ to some extent in the extract of uncoated sand. Based on the differences in As concentration between inside and outside $500 \mathrm{Da}$ membrane, it was estimated that about 95, 88, and $87 \%$ of As inside the dialysis bag were associated with substances with MW $>500 \mathrm{Da}$ in the extracts of P, NCP and UCP, respectively. For soils without peat (UC and NC), these were about 63 and $4 \%$. Similarly, only $15,25,10,2$, and $1 \%$ As inside the 3,500 Da membrane were associated with substances with $\mathrm{MW}>3,500 \mathrm{Da}$ for $\mathrm{P}, \mathrm{NCP}, \mathrm{UCP}, \mathrm{UC}$ and NC soils, respectively.

$\mathrm{Fe}, \mathrm{Al}$ and $\mathrm{Ca}$ distribution. Analysis of all five soil extracts for common metal ions indicated that the concentrations of $\mathrm{Mn}, \mathrm{Co}, \mathrm{Cr}, \mathrm{Ni}, \mathrm{Cu}, \mathrm{Zn}$, and $\mathrm{Pb}$ were all below 20 $\mu \mathrm{g} / \mathrm{L}$, whereas the concentrations of $\mathrm{Fe}, \mathrm{Al}, \mathrm{Ca}$, and $\mathrm{Mg}$ varied dramatically among different soils (Table 3.1). Special attention was directed to the contents of $\mathrm{Al}, \mathrm{Fe}$ and $\mathrm{Ca}$ because their importance in the biogeochemical cycling of As and their high concentrations in the soil extracts. The concentrations of $\mathrm{Fe}$ and $\mathrm{Al}$ in the outside solutions after dialysis equilibrium were below the detection limit of AAS $(1 \mu \mathrm{g} / \mathrm{L})$ for both 500 and $3500 \mathrm{Da}$ membranes. The concentrations of $\mathrm{Ca}$ in the outside solutions were also much lower than that of the inside solutions for both membranes (Figure 3.4). The distribution patterns of most elements were similar whether 500 or $3,500 \mathrm{Da}$ membrane was used. The majority of these elements were retained inside the dialysis bags for most soil extracts regardless the dialysis membranes used. 

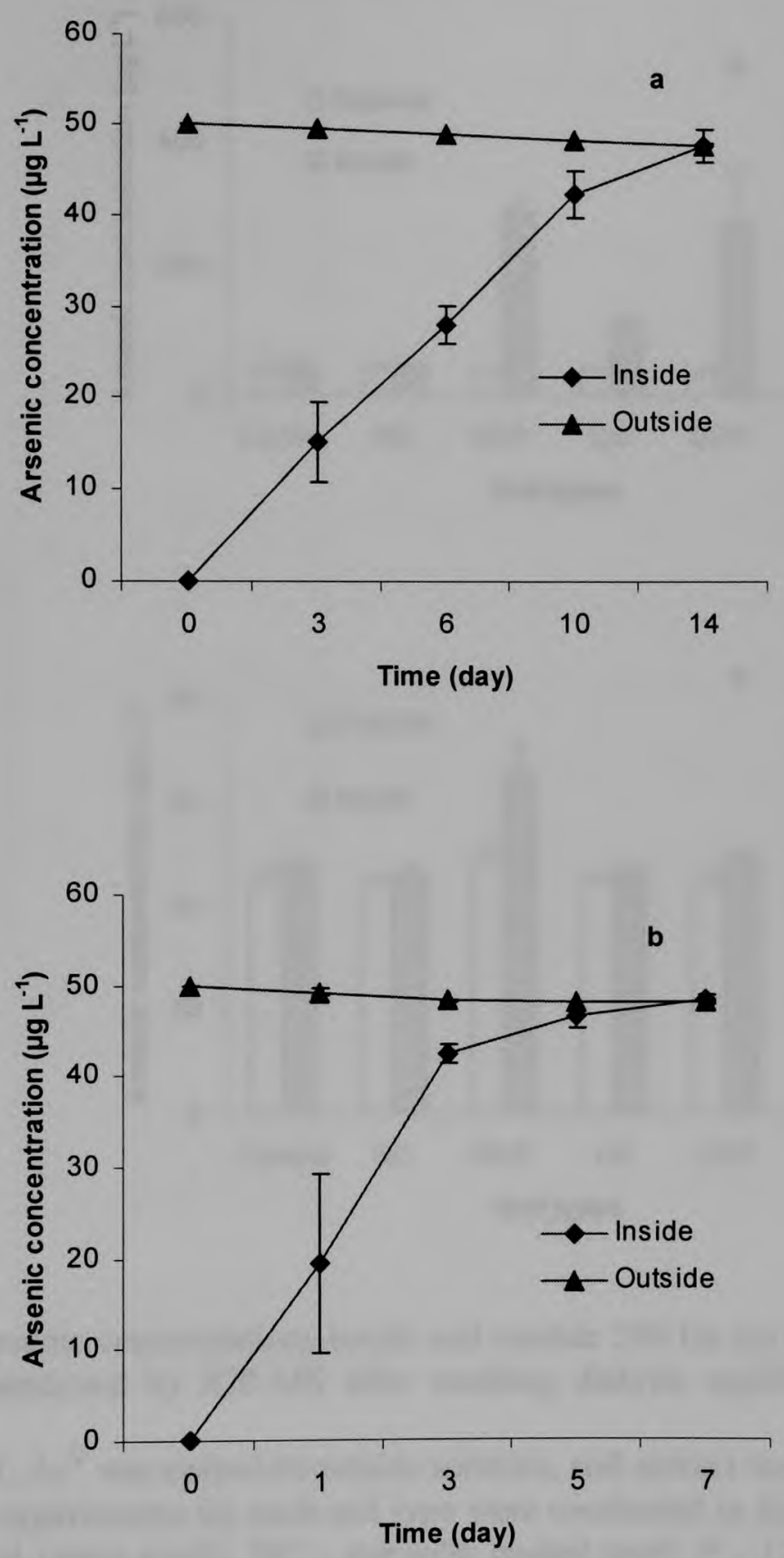

Figure 3.2 Dialysis equilibrium time tests for $500 \mathrm{Da}$ (a) and $3500 \mathrm{Da}$ (b) membranes 


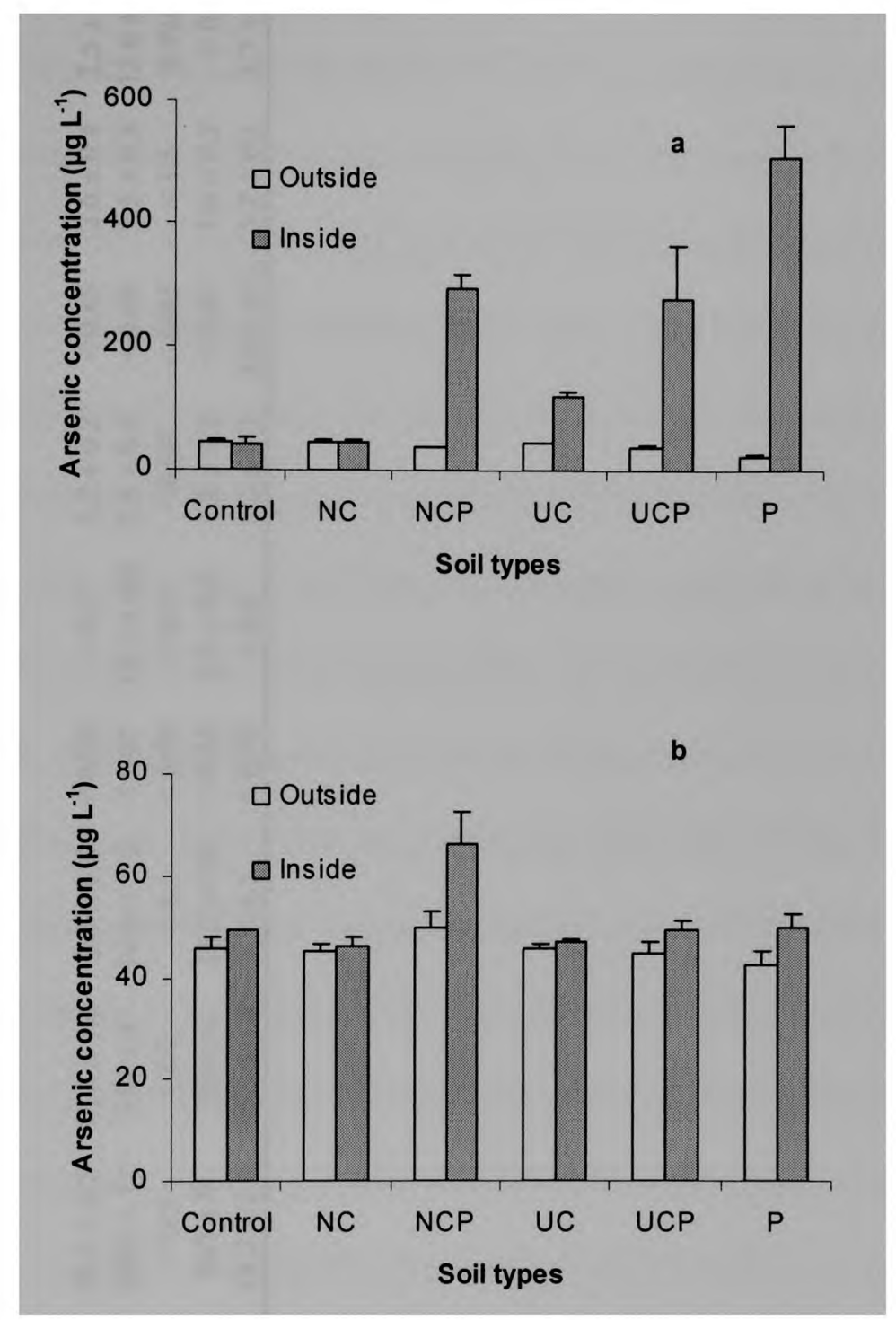

Figure 3.3 Arsenic concentrations inside and outside $500 \mathrm{Da}$ (a) and $3500 \mathrm{Da}$ (b) dialysis membranes analyzed by ICP-MS after reaching dialysis equilibrium for different soil extracts

Note: $50 \mu \mathrm{g} / \mathrm{L} \mathrm{As}{ }^{\mathrm{V}}$ was spiked in outside solution, soil extract was put inside dialysis bag. The dialysis experiments for each soil type were conducted in duplicate. Soil types: UC uncoated sand (plain sand); NC - naturally coated sand; P - Canadian Sphagnum peat moss; UCP - uncoated sand plus peat $(9: 1 \mathrm{v} / \mathrm{v}) ; \mathrm{NCP}$ - naturally coated sand plus peat $(9: 1 \mathrm{v} / \mathrm{v})$. 
Table $3.1 \mathrm{pH}$ and concentrations of some major and minor elements in soil extracts before equilibrium dialysis

\begin{tabular}{|c|c|c|c|c|c|c|c|c|c|c|c|c|}
\hline \multirow[b]{2}{*}{ Soil extracts } & \multirow[b]{2}{*}{ pH } & \multicolumn{11}{|c|}{ Metal Concentration $(\mu \mathrm{g} / \mathrm{L})$} \\
\hline & & $\mathbf{F e}$ & Al & $\mathrm{Ca}$ & $\mathbf{M g}$ & Mn & Co & $\mathrm{Cr}$ & $\mathrm{Ni}$ & $\mathrm{Cu}$ & Zn & $\mathrm{Pb}$ \\
\hline $\mathrm{NC}$ & 4.8 & $64.5 \pm 2.9$ & $79.7 \pm 3.1$ & $76.1 \pm 2.5$ & $12.3 \pm 1.8$ & $3.0 \pm 0.8$ & $<0.05$ & $<0.5$ & $1.2 \pm 0.2$ & $<0.05$ & $2.6 \pm 0.4$ & $2.5 \pm 0.1$ \\
\hline $\mathrm{NCP}$ & 4.5 & $6089 \pm 11$ & $18517 \pm 21$ & $2881 \pm 12$ & $951 \pm 8$ & $14.6 \pm 1.2$ & $<0.05$ & $14.1 \pm 0.6$ & $3.5 \pm 0.4$ & $<0.05$ & $3.5 \pm 0.3$ & $13.0 \pm 0.5$ \\
\hline $\mathrm{UC}$ & 4.6 & $220 \pm 6$ & $718 \pm 11$ & $<0.5$ & $<0.2$ & $<0.1$ & $<0.05$ & $<0.5$ & $<0.02$ & $<0.05$ & $<1.5$ & $3.7 \pm 0.3$ \\
\hline UCP & 4.2 & $511 \pm 7$ & $3099 \pm 15$ & $865 \pm 9$ & $338 \pm 6$ & $13.2 \pm 0.8$ & $<0.05$ & $2.1 \pm 0.4$ & $1.8 \pm 0.2$ & $<0.05$ & $1.6 \pm 0.2$ & $<0.1$ \\
\hline $\mathbf{P}$ & 4.0 & $56.7 \pm 3.2$ & $157 \pm 4$ & $18.3 \pm 2.0$ & $58.2 \pm 1.8$ & $<0.1$ & $<0.05$ & $<0.5$ & $3.2 \pm 0.3$ & $2.0 \pm 0.1$ & $3.2 \pm 0.3$ & $3.7 \pm 0.4$ \\
\hline
\end{tabular}


Concentrations in the inside solutions for some metals were sometimes lower than their concentrations in the initial soil extracts (Table 3.1 and Figure 3.4) (e.g. for soils NC and UC) even though these metals were not detectable in the outside solutions. Several processes could cause this to happen. Aggregation of colloids containing these metals and precipitation of the generated large particles could occur with time, resulting in decrease in metal concentration in the solution. This process is apparently dependent, among other factors, on the physicochemical properties of the dissolved substances in the soil extracts and experimental time period used. In some cases, a slight coagulation could be visually observed. Adsorption of metals on the inner surface of the membrane was also possible during the dialysis processes. In addition, deceased concentration in the inside solution after dialysis could also be attributed to the partitioning of metals into the outside solution. The increase in metal concentration in outside solution was not observed because their concentration was below the detection limit of the analytical methods (note the dilution effect caused by the large volume ratio of outside to inside solutions). However, the latter process was unlikely to occur because the similar distribution patterns observed for both 500 and 3,500 Da membranes. If significant amount of metals could pass the membranes, larger amounts would be expected in the outside solution for the 3,500 Da compared to the 500 Da membranes.

The dialysis results indicated that most of $\mathrm{Al}, \mathrm{Fe}$ and $\mathrm{Ca}$ in the soil extracts existed in the fraction larger than 3,500 Da. By comparing the results of As (Figure 3.3) and that of $\mathrm{Al}, \mathrm{Fe}$, and $\mathrm{Ca}$ (Figure 3.4), it is clear that the distribution of As inside and outside dialysis membranes did not correlate with that of $\mathrm{Fe}, \mathrm{Al}$ and $\mathrm{Ca}$. It appears that $\mathrm{Fe}$, $\mathrm{Al}$ and $\mathrm{Ca}$ were mainly present in the soil extracts with $\mathrm{MW}>3,500 \mathrm{Da}$ and $\mathrm{As}$ was not 
primarily associated with these metals in this fraction. Furthermore, comparing the results of $\mathrm{Fe}, \mathrm{Al}$ and $\mathrm{Ca}$ in soil extracts for the same soil type with or without the presence of peat (NC and NCP or UC and UCP), the presence of peat greatly enhanced the release of $\mathrm{Fe}, \mathrm{Al}$ and $\mathrm{Ca}$ from soils. DOM, particularly humic substances, has a strong influence on the stability of inorganic colloids. Inorganic colloids are stabilized by charge reversal through sorption of humic substances (Kretzschmar and Sticher, 1997; Puls et al., 1993). Similarly, sediment grain dissolution and mobilization of clay colloids by sorption of humic substances is observed (Swartz and Gschwend, 1998). Dissolved substances from peat could act as reactants or ligands to promote the dissolution of $\mathrm{Fe}, \mathrm{Al}$ and $\mathrm{Ca}$ minerals from soils either by competing soil surface adsorption sites for $\mathrm{Fe}, \mathrm{Al}$ and $\mathrm{Ca}$ or by forming complexes with $\mathrm{Fe}, \mathrm{Al}$ and $\mathrm{Ca}$ originally existing on soil surface. Kaurichev et al. (Kaurichev et al., 1974) found that aqueous extracts of fresh or humified plant material (peat moss, etc.) acting on minerals and rocks such as blanket loam, bentonite, and vermiculite, gradually released $\mathrm{Fe}$ and $\mathrm{Al}$ from the crystal lattice in more available forms.

These results again indicate that the dissolved substances derived from peat play an important role in As partitioning in the water/soil systems studied. On the one hand, the reactive functional groups of the dissolved materials could readily scavenge the adsorption/binding sites generated on the $\mathrm{Fe}, \mathrm{Al}$ and Ca-containing colloids (CanoAguilera et al., 2005; Reddad et al., 2002), making the adsorption/binding sites not available for As. On the other hand, the dissolved materials released from peat could interact with As directly, providing less "free" As available for the adsorption by $\mathrm{Fe}, \mathrm{Al}$ and Ca-containing colloids/surfaces. 

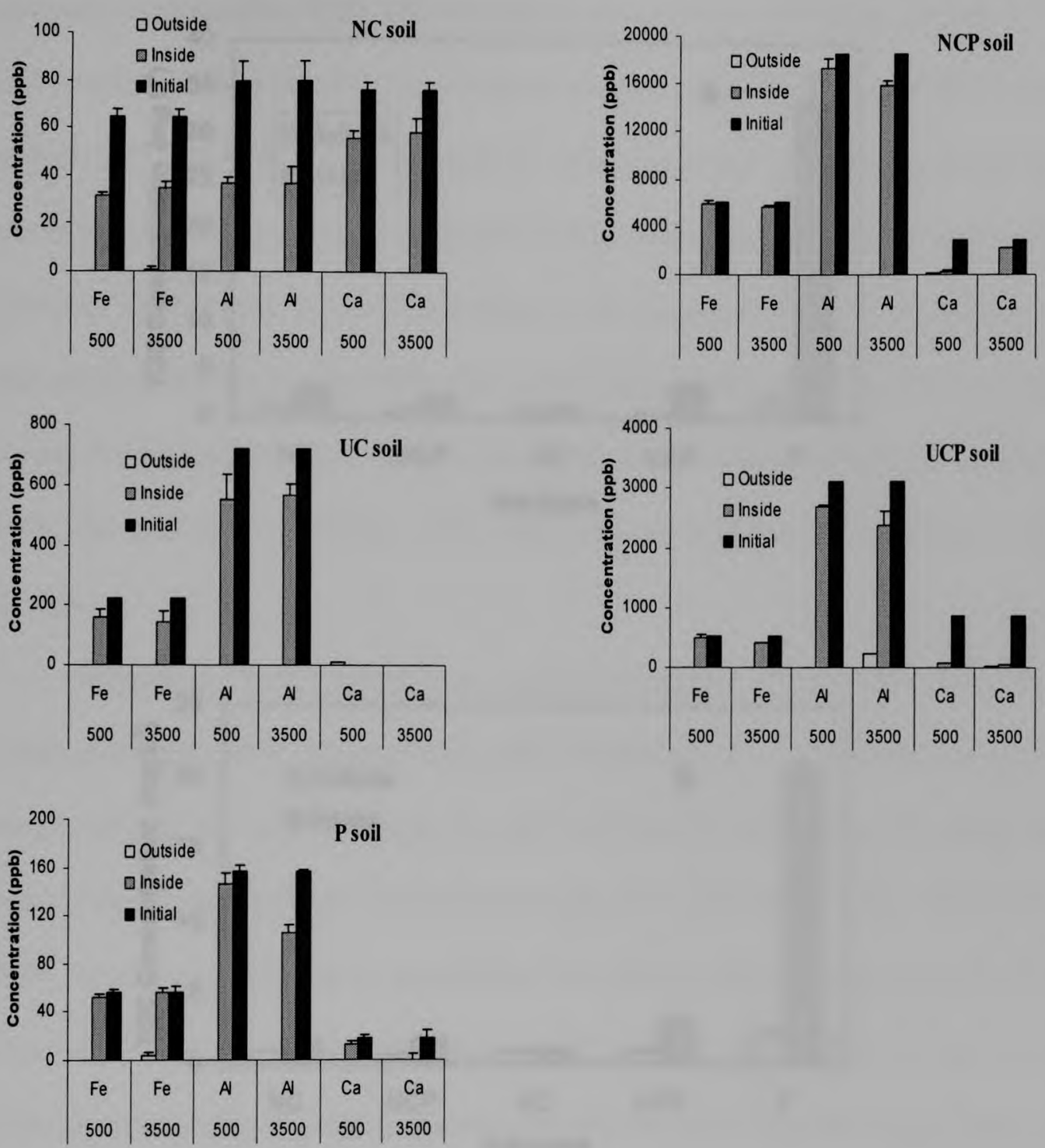

Figure 3.4 Concentrations of $\mathrm{Fe}, \mathrm{Al}$, and $\mathrm{Ca}$ inside and outside 500 and $3500 \mathrm{Da}$ membranes after reaching dialysis equilibrium for different soil extracts

Note: Soil types: UC - uncoated sand (plain sand); NC - naturally coated sand; P Canadian Sphagnum peat moss; UCP - uncoated sand plus peat $(9: 1 \mathrm{v} / \mathrm{v})$; NCP - naturally coated sand plus peat $(9: 1 \mathrm{v} / \mathrm{v})$ 

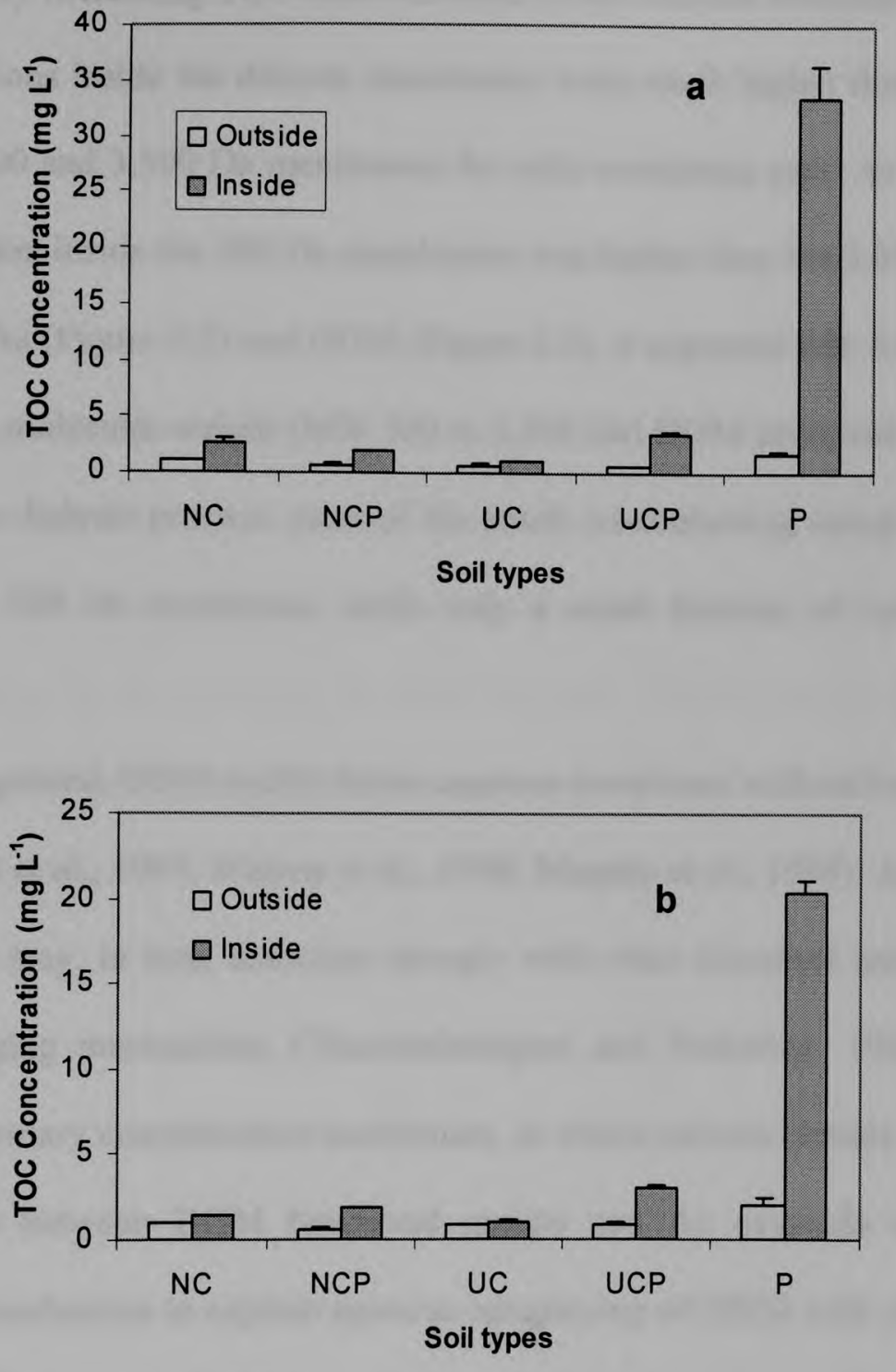

Figure 3.5 TOC concentrations inside and outside $500 \mathrm{Da}$ (a) and $3500 \mathrm{Da}$ (b) dialysis membranes after reaching equilibrium

Note: Soil types: UC - uncoated sand (plain sand); NC - naturally coated sand; P Canadian Sphagnum peat moss; UCP - uncoated sand plus peat $(9: 1 \mathrm{v} / \mathrm{v}) ; \mathrm{NCP}$ - naturally coated sand plus peat $(9: 1 \mathrm{v} / \mathrm{v})$ 
DOM distribution. The effects of DOM on As distribution can be further evaluated by measuring TOC concentrations in the dialysis solutions (Figure 3.5). DOM concentrations inside the dialysis membranes were much higher than outside membrane for both 500 and 3,500 Da membranes for soils containing peat. As expected, the DOM concentration inside the $500 \mathrm{Da}$ membranes was higher than the 3,500 Da one. From the results of As (Figure 3.3) and DOM (Figure 3.5), it appeared that As tended to associate with small molecular weight (MW 500 to 3,500 Da) DOM presumably by complexation. During the dialysis process, most of the small As-containing complexes could retained inside the $500 \mathrm{Da}$ membrane, while only a small fraction of complexes could pass through.

In general, DOM readily forms aqueous complexes with cationic metals and metal oxides (Gu et al., 1995; Majone et al., 1998; Murphy et al., 1999). Aqueous DOM-metal complexes may, in turn, associate strongly with other dissolved anions, presumably by metal-bridging mechanisms (Thanabalasingam and Pickering, 1986; Warwick et al., 2005). A ternary complexation mechanism, in which cationic metals mediated the strong association between DOM functional groups and As oxyacids was proposed as a plausible mechanism to explain aqueous complexing of DOM with As oxyanions (Lin et al., 2004; Redman et al., 2002), although no solid proof has confirmed this hypothesis. From the present study, it seems that most of anionic arsenate associated with DOM with molecular weight less that $3500 \mathrm{Da}$. DOM is highly variable in composition, ranging from simple ligands, like acetate or amino acids, to high molecular weight compounds with many phenolic, carboxylic and amino chelating groups, such as those in fulvic and humic substances (Chian, 1977; Chian and DeWalle, 1977; Gourdon et al., 1989; Oeman 
and Hynning, 1993; Sawhney and Kozloski, 1984). The complexing ability of different fraction of DOM also varied considerably for different metal elements (Harmsen, 1983; Majone et al., 1998). Kalbitz \& Wennrich (Kalbitz and Wennrich, 1998) found DOM content correlated very well with As in the aqueous extracts of the soils they studied.

Since As was mainly present in the fraction from MW 500 to 3,500 Da, the capability of As association with the dissolved substances derived from different soils was estimated by apparent partitioning coefficients $\left(\mathrm{K}_{d}\right)$ between the truly dissolved and the associated phases, operationally defined here as MW $<500 \mathrm{Da}$ and between 500 and $3500 \mathrm{Da}$, respectively. These apparent $\mathrm{K}_{d}$ values were calculated on the basis of DOM concentrations in the solutions of inside 500 and $3500 \mathrm{Da}$ bags after reaching dialysis equilibrium (Table 3.2). Distribution coefficients $\left(\mathrm{K}_{\mathrm{d}}\right)$ that describe the distribution of chemicals between dissolved and associated phases are defined as (Stumm, John Wiley \& Sons: New York 1992),

$$
\mathrm{K}_{\mathrm{d}}=\mathrm{Cs} / \mathrm{C}_{1} \quad[\mathrm{~L} / \mathrm{kg}]
$$

Where Cs is As concentration in the associated phase $(\mu \mathrm{g} / \mathrm{kg})$ and $\mathrm{C}_{\mathrm{l}}$ is As concentration in the dissolved phase $(\mu \mathrm{g} / \mathrm{L}) . \mathrm{K}_{d} \mathrm{~S}$ for the two soils without the addition of peat (NC and UC) could not be calculated because no significant differences in As concentration for NC (Figure 3.3) and in DOM concentration for UC (Figure 3.5) were observed between inside and outside solutions for both 500 and 3,500 Da membranes. $\operatorname{LogK}_{d} \mathrm{~S}$ for NCP, UCP and P were 7.6, 7.2, and 6.2, respectively. The lower $\mathrm{K}_{d}$ observed for $\mathrm{P}$ was likely attributed to the fact that much higher DOM concentration was obtained in the peat extract compared to NCP and UCP where only $10 \%(\mathrm{~V} / \mathrm{V})$ peat were added (Figure 3.5), and not all the DOM with MW between 500 and 3,500 Da were involved in 
the association with As. Inclusion of the part of DOM that does not interact with As in the $K_{d}$ calculation would generate a smaller $K_{d}$ value. It should be noted that although DOM (500 to 3,500 Da) likely dominated in the As partitioning in the soil solutions, other factors including $\mathrm{pH}$ and the contents of $\mathrm{Fe}$ and $\mathrm{Al}$ may also play a role. Nevertheless the apparent $K_{d}$ values calculated using this method could roughly estimate the strength of interactions between As and DOM.

Table 3.2 Estimated arsenic fraction associated with DOM and the apparent distribution coefficients $(\mathrm{Kd})$ of arsenic between dissolved $(<500 \mathrm{Da})$ and DOM associated $(500-$ $3,500 \mathrm{Da}$ ) in different soil extracts after equilibrium dialysis

\begin{tabular}{|c|c|c|c|c|c|}
\hline $\begin{array}{c}\text { Soil } \\
\text { extracts }\end{array}$ & $\begin{array}{c}\text { As in } \\
\text { dissolved } \\
\text { phase }(<500 \\
\text { Da), C } \\
(\mu g / L)\end{array}$ & $\begin{array}{c}\text { As in } \\
\text { associated } \\
\text { phase ( 500 - } \\
3500 \mathrm{Da}) \\
(\mu \mathrm{g} / \mathrm{L})\end{array}$ & $\begin{array}{c}\text { DOM between } \\
500-3500 \mathrm{Da} \\
\left(\times 10^{-9}\right)(\mathrm{kg})\end{array}$ & $\begin{array}{l}\operatorname{Cs}\left(\times 10^{9}\right) \\
(\mu \mathrm{g} / \mathrm{kg})^{6}\end{array}$ & $\begin{array}{l}\operatorname{LogK}_{d} \\
(\mathrm{~L} / \mathrm{kg})\end{array}$ \\
\hline $\mathrm{NC}$ & 45.0 & 1.9 & 18.6 & 0.03 & - \\
\hline NCP & 36.2 & 258 & 2.33 & 3.87 & 7.66 \\
\hline UC & 44.0 & 76.0 & 0.09 & 1.14 & - \\
\hline UCP & 37.7 & 243 & 7.28 & 3.65 & 7.12 \\
\hline $\mathrm{P}$ & 24.0 & 485 & 199 & 7.28 & 6.18 \\
\hline
\end{tabular}

"Note: concentration of the "associated As", Cs in $\mu \mathrm{g} / \mathrm{kg}$ was calculated using the amount of arsenic associated with DOM (which is calculated by column 3 times $15 \mathrm{ml}$ ) divided by the weight of DOM between 500 and $3500 \mathrm{Da}$ (column 4).

Table 3.3 Some apparent distribution coefficient $(\mathrm{Kd})$ of arsenate on different soil materials

\begin{tabular}{lcl}
\hline Soils & LogK $_{\mathbf{d}}$ & Ref. \\
\cline { 2 - 3 } Olivier loam & $\sim 2.1$ & \\
Sharkey clay & $\sim 2.3$ & \\
Windsor Sand & $\sim 2.3$ & (Zhang and Selim, 2005) \\
10 surface soils & 0.1 to 1.8 & (Smith et al., 1999) \\
16 Chinese soils & 2.2 to 3.5 & (Jiang et al., 2005a) \\
30 uncontaminated soils & 1.1 to 3.6 & (De Brouwere et al., 2004) \\
Magnetite crystal & $\sim 4.0$ & (Wakui et al., 2005) \\
\hline
\end{tabular}


Since the lack of data on DOM effects in As partitioning in soil solutions, direct comparisons of our results to others are impossible. Some $\mathrm{K}_{\mathrm{d}}$ values can be obtained from literature where As adsorption studies were conducted using varied soil and synthetic mineral materials (Table 3.3) (De Brouwere et al., 2004; Jiang et al., 2005a; Smith et al., 1999; Wakui et al., 2005; Zhang and Selim, 2005). In a study on As extraction using dispersed ultrafine magnetite $\left(\mathrm{Fe}_{3} \mathrm{O}_{4}\right)$ from aqueous solution, $\log \mathrm{K}_{\mathrm{d}}$ of As was observed to be around 4 (Wakui et al., 2002). Most of the $\log \mathrm{K}_{d}$ for soil samples listed in Table 3.3 is less than 4 . The $K_{d}$ values calculated based on low MW DOM derived from peat were two to three orders higher than those obtained using soils or other solid materials, indicating strong association between these DOM and As.

DOMAs interactions and As speciation. Arsenic species transformation was found during equilibrium dialysis process. Figure 3.6 is regenerated from Figure 3.3 by including As speciation data. Total As was analyzed using ICP-MS and the results were in good agreement with the sum of As species measured using HPLC-HG-AFS (by comparing Figures 3.3 and 3.6). Only $\mathrm{As}^{\mathrm{V}}$ and $\mathrm{As}^{\mathrm{III}}$ were detected and both were present in all dialysis solutions after equilibrium. For the 500 Da membrane dialysis (Figure 3.6a), the major As species outside the membranes was $\mathrm{As}^{\mathrm{III}}$ for all soils and the control. As ${ }^{\mathrm{III}}$ also predominated in the inside solutions of soil NC and the control. It should be noticed that $\mathrm{As}$ remained in $\mathrm{As}^{\mathrm{V}}$ form inside the membrane for soils containing peat. $\mathrm{As}^{\mathrm{V}}$ was also dominant in inside solution of soil UC. For the 3,500 Da membrane experiments (Figure 3.6b), similar As speciation pattern was observed with $\mathrm{As}^{\mathrm{V}}$ was the major form in both inside and outside the membrane with the presence of peat, while As ${ }^{\text {III }}$ predominated for the trials without the presence of peat. 
Table 3.4 Eh $-\mathrm{pH}$ data before and after membrane dialysis

\begin{tabular}{lccccc}
\hline \multirow{2}{*}{$\begin{array}{c}\text { Soil } \\
\text { extracts }\end{array}$} & pH & \multicolumn{2}{c}{$\begin{array}{c}\text { Eh (500 Da Membrane) } \\
\text { (mv) }\end{array}$} & $\begin{array}{c}\text { Eh (3500 Da Membrane) } \\
\text { (mv) }\end{array}$ \\
\cline { 3 - 6 } & & $\begin{array}{c}\text { Before } \\
\text { dialysis }\end{array}$ & $\begin{array}{c}\text { After } \\
\text { dialysis }\end{array}$ & $\begin{array}{c}\text { Before } \\
\text { dialysis }\end{array}$ & $\begin{array}{c}\text { After } \\
\text { dialysis }\end{array}$ \\
NC & 4.81 & 549 & 338 & 553 & 344 \\
NCP & 4.52 & 549 & 361 & 552 & 354 \\
UC & 4.63 & 562 & 346 & 561 & 360 \\
UCP & 4.21 & 553 & 339 & 549 & 309 \\
P & 4.01 & 519 & 369 & 519 & 350 \\
\hline
\end{tabular}

Initially, only $\mathrm{As}^{\mathrm{V}}$ was spiked in the outside solutions. It appears that As tends to remain in $\mathrm{As}^{\mathrm{v}}$ form when strong interactions between $\mathrm{As}$ and the dissolved substances exist. In other words, absence of such interaction promoted transformation of $\mathrm{As}^{\mathrm{V}}$ to $\mathrm{As}{ }^{\mathrm{III}}$. The $\mathrm{pH}$ values of the soil extracts and the oxidation-reduction potential (Eh) of the dialysis systems before and after membrane dialysis are presented in Table 3.4. Decreases in Eh values were observed under each experimental condition. According to the $\mathrm{pH}$-Eh diagram (Bohn, 1976; Brookins, 1986; Vink, 1996), it is unlikely that the reduction of $\mathrm{As}^{\mathrm{V}}$ to $\mathrm{As}{ }^{\mathrm{III}}$ was caused by the decrease in Eh during the course of the dialysis.

Microbial reduction of $\mathrm{As}^{\mathrm{V}}$ to $\mathrm{As}^{\mathrm{III}}$ may occur under both anoxic and aerobic conditions over relatively short time scales (Ahmann et al., 1994a; Macur et al., 2001). The observed As transformation was possibly mediated by microbial involvement. Since our dialysis experiments were not conducted under sterilized condition, microbes could be introduced from reagents, container, and air to the dialysis system. Particularly the relatively long dialysis time would promote microbial growth at low arsenic concentration used in this study (Smedley and Kinniburgh, 2002; Stollenwerk, 2003). 

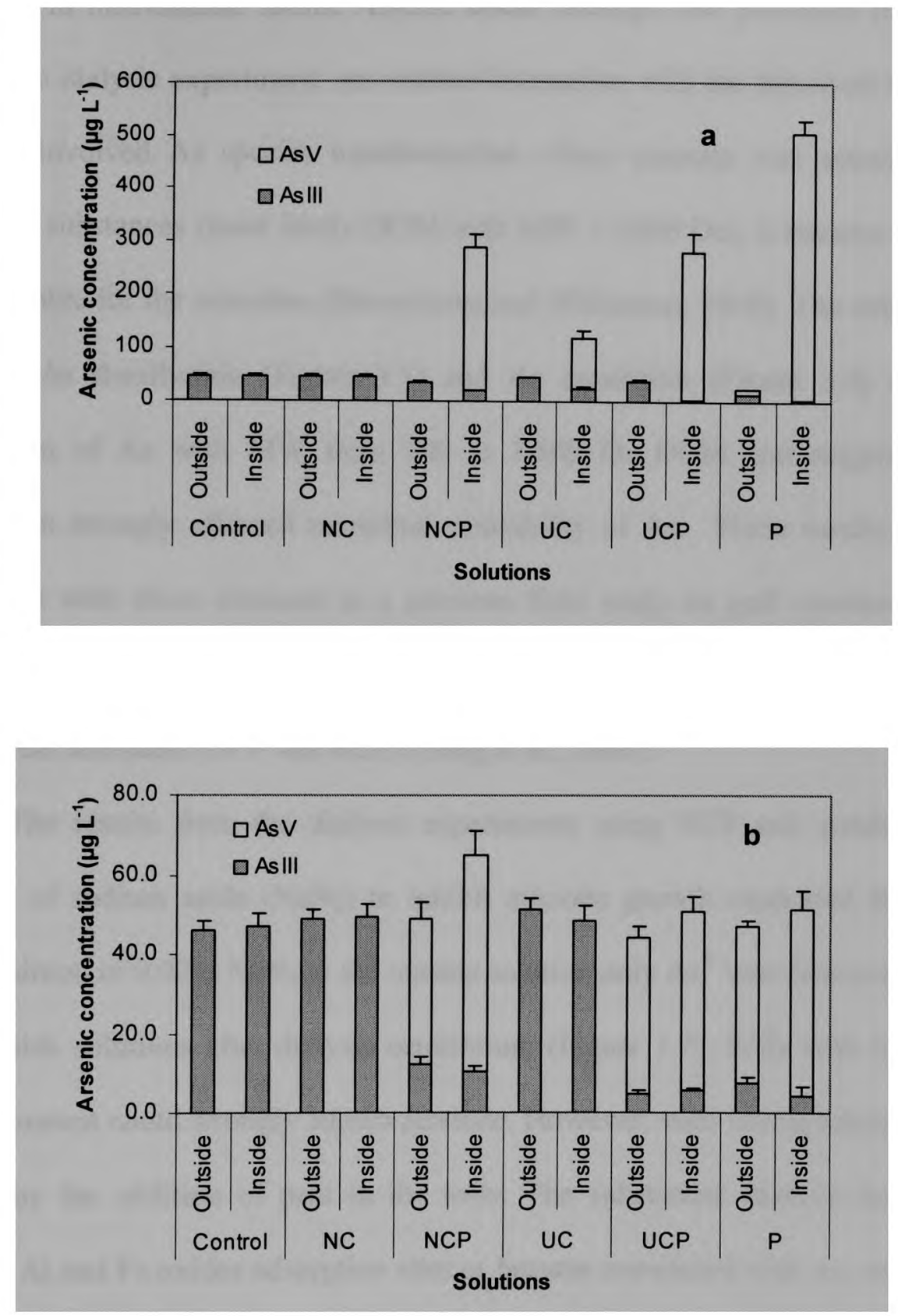

Figure 3.6 Arsenic concentrations with speciation information inside and outside $500 \mathrm{Da}$ (a) and $3500 \mathrm{Da}$ (b) dialysis membranes analyzed by HPLC-HG-AFS after reaching dialysis equilibrium for different soil extracts Note: Soil types: UC - uncoated sand (plain sand); NC - naturally coated sand; P Canadian Sphagnum peat moss; UCP - uncoated sand plus peat $(9: 1 \mathrm{v} / \mathrm{v}) ; \mathrm{NCP}$ - naturally coated sand plus peat $(9: 1 \mathrm{v} / \mathrm{v})$ 
In order for As to be accessible by microorganisms, As should be present in the solutions in bioavailable forms. Arsenic could undergo two processes in the solutions during the dialysis experiment: association/interaction with the dissolved substances and microbe involved As species transformation. Once arsenate was associated with the dissolved substances (most likely DOM with $\mathrm{MW}<3500 \mathrm{Da}$ ), it became unavailable or less available for the microbes (Slaveykova and Wilkinson, 2005). The strong correlation between As distribution (Figure 3.3) and As speciation (Figure 3.6) confirmed the association of As with MW from 500 to 3,500 Da DOM and suggested that such association strongly affected microbial availability of As. These results were in good agreement with those obtained in a previous field study on golf courses where higher $A s^{\text {III }}$ concentration was found in the percolate water of $\mathrm{NC}$ and UC sands compared with that of peat amended (UCP and NCP) (Feng et al., 2005).

The results from the dialysis experiments using NCP soil conducted with the addition of sodium azide $\left(\mathrm{NaN}_{3}\right)$ to inhibit microbe growth supported this conclusion. With addition of $0.02 \% \mathrm{NaN}_{3}$ to the outside solution only $\mathrm{As}^{\mathrm{V}}$ was detected in both inside and outside solutions after dialysis equilibrium (Figure 3.7). Soils with high $\mathrm{Al}$ and $\mathrm{Fe}$ oxides content could strongly adsorb arsenate. However, such strong adsorption could be altered by the addition of peat in the soils. The substances derived from peat either covered $\mathrm{Al}$ and $\mathrm{Fe}$ oxides adsorption sites or became associated with As, which competed with the adsorption of $\mathrm{Fe}$ and $\mathrm{Al}$ oxides. Both adsorption site covering and binding/association by peat-derived DOM will affect As mobility and transformation in the soil-ground water systems. 


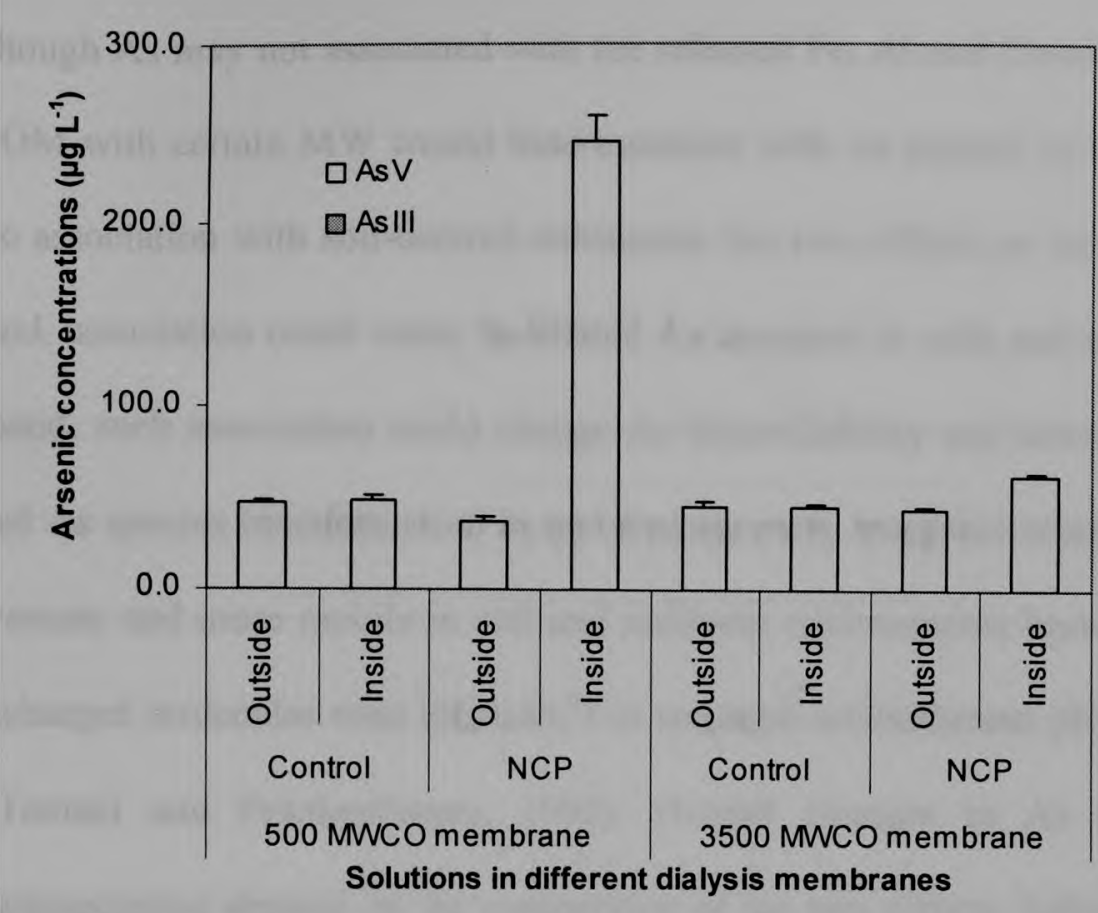

Figure 3.7 Arsenic speciation for dialysis experiment using NCP, naturally coated sand plus peat $(9: 1 \mathrm{v} / \mathrm{v})$, with the presence of NaN3. AsIII was detected neither inside nor outside solutions

Environmental implications Understanding the factors affecting As trapping and transport within porous soil media is an important step toward developing comprehensive plans for managing or re-mediating As contaminated environments. Low soil organic matter content and limited soil water holding are the major natural constraints of dry land cropping on sandy soils. The peat-amended soils are higher in water content, soil organic matter and total porosity. The treatments consisting of Sphagnum peat moss are considered as one of most common soil amendments (Bigelow, 2000) and this could pose potential environmental problems associated with As contaminated soils. DOM derived from peat could promote the release of $\mathrm{Fe}$ and $\mathrm{Al}$ oxides and $\mathrm{Ca}$, which in turn would 
alter the adsorption of As on the oxide surfaces and hence affect the fate and transport As even though As may not associated with the released Fe, Al and Ca-containing colloids. The DOM with certain MW would bind/associate with As present in the soil solutions. Arsenic association with soil-derived substances has two effects on As mobility. On the one hand, association could cause facilitated As transport in soils and sediments. On the other hand, such association could change As bioavailability and hence affect microbeinvolved As species transformation in real environment. Inorganic arsenite is more toxic than arsenate and more mobile in soil and sediment environments because of its neutral and uncharged molecular state $\left(\mathrm{H}_{3} \mathrm{AsO}_{3}{ }^{0}\right)$ in common soil/sediment $\mathrm{pH}$ ranges (e.g., $\mathrm{pH}$ 5-8) (Tamaki and Frankenberger, 1992). Overall changes in As mobility due to binding/association depend on the competition of the two effects. Laboratory batch and column experiments are currently underway to evaluate the effects of major factors controlling As transport and transformation in the soil/water system such as those that occur at golf courses. 
CHAPTER 4

Assessment of Arsenic Transport and Speciation in Golf Course Soils Using Column

\section{Experiment}




\subsection{Abstract}

Predicting the fate of arsenic in soil under various environmental conditions is critical for proper risk assessment and remediation feasibility studies. Dissolved substances derived from soil may interact with both soil surfaces and with arsenic and subsequently influence arsenic mobility and species transformation. The purpose of this paper was to investigate arsenic transport and transformation in porous soil media used in golf courses with a specific focus on the impact of soil-derived heterogeneous substances. Column techniques can be considered as a useful tool both to perform transport experiments and to obtain equilibrium adsorption data without any perturbation of the actual solid/liquid interface. Column experiments were set up in the laboratory to simulate arsenic transport through soils in the presence or absence of the soil-derived dissolved substances under saturated conditions. Two types of soils often used in Florida Golf courses were selected as column packing material and two arsenic species, arsenate, $\left(\mathrm{As}^{\mathrm{V}}\right)$ and monomethylarsonic acid $\left(\mathrm{MMA}^{\mathrm{V}}\right)$ were tested in this study. Arsenic transport and transformation and changes in $\mathrm{pH}$ and Eh values in the column were continuously monitored during the courses of the experiments. Arsenic transport through the column was clearly enhanced (15 to $30 \%$ ) by soil dissolved substances (colloids and/or DOM) depending on soil types and spiked As species. $\mathrm{pH}$ and $\mathrm{Eh}$ results indicated that no strong reducing environments (causing significant As species conversion) were generated in column systems during the column experiment processes. Arsenic species transformation was rapid and extensive under the column conditions and had a significant impact on arsenic transport for both trials using $\mathrm{As}^{\mathrm{V}}$ or $\mathrm{MMA}^{\mathrm{V}}$. In addition to the effect on arsenic transport, the association of arsenic species to soil-derived substances influenced arsenic 
bioavailability, subsequently affected microorganism-involved arsenic transformation. These column studies complemented a range of other experiments conducted in the field as well as laboratory batch studies which are being reported in separate papers. These studies yielded additional insight into processes and mechanisms affecting the geochemical cycling of arsenic in the environment, and provided essential information of key parameters (e.g., extent and rate of adsorption, association reaction, microbe involved species transformation etc.) for risk assessment at arsenic contaminated soil sites. Especially in South Florida golf-courses, after As- containing herbicide MMA application, dissolved substances facilitated As transport and intensive As species transformation could pose serious groundwater As contamination due to local shallow water table.

\subsection{Introduction}

Organoarsenicals are widely used as pesticides and herbicides in the US (Bednar et al., 2002; USGS, 1992). Large quantities of sodium salts of monomethylarsonic acid (MMA) are utilized as herbicides in cotton production (Bednar et al., 2002). The monosodium salt of MMA is among the top pesticides utilized in the United States with approximately 1.2 million $\mathrm{kg}$ of arsenic applied annually to 3.8 million acres (Thelin and Gianessi, 2000). In addition, approximately $35,000 \mathrm{~kg}$ of arsenic from dimethylarsinic acid (DMA) is applied annually as defoliant (Bednar et al., 2002). Occurrence of these organoarsenic pesticides have been reported in varied environmental matrices. In cottonproducing areas, MMA and DMA are detected in surface water, groundwater, and rivers (Bednar et al., 2002). These pesticides were also detected in soil 1-1.5 years after their application to experimental field plots (Akkari et al., 1986; Woolson et al., 1982). It was 
reported that about $96 \%$ of Florida golf courses spray herbicides containing the active ingredient monosodium methylarsonate (MSMA) 2-3 times every year at an application rate of $\sim 0.224 \mathrm{~g} / \mathrm{m}^{2}$ (Chen et al., 2003). Following administration, a variety of chemical and biological processes occurring in the heterogeneous environment produce several arsenic (As) species, and quantities of As may transport through soil to subsurface, resulting in contamination of the ground water aquifer (Di Carlo and Fuentes, 2000; Feng et al., 2005). Different As species exhibit dramatically different sorption and transport behavior in soils and vary substantially different in toxicity (Juhasz et al., 2003). Therefore, it is imperative, that occurrence of a variety of As species and transformation between these species are fully considered when assessing the biogeochemical behavior of As in the environment.

Biogeochemical cycling of toxic chemicals in the environment is governed by many physical, chemical, and biological processes. Transport of chemicals through natural porous media (e.g., soils and aquifers) typically occurs through molecular species dissolved in the pore water (Manning, 1998). The transport of dissolved ions can be modeled by means of a classical convection dispersion model coupled to chemical/biological reactions. Understanding the mobility, bioavailability and transform mechanisms, which are inherent to speciation and the nature of minerals and microbes, is as indispensable as the identification of the pollutants. It is well established that Fe and $\mathrm{Al}$ oxides and hydroxides have a high affinity to As. Many studies have demonstrated that As adsorption on soils is correlated with soil Al and Fe oxides contents (Hartley et al., 2004; Livesey and Huang, 1980; Pierce and Moore, 1982; Sakata, 1987; Zhang and Selim, 2005). However, studies on the adsorption and desorption of organoarsenicals, such as 
monomethylarsonic acid (MMA) on metal oxides are very limited (Lafferty and Loeppert, 2005; Wauchope and McDowell, 1984).

Natural organic matter (NOM) is potentially an important factor influencing As biogeochemistry. Soil derived organic matter such as humic and fulvic acids may interfere strongly with As adsorption and increase As mobility (Jackson and Miller, 1999; Redman et al., 2002). The effect of NOM on the fate and transport of As on farmland and golf courses is particularly important because soil amendment with organic matter is a common practice. For example, the treatment using peat moss is considered as one of most common soil amendments (Bigelow, 2000) and is widely used in golf courses. The peat-amended soils are higher in water content, soil organic matter and total porosity. It is, therefore important to understand how addition of peat affects the behavior of As species, including MMA in peat-containing soils.

It is generally accepted that metal transport in natural aquatic systems strongly depends on the metal binding form. Besides interaction with colloidal particles and soil materials, complex formation is one of the most important reactions of metal ions in aquatic systems. Apart from well-defined inorganic and organic ligands, the heterogeneous mixture of refractory organic substances from microbial degradation and synthesis processes, which will be referred to as dissolved organic matter (DOM), is an important complexing agent for metal ions (Schmitt et al., 2003). In most cases, DOM is found to facilitate metal transport in aqueous systems. DOM competing with the soil matrix for metal binding can also accelerate metal transport (Artinger et al., 1998). A number of investigations have demonstrated that significant correlation between organic carbon content and As distribution suggests organic matter plays a significant role in 
controlling As transport (Anawar et al., 2003; Kalbitz and Wennrich, 1998; McArthur et al., 2004; Tseng et al., 1968).

Studies of As are complicated by the fact that As is presented in oxyanion forms and it readily undergoes transformation between species in environmental conditions. Transformation of As under environmental conditions has important implications because different As species have different sorption and toxicological characteristics. For example, inorganic $\mathrm{As}^{\mathrm{III}}$ is often considered the more mobile and toxic species than inorganic $\mathrm{As}^{\mathrm{V}}$ and thus more problematic regarding contamination of natural waters (Masscheleyn et al., 1991b; Pierce and Moore, 1982; Tamaki and Frankenberger, 1992). Microbes are widely recognized to be of great importance to the transformation of pollutant due to their omnipresence and their metabolic flexibility (Brown et al., 2004; McLean et al., 2002; Toes et al., 2004). Microbial activity may exert direct and indirect influence on As speciation and are attributable to many reactions that result in changes in speciation of As, oxidation of $\mathrm{As}^{\mathrm{III}}$ to $\mathrm{As}^{\mathrm{V}}$ or reduction of $\mathrm{As}^{\mathrm{V}}$ to $\mathrm{As}^{\mathrm{III}}$ (Jackson et al., 2003; Mukhopadhyay et al., 2002; Oremland et al., 2005; Oremland et al., 2004). These inorganic forms can also be biomethylated by certain microbes to gaseous arsines or to MMA and DMA, while other microbes can demethylate organic forms to inorganic species (Pongratz, 1998; Sohrin et al., 1997; Turpeinen et al., 2002).

Soil column leaching tests are a common laboratory scale tool for assessing the fate of chemicals in the environment (Gong and Donahoe, 1997; Haberhauer et al., 2002; Miretzky et al., 2005). The participation of the individual factors in the possible displacement of As to the groundwater can be determined by percolation experiments in columns under saturated flow conditions (Hutson et al., 1990). A constant flow rate of 
water is typically pumped through the column to mimic groundwater or surface water movement in a saturated soil. It was therefore deemed worthwhile to investigate As transport and transformation in a more replicated fashion using laboratory soil columns.

The negative impact to the environment and potential effect on human health of applying organoarsenicals as herbicides has drawn great attention over the last few years (Janet, 2005). The lack of understanding the fate, transport, and transformation of organoarsenicals following application in the field and the factors controlling these processes hampers an appropriate decision making on the future use of these organoarsenicals. The purpose of this work was to investigate the transport and transformation of two As species, inorganic $\mathrm{As}^{\mathrm{V}}$ and MMA using column experiments under simulated environment conditions. The selection of these two species was based on the fact that MMA is widely used as herbicide and inorganic $\mathrm{As}^{\mathrm{V}}$ is the major degradation product of the MMA application (Feng et al., 2005). Several parameters, particularly the soil-derived heterogeneous dissolved substances (DOM and colloids) were studied for their roles in As mobility, species transformation, and microbial bioavailability.

\subsection{Experimental Section}

Chemicals and Materials Inorganic $\mathrm{As}^{\mathrm{III}}$ and $\mathrm{As}^{\mathrm{V}}$ individual stock solutions $(1000 \mathrm{mg} / \mathrm{L})$ were prepared by dissolving appropriate amounts of sodium metaarsenite (Aldrich) and sodium hydrogen arsenate heptahydrate (Aldrich) in distilled deionized (DDI) water. MMA was obtained as a sodium salt (monosodium acid methane-arsonate sesquihydrate, $\mathrm{CH}_{4} \mathrm{AsNaO}_{3}$ ), and DMA was obtained in the acid form (dimethylarsenic acid, $\mathrm{C}_{2} \mathrm{H}_{7} \mathrm{AsO}_{2}$ ), both from Chem Service (West Chester, PA). MMA and DMA individual stock solutions $(1000 \mathrm{mg} / \mathrm{L})$ were also prepared by dissolving appropriate amounts of solid powder in 
DDI water. All other chemicals used were analytical grade and were obtained from Fisher (Pittsburgh, PA).

Four types of soil components well characterized in our previous studies were used in this study (Chen et al., 2006; Snyder, 2003). Uncoated sand (plain sand) - UC; Naturally coated sand (coated with hydroxy-interlayered vermiculite and Kaolinite) - NC; Uncoated sand plus Canadian Sphagnum peat Moss (9:1 v/v) - UCP; Naturally coated sand plus Canadian Sphagnum peat Moss (9:1 v/v) - NCP. Canadian sphagnum peat moss was added at $10 \%(\mathrm{~V} / \mathrm{V})$ in UCP and NCP mixture. Uncoated sands and naturally coated sands are the normal substrates for golf courses putting greens. The uncoated sand used was common quartz sand, light gray or colorless, and did not have clay-sized coatings. Naturally coated sands, collected from Lake County, Florida, had a reddishbrown hue due to oxidized $\mathrm{Fe}$ and $\mathrm{Al}$ in the clay-sized fraction of the coating. It consisted of quartz and clay fractions including hydroxy-interlayered vermiculate $\left(\left(\mathrm{Mg}, \mathrm{Fe}^{++}, \mathrm{Al}\right)_{3}(\mathrm{Al}, \mathrm{Si})_{4} \mathrm{O}_{10}(\mathrm{OH})_{2} \cdot 4\left(\mathrm{H}_{2} \mathrm{O}\right)\right)$, kaolinite $\left(\mathrm{Al}_{2} \mathrm{Si}_{2} \mathrm{O}_{5}(\mathrm{OH})_{4}\right)$, geothite $(\mathrm{FeO}(\mathrm{OH}))$ and gibbsite $\left(\mathrm{Al}(\mathrm{OH})_{3}\right)$. The cation exchange capacities of uncoated sands, naturally coated sands and Canadian Sphagnum peat moss were 0.1, 4-5 and 110-130 cmol/kg, respectively (Snyder, 2003).

The column influent solutions used were artificial rain water (ARW) and soil extracts using artificial rain water. Brielfly, an ARW stock solution was prepared with the following chemicals at the final concentrations as specified: $\left(\mathrm{NH}_{4}\right)_{2} \mathrm{SO}_{4}, 925 \mathrm{mg} / 1 ; \mathrm{NaCl}$, $386 \mathrm{mg} / \mathrm{l} ; \mathrm{CaCO}_{3}, 200 \mathrm{mg} / \mathrm{l} ; \mathrm{MgSO}_{4}, 180 \mathrm{mg} / \mathrm{l} ; \mathrm{KCl}, 37 \mathrm{mg} / \mathrm{l} ; \mathrm{KH}_{2} \mathrm{PO} 4,14 \mathrm{mg} / \mathrm{l} ; \mathrm{NaNO}_{3}$, $40 \mathrm{mg} / \mathrm{l} ; \mathrm{HNO}_{3}, 7.0 \mathrm{mM} ; \mathrm{HCl}, 1.0 \mathrm{mM}$ (Velthorst, 1993). This stock solution was diluted 100 times with DDI water prior to use. To prepare the soil extracts, UCP and NCP (peat- 
amended UC and NC, respectively), were extracted with ARW. It was found in our previous studies that the presence of peat in soils dramatically alters the transport and transformation of As in soil and enhanced greatly the release of Al- and Fe-containing colloids from soil (Chen et al., 2006; Feng et al., 2005). Therefore, we chosen soil extracts of UCP and NCP, two soil components amended with peat, for the current study.

Soil (20g) was placed in a $125 \mathrm{ml}$ Nalgene HDPE bottle (Fisher Scientific) followed by adding $100 \mathrm{ml}$ ARW solution. The mixture was subsequently agitated on a rotary platform shaker at $300 \mathrm{rpm}$ for $24 \mathrm{~h}$. Soil particulates were removed by centrifugation at $2800 \mathrm{~g}$ for $10 \mathrm{~min}$. The supernatant was then separated and filtered with a Whatman GF/C glass microfiber with pore size of $1.2 \mu \mathrm{m}$. The fresh filtered ARW soil extract or ARW $(500 \mathrm{ml})$ was spiked with testing As species at predetermined concentrations. This solution was stored in nitric acid cleaned glass bottle and used immediately as influent solution. Taking the colloidal stability into consideration, new influent solutions were generated after five days of column experiments.

\section{Methods}

Continuous-flow Column Experiments. The column experiment was designed to investigate the effect of the dissolved soil substances in soil extract on As transport and transformation. Two sets of column experiments, one for $\mathrm{As}^{\mathrm{V}}$ and other for MMA, were conducted. Each set of experiment included four columns, two as duplicate testing columns (A and B) fed with soil extract and the other two as duplicate controls (C and D) fed with ARW solution. The NC and UC soil components were selected as column packing materials. Both were cleaned with flowing DDI water before being packed into columns in order to remove loosely attached material that may detach during the 
experiment. The clean soils were oven dried at $60^{\circ} \mathrm{C}$. A glass wool plug was placed in the bottom of the column to prevent leaching of soil particles. All purpose cement (manufactured by OATEY, OH, U.S.A) for polyvinyl chloride (PVC) was used to coat a thin layer of plain sand onto column inside wall to minimize boundary flow. After the pretreatment of coating, all columns were soaked in $10 \%$ nitric acid for three days, and then rinsed thoroughly with DDI water before use. The dried soil $(800 \mathrm{~g})$ was packed into each column, which was made of PVC pipe with a dimension of $5 \mathrm{~cm}$ (i.d.) $\times 31 \mathrm{~cm}$ (length). The columns were then fed with solutions delivered with an Ismatec IPC-12 pump (Ismatec, Germany) with a constant flow rate at the inlet $(90 \mathrm{ml} /$ day). The soil inside each column was covered with a layer of influent solution $(5 \mathrm{~cm})$ during the course of the experiment. All columns were preconditioned by percolation with 100 pore volumes of ARW to homogenize the composition of ion exchange surfaces and stabilize ionic strength. Then, each column was leached with a solution (either ARW or soil extract) spiked with As at $90 \mathrm{ml} /$ day. The influent solutions were spiked with 100 or 200 $\mu \mathrm{g} / \mathrm{L}$ As (inorganic $\mathrm{As}^{\mathrm{V}}$ or MMA) for UC or NC soil column experiments, respectively. Our preliminary experiments indicated that NC soil possesses much higher As adsorption capability than UC soil. Therefore, influent solution for NC column was spiked with higher As concentration to reduce experimental time. The column effluent was collected from the bottom end of the column in a polypropylene bottle and pooled for As speciation analysis each day. Bromide ion, applied in the influent solution at a concentration of $0.6 \mathrm{mM}$, was used as nonsorbing tracer to determine the hydraulic characteristics of the columns. The concentration of bromide ion in the eluent was determined by a bromide ion selective electrode (Accumet, Fisher Scientific, Pittsburgh, 
PA). At the end of the experiment, soil core in each column was sectioned into 4 portions and representative sample soils from each section were digested with concentrated nitric acid (open vessel digestion outlined in EPA method 3050A). The resulting solutions were analyzed for total As by ICP-MS using a Hewlett Packed inductively coupled plasma mass spectrometer (ICP-MS) (Model HP4500 PLUS, Hewlett-Packard Co., Wilmington, DE, USA).

pH-Eh monitoring. Both $\mathrm{pH}$ and Eh were monitored during the course of the experiments by a pH/ORP controller (Model 3671, JENCO Instruments, INC. San Diego, USA). A microProbe glass body $\mathrm{pH}$ electrode (Accumet, Fisher Scientific, Pittsburgh, PA) was placed on top of each column. The probe was inserted into top layer of the influent solution and served as a $\mathrm{pH}$ sensor. The probe was modified in our laboratory so that the $\mathrm{KCl}$ saturated $\mathrm{Ag} / \mathrm{AgCl}$ reference electrode inside this probe was served as a reference electrode for the Eh monitoring. A home made noble metal electrode $(99.95 \%$ platinum wire) was inserted into the bottom of each column. The pair of electrodes (platinum working electrode and $\mathrm{Ag} / \mathrm{AgCl}$ reference electrode) was used for reductionoxidation potential (ORP) measurement. The sole function of the inert metal electrode was to acquire the electrochemical potential of electrons. The actual potential measured was the difference between that of the noble metal electrode and the reference electrode. Two $\mathrm{pH} / \mathrm{ORP}$ controller were used for each column, one was used for Eh monitoring and the other for $\mathrm{pH}$. The Eh was reported versus standard hydrogen electrode (NHE), which means that the Eh value was calculated by adding the reference electrode potential to potential measured by the $\mathrm{pH} / \mathrm{ORP}$ controller (Patrick and Henderson, 1981; Vorenhout et al., 2004). 
Arsenic speciation analysis. Arsenic speciation was conducted on daily basis using a high performance liquid chromatography coupled with hydride generation atomic fluorescence spectroscopy (HPLC-HG-AFS) (Chen et al., 2006). Separation of the individual As species was performed using a HPLC system from SpectraSYSTEM P4000 Thermo Separation Products. This HPLC system was coupled to an atomic fluorescence spectrometer (AFS) (PS Analytical Millenium System, PS Analytical, UK). Mobile phase (1.5 $\mathrm{mM}$ phosphate, $\mathrm{pH} \mathrm{5.8)}$ was pumped isocratically at $1 \mathrm{ml} / \mathrm{min}$ through a Hamilton PRP-X100 polymeric guard and analytical anion exchange columns (Hamilton Company, NV, USA).

Fe, Al and DOM analysis. $\mathrm{Al}$ and $\mathrm{Fe}$ analysis was conducted by a Perkin Elmer atomic absorption spectrometer (Model AAnalyst 600, PerkinElmer). DOC in the effluent solution was measured by acidifying to $\mathrm{pH}<2$ with $3 \mathrm{~N} \mathrm{HCl}$, purging the sample with $\mathrm{CO}_{2}$ - free air, and analyzing for total carbon using a hot platinum catalyst direct injection analyzer (Shimadzu TOC 5000). Soil total organic matter (TOC) was determined as the loss of weight of soil on ignition at $550{ }^{\circ} \mathrm{C}$ for 5 hours (Svendsen et al., 1993).

\subsection{Results and Discussion}

Total As elution The mobility of As and tracer bromide ion in the columns under different conditions was evaluated using the ratio of $\mathrm{As}$ or $\mathrm{Br}^{-}$concentrations in the effluent vs. those in the influent. A ratio value around 1 indicates that the retention/adsorption of $\mathrm{As}$ or $\mathrm{Br}^{-}$on the column reached equilibrium. The elution of $\mathrm{As}$ and $\mathrm{Br}^{-}$was monitored up to 25 and 16 pore volumes for $\mathrm{UC}$ and $\mathrm{NC}$, respectively. Total input $\mathrm{As}$ for both $\mathrm{As}^{\mathrm{V}}$ and MMA experiments for all columns during the entire experimental period was $480 \mu \mathrm{g}$ as As. 

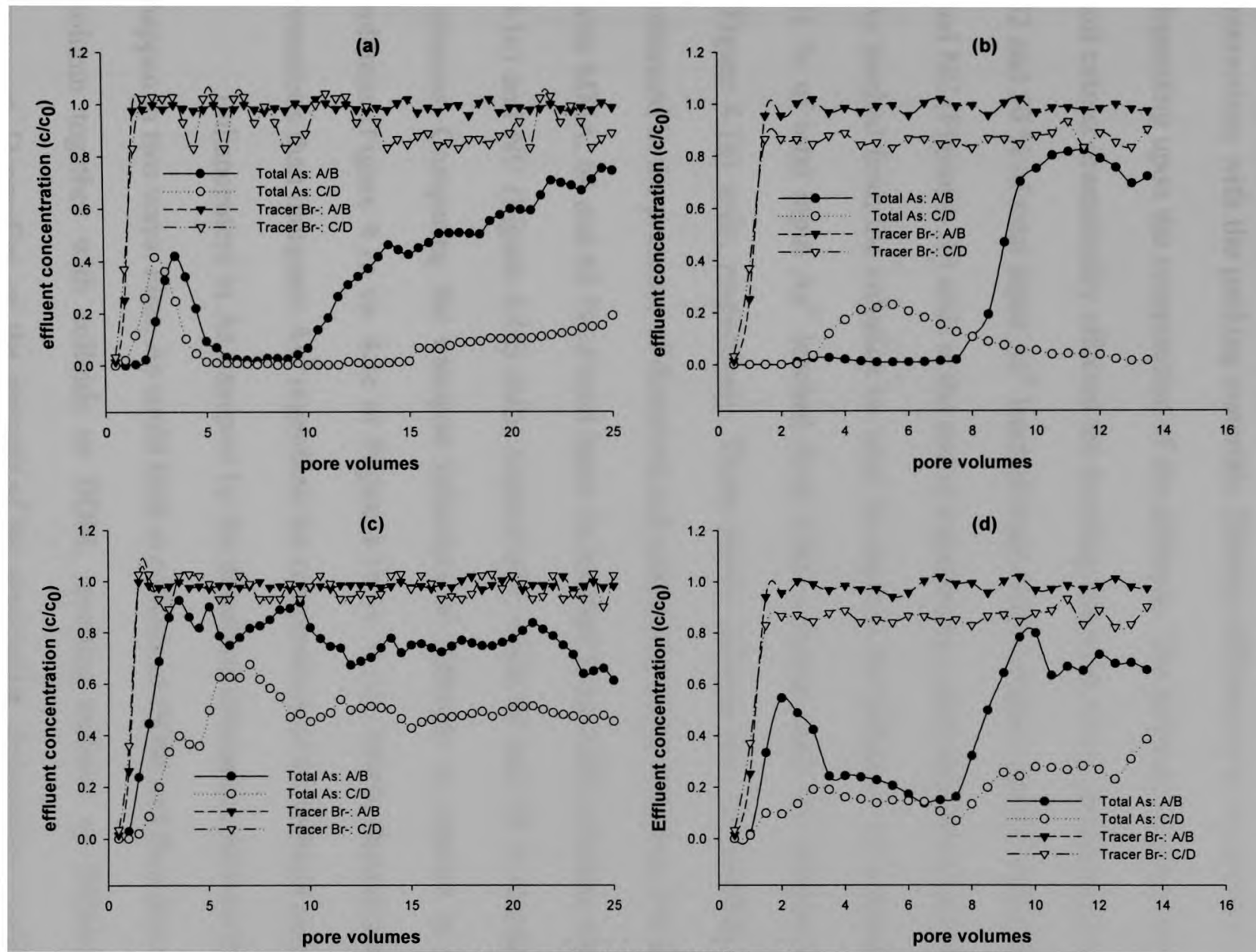

Figure 4.1 Breakthrough curves for total arsenic and tracer in UC and $\mathrm{NC}$ columns

Note: (a) UC column, influent spiked $\mathrm{As}^{\mathrm{V}}, \mathrm{c}_{0}=100 \mu \mathrm{g} / \mathrm{L}$, (b) $\mathrm{NC}$ column, influent spiked $\mathrm{As}{ }^{\mathrm{V}}, \mathrm{c}_{0}=200 \mu \mathrm{g} / \mathrm{L}$, (c) UC column, influent spiked MMA, $c_{0}=100 \mu \mathrm{g} / \mathrm{L}$, (d) NC column, influent spiked MMA, $c_{0}=200 \mu \mathrm{g} / \mathrm{L}$. Each data point was the average of samples from the duplicated columns 
The concentration of tracer reached equilibrium shortly after influent application (about 2 pore volumes) for all column experiments (Figure 4.1). Compared to the tracer, As movement (for both $\mathrm{As}^{\mathrm{V}}$ and MMA) exhibited significant retardation due to its interactions with the packing materials. Distinct differences in As elution were observed depending upon the composition of the influents. The presence of dissolved substance in soil extract dramatically affected the leaching behavior of As, particularly for $\mathrm{As}^{\mathrm{V}}$. About 52 and $50 \%$ of total input $\mathrm{As}^{\mathrm{V}}$ leached from $\mathrm{A} \& \mathrm{~B}$ columns packed with UC (Figure 4.1a) and NC (Figure 4.1b) soils at the end of experiments calculated based on the accumulated As leached from the columns vs. total As input in the influents. In contrast, only 23 and $21 \%$ of total input $A s^{\mathrm{V}}$ leached from C\&D columns with UC (Figure 4.1a) and NC (Figure 4.1b) soils, respectively. These results indicate that As mobility was strongly enhanced in the presence of dissolved soil substances in the influents. For influent spiked with MMA, 64 and $63 \%$ of total input As leached from A\&B columns with UC (Figure 4.1c) and NC (Figure 4.1d) soils, respectively, while 46 and $28 \%$ leached from C\&D columns. Comparing the transport behaviors of different As species in the same soil columns (Figure $4.1 \mathrm{a}$ vs. $4.1 \mathrm{c}$ or Figure $4.1 \mathrm{~b}$ vs. $4.1 \mathrm{~d}$ ), MMA showed relatively lower retentions than inorganic $\mathrm{As}^{\mathrm{V}}$ regardless the composition of the influent composition.

Enhancement in As transport by the dissolved substances derived from soil could happen in two ways. First, As could bind to colloids or DOM and then moves through the column together with colloids or DOM, resulting colloid- or DOM-facilitated As transport. Depending on the strength of the association, dissociation could occur during the transport because of the interactions of As or colloids/DOM with column packing material. Second, colloids or DOM could reduce As sorption by competing with As 
Table 4.1 Characteristics of the soils used

\begin{tabular}{|c|c|c|c|c|c|c|c|}
\hline \multirow[t]{2}{*}{ Soils } & \multirow[t]{2}{*}{$\mathrm{pH}$} & \multirow[t]{2}{*}{$\begin{array}{l}\text { TOC (Total Organic } \\
\text { carbon) }(\%)\end{array}$} & \multirow[t]{2}{*}{$\begin{array}{l}\text { ARW-extractable } \\
\text { DOC }\left(\mathrm{mg} \mathrm{L}^{-1}\right)\end{array}$} & \multicolumn{2}{|c|}{$\begin{array}{l}\text { ARW-extractable (mg L' } \\
\left.{ }^{1}\right)\end{array}$} & \multicolumn{2}{|c|}{ Nitric acid digested $\left(\mathrm{mg} \mathrm{kg}^{-1}\right)$} \\
\hline & & & & $\mathrm{Fe}$ & $\mathrm{Al}$ & $\mathrm{Fe}$ & $\mathrm{Al}$ \\
\hline UC & 4.5 & 0.01 & 1.03 & 0.24 & 0.58 & 37.1 & 54.2 \\
\hline UCP & 4.1 & 0.17 & 6.38 & 2.18 & 11.56 & 48.7 & 62.5 \\
\hline $\mathrm{NC}$ & 4.8 & 0.02 & 2.01 & 0.06 & 0.24 & 331 & 216 \\
\hline NCP & 6.4 & 0.15 & 2.96 & 21.4 & 20.4 & 344 & 224 \\
\hline $\mathrm{P}$ & 3.4 & 53.2 & 35.57 & 0.76 & 0.59 & 693 & 490 \\
\hline
\end{tabular}


molecules for sorption sites on the soil surface, allowing enhanced leaching of As. Once the adsorption of colloids/DOM with or without association with As to the packing materials reaches equilibrium after a certain period of time, the facilitated As transport is expected to occur. With $\mathrm{As}^{\mathrm{V}}$ presented in the influent solutions, dissolved substance in soil extract exhibited strong capability in facilitating As transport after 10 pore volumes elution for UC soil (Figure 4.1a); the same was true for NC after 8 pore volumes (Figure 4.1b). Less distinct differences in As concentrations were observed in the effluents from A\&B and C\&D columns when MMA was presented in the influent solutions for both UC (Figure 4.1c) and NC (Figure 4.1d) columns. Nevertheless, the dissolved substances in soil extract showed clearly enhanced As transport for both As species. Some irregularity in As leaching pattern was observed at the beginning of the experiments for some columns (e.g. Figures 4.1a and 4.1c). Arsenic concentrations in the effluents were increased at the beginning and then decreased after several pore volumes. This could be caused by less well conditioned columns that resulted in preferential flow.

Some irregularity in As leaching pattern was observed at the beginning of the experiments for some columns (e.g. Figure 4.1a and 4.1c). The increases in As concentrations in the effluents occurred at the beginning of the experiment and decreased after several pore volumes. This could be caused by less well conditioned columns that resulted in preferential flow at the beginning of experiments.

Soil As adsorption capability is determined strongly by soil characteristics and As species. Soil Fe/Al - oxides are considered as sink for As (Fuller et al., 1993; Wilkie and Hering, 1996). The ARW extractable Fe and $\mathrm{Al}$ were much lower compared to that of the acid extractable. Acid extractable $\mathrm{Fe}$ and $\mathrm{Al}$ were much higher in $\mathrm{NC}$ than in $\mathrm{UC}$ soil 
(Table 4.1). The high content of $\mathrm{Fe}$ and $\mathrm{Al}$ in NC soil likely contributed to the stronger retention of $\mathrm{As}^{\mathrm{V}}$ and MMA on NC compared to UC soil (Figure 4.1). This is particularly true when ARW was used as influent. The presence of soil-derived substances in the influent seems to control the retention of As species, therefore minimizing the role of $\mathrm{Fe}$ and $\mathrm{Al}$ present in the soils. Inorganic $\mathrm{As}^{\mathrm{V}}$ was much more retainable than organic MMA on same soil. As arsenic is more highly methylated its adsorption affinity generally decreases (Lafferty and Loeppert, 2005). A study conducted to calculation soil adsorption coefficients for $\mathrm{As}^{\mathrm{V}}$ and MMA for golf courses in South Florida found that organic arsenical (MMA) was between four and 22 times more prone to leaching than arsenate in low organic carbon soils (Di Carlo, 1999). The adsorption of methyl arsenic likely plays a significant role in behavior of the total arsenic in soil systems especially in those areas that organoarsenicals are applied as pesticides or herbicides. The reduced adsorption affinity of methyl arsenic species could cause increased levels of arsenic to move into ground and surface water when these species are present.

$F e, A l$ and DOM elution and their effects on As transport Similar breakthrough curves (BTCs) for $\mathrm{Fe}$ and $\mathrm{Al}$ were observed for the columns with same packing material (Figure 4.2a and $4.2 \mathrm{c}$ or Figure $4.2 \mathrm{~b}$ and $4.2 \mathrm{~d}$ ) regardless the type of As species spiked in the influent. For UC soil (Figure 4.2a and 4.2c), a steady increase in $\mathrm{Al}$ concentration in the effluent was observed for $\mathrm{A} \& \mathrm{~B}$ columns up to 15 pore volumes. Fe concentration was also increased at the beginning, but remained relatively constant after 3 pore volumes. The concentrations of $\mathrm{Al}$ after 15 pore volumes and $\mathrm{Fe}$ after 3 pore volumes in the effluent were similar to their concentrations in the influent (Table 4.1), suggesting equilibrium was almost reached. For NC soil (Figure 4.2b and 4.2d), both Fe and $\mathrm{Al}$ were 
strongly adsorbed on columns A\&B, leaching starting from 6.5 and 8 pore volumes for $\mathrm{As}^{\mathrm{V}}$ and MMA tests, respectively. The concentrations of $\mathrm{Fe}$ and $\mathrm{Al}$ in the influent of $\mathrm{NC}$ column were 21.4 and $20.4 \mathrm{mg} / \mathrm{L}$, respectively (Table 4.1 ). The elution results indicated that $\mathrm{Fe}$ present in the influent was adsorbed on the soil, while $\mathrm{Al}$ was rapidly released from soil with time exceeding its concentration in the influent $(20.4 \mathrm{mg} / \mathrm{L})$. By the end of the experiment, Fe was still far from equilibrium comparing to influent Fe concentration (Table 4.1). Some irregular up and down in $\mathrm{Fe}$ and $\mathrm{Al}$ concentrations in the effluents was possibly attributed to the coagulation of Fe/Al-containing colloids during the transport process. If particles resulted from the coagulation of $\mathrm{Fe}$ and $\mathrm{Al}$ retained inside the columns, it would cause decrease in Fe/Al concentration in the effluent solution. An abrupt increase in Fe/Al concentration is expected if such particles were eluted from the columns due to hydrodynamic flow. Without the presence of dissolved soil substances, very little $\mathrm{Fe}$ and $\mathrm{Al}$ were leached (all $\mathrm{C} \& \mathrm{D}$ column results in Figure 4.2).

DOC concentrations in the effluents were increased with time for both $\mathrm{UC}$ and $\mathrm{NC}$ in the presence of soil extracts extracts (Figure 4.3, A\&B columns). The DOC concentrations in the influents, i.e. the soil ARW extracts, used for UC and NC columns were 6.4 and 3.0, respectively (Table 4.1 ). It appears that DOC in the effluents was almost reach equilibrium by the end of the experiments for UC columns. Considerable DOC adsorption on NC columns was also observed when $\mathrm{As}^{\mathrm{V}}$ was spiked. Effluent DOC concentrations were higher when MMA was spiked in the influent compared with $\mathrm{As}^{\mathrm{V}}$ spiked.

$\mathrm{Fe} / \mathrm{Al}$ containing colloids and DOM are the two categories of the dissolved substances in soil extracts, which probably dictate the As transport through the soil 
column. The reasonably good correlations between $\mathrm{Fe} / \mathrm{Al}$ and $\mathrm{As}$ concentrations in the effluents suggest that a facilitated As transport by Fe/Al probably existed. However, it is recognized that good correlations do not necessarily indicate that As was directly bound to $\mathrm{Fe} / \mathrm{Al}$ colloids or DOM because they could just elute simultaneously without any strong associations. Simply comparing the elution curves may be misleading. Although we are lack in direct evidence from this study on whether or not As was associated with $\mathrm{Fe}, \mathrm{Al}$ or DOM during the transport, our previous study using membrane equilibrium dialysis using the same soil components could provide some insight (Chen et al., 2006). It was found that As was mainly associated with small dissolved substances (MW between 500 to $3500 \mathrm{Da}$ ) in soil extracts and the vast majority of the dissolved $\mathrm{Fe} / \mathrm{Al}$ was present in the fraction of larger than $3500 \mathrm{Da}$. It has been concluded that that these dissolved substances with small MW mainly composed of DOM in the studied soil extracts. The strong association of As with DOM, rather than $\mathrm{Fe}$ and $\mathrm{Al}$ suggests that DOM was likely responsible for the facilitated transport of both As species in the present column experiments. A general conclusion drawn from other studies is that low MW DOM components are highly mobile and could influence metal transport in aquifer material (Han and Thompson Michael, 2003; McCarthy et al., 1996). Peat-derived DOM may has a strong metal-binding ability and small MW DOM-bound metals might be more mobile than dissolved, uncomplexed metals ions (Han and Thompson, 1999).

Elucidating the mechanism of DOM and As interactions in the column is complicated by the fact that several processes may occur concurrently. After the influent composed of soil extract is induced into the column, DOM will partition between the soil solid phase and the mobile phase. This can be supported by the lower DOM 
concentration observed in the effluent compared with that in the influent (the DOC concentrations were 6.4 and $3.0 \mathrm{mg} / \mathrm{L}$ for $\mathrm{UCP}$ and $\mathrm{NCP}$ soil extracts, respectively) (Table 1). The DOM could scavenge column soil adsorption sites for both 'free' and 'associated' As. Highly mobile small MW DOM could elute from column and present in the effluent from the beginning of the column experiments. Once the adsorption reached equilibrium, facilitated transport would be observed.

Although the MW distribution of DOM was not measured in the influent and effluent solutions, it is expected that lower MW DOM could be more mobile and passed the column faster than the larger ones (Han and Thompson, 2003). Arsenic present in the influent could undergo a series of interactions between As and soil surfaces, DOM sorbed on the soil surfaces, and DOM in the mobile phase. The former two types of interactions could significantly slow down the As transport, causing small As eluted at the beginning of the experiments (Figure 1). After certain period of time, the interaction of As with soil surfaces became week and toward equilibrium. The interactions between As and DOM (most likely the small MW ones) in the mobile phase became dominant and the facilitated transport was clearly observed. This could be the situation in a real environment where organoarsenicals are applied in the organic matter amended soils. A study on Fecontaining colloids/DOM associated transport of major and trace elements in small boreal rivers and their estuaries (NW Russia) has indeed found that As was not associated with colloidal Fe and presented in the form of "dissolved" species with molecular weight less 

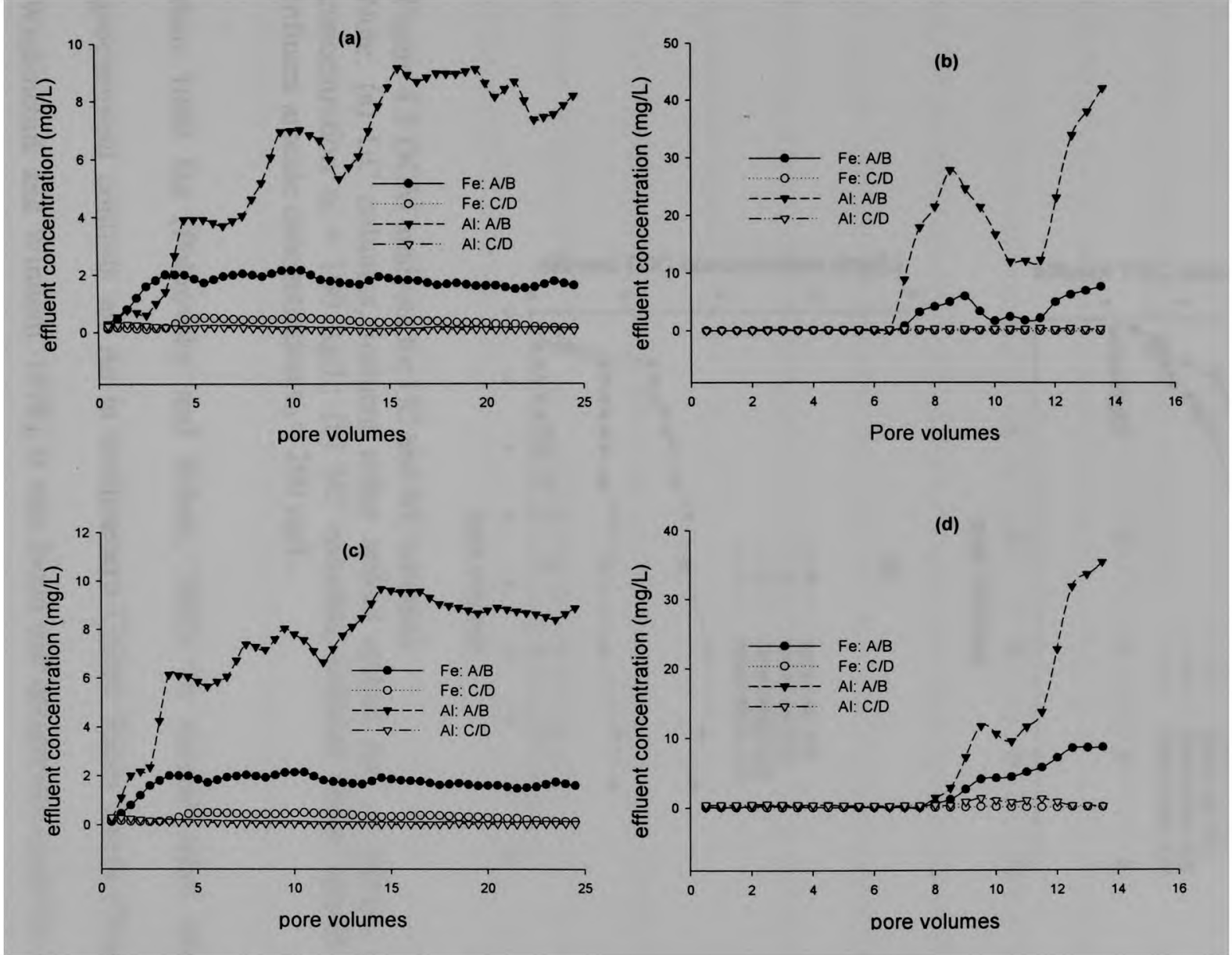

Figure 4.2 Effluent $\mathrm{Fe}, \mathrm{Al}$ analysis for $\mathrm{UC}$ and $\mathrm{NC}$ columns

Note: (a) UC columns, influent spiked $\mathrm{As}^{\mathrm{V}}, \mathrm{c}_{0}=100 \mu \mathrm{g} / \mathrm{L}$; (b) NC columns, influent spiked $\mathrm{As}^{\mathrm{V}}, \mathrm{c}_{0}=200 \mu \mathrm{g} / \mathrm{L}$; (c) UC columns, influent spiked MMA, $c_{0}=100 \mu \mathrm{g} / \mathrm{L}$; (d) NC columns, influent spiked MMA, $c_{0}=200 \mu \mathrm{g} / \mathrm{L}$ 


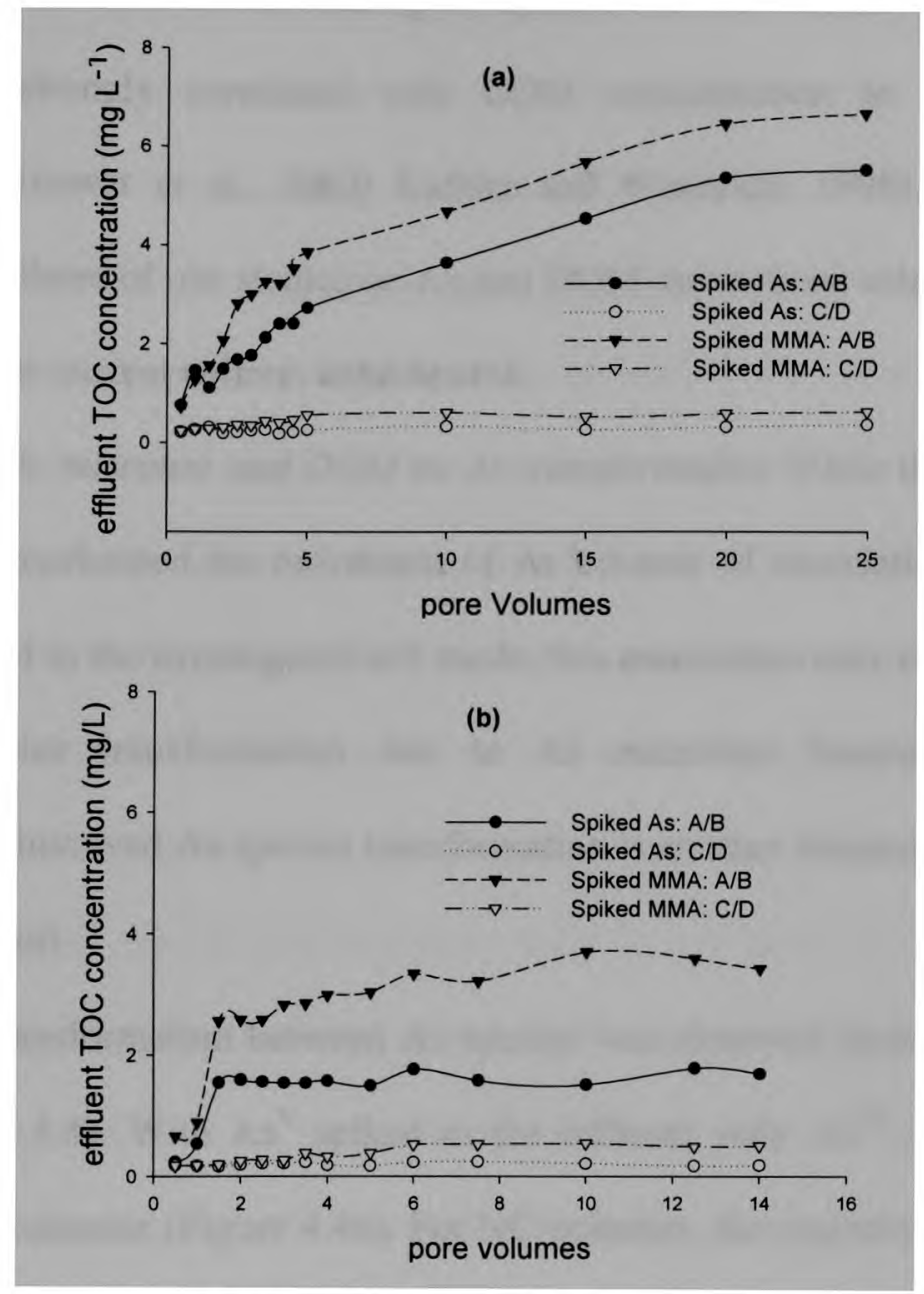

Figure 4.3 DOM analysis for UC and NC columns

Note: (a) UC columns, influent either spiked spiked $A s^{V}$ or MMA, influent arsenic concentration $\mathrm{c}_{0}=100 \mu \mathrm{g} / \mathrm{L}$; (b) $\mathrm{NC}$ columns, influent either spiked $\mathrm{As}^{\mathrm{V}}$ or MMA, influent arsenic concentration $\mathrm{c}_{0}=200 \mu \mathrm{g} / \mathrm{L}$.

than $1000 \mathrm{Da}$ (Pokrovsky and Schott, 2002). In several other studies about the geochemical controls on As in southeastern United States rivers (Waslenchuk, 1979; Waslenchuk and Windom, 1978), it was found that complexes could be formed between As and low MW DOM. Unlike high MW organic matter, this fraction passes through the estuary carrying the complexed As. These complexes apparently prevent adsorptive and co-precipitative interactions between dissolved As and active solid-phase organic and 
inorganic materials such as flocculating Fe hydroxides and humics. Other studies found that As was strongly correlated with DOM concentration in soil percolates or groundwater (Anawar et al., 2003; Kalbitz and Wennrich, 1998). These results are consistent with those of our studies on As and DOM interactions using dialysis (Chen et al., 2006) and the current column experiments.

Effects of pH-Eh, microbes and DOM on As transformation While dissolved substances in soil extract accelerated the movement of As because of association between As and small MW DOM in the investigated soil sands, this association may cause another effects - arsenic species transformation due to As microbial bioavailability alteration. Microorganism involved As species transformation is another determining factor for total As mobility in soil.

Rapid transformation between As species was observed during column transport process (Figure 4.4). With $\mathrm{As}^{\mathrm{V}}$ spiked in the influent, only $\mathrm{As}^{\mathrm{III}}$ was detected in the effluent of UC columns (Figure 4.4a). For NC columns, the majority As species present in the effluent was also As ${ }^{\mathrm{III}}$ although accountable amounts of $\mathrm{As}^{\mathrm{V}}$ were observed at the end of BTC curves (Figure 4.4b). With MMA spiked in the influent, all four method detectable As species, $\mathrm{As}^{\mathrm{III}}, \mathrm{As}^{\mathrm{V}}, \mathrm{MMA}$, and DMA were present in the effluents for both UC (Figure 4.4c and 4.4e) and NC (Figure 4.4d and 4.4f) columns. The occurrence and high concentration of DMA in the effluents indicated that methylation of MMA to DMA occurred rapidly and extensively in each of the eight columns. In fact, MMA, which was originally spiked in the influent, was only account for a small portion of As eluted as can be seen from the elution curves. The increase in the concentrations of $\mathrm{As}^{\mathrm{V}}$ (Figure 4.4c) or As ${ }^{\text {III }}$ (Figure 4.4d) with time was generally observed and seemed reversely 
corresponding to the changes in the concentrations of MMA and DMA (Figure 4.4e and 4.4f). It should be pointed out that $A s^{\mathrm{V}}$ was the major inorganic As species for UC columns after 12 pore volumes (Figure 4.4c), while $\mathrm{As}^{\mathrm{III}}$ dominated for NC after 7 pore volumes (Figure 4.4d). These results suggest that the metabolic products of As in the soils are determined by the original As species applied in the soil and by the soil types. The reason why this would occur is currently unknown. However, it is plausible that the different metabolic pathways used by inorganic $\mathrm{As}^{\mathrm{V}}$ and MMA and the possible effects of soil characteristics on As species bioavailability could play important roles. Generally, the concentrations of all four As species eluted from $A \& B$ columns were higher than the corresponding $C \& D$ controls.

The fast As species transformation could be facilitated by a number of abiotic and/or biotic factors. Redox potential (Eh) and $\mathrm{pH}$ are two of the most important factors controlling As speciation. From inorganic As pH - Eh digram (Brookins, 1986), $\mathrm{H}_{2} \mathrm{AsO}_{4}{ }^{-}$ is the dominant form at low $\mathrm{pH}$ (less than about $\mathrm{pH}$ 6.9) and oxidizing conditions, At higher $\mathrm{pH}, \mathrm{HAsO}_{4}{ }^{2-}$ becomes dominant. $\mathrm{H}_{3} \mathrm{AsO}_{4}{ }^{0}$ and $\mathrm{AsO}_{4}{ }^{3-}$ may be present in extremely acidic and alkaline conditions respectively. Under reducing conditions at $\mathrm{pH}$ less than 9.2, the uncharged arsenite species $\mathrm{H}_{3} \mathrm{AsO}_{3}{ }^{0}$ will predominate. The $\mathrm{pH}$ of the effluent for each individual column remained relatively constant throughout the experiment, about 4 for all experiments using $\mathrm{ARW}$ as influent. The $\mathrm{pH}$ for $\mathrm{A} \& \mathrm{~B}$ columns with soil extract as influent was higher than C\&D, ranging from 4 to 6 (Figure 4.5). Under these conditions the conversion of $\mathrm{As}^{\mathrm{V}}$ to $\mathrm{As}^{\mathrm{III}}$ would only happen when Eh approximately drops to blow $300 \mathrm{mv}(\mathrm{pH}$ 4) to $100 \mathrm{mv}(\mathrm{pH}$ 6) at respective $\mathrm{pH}$ according 

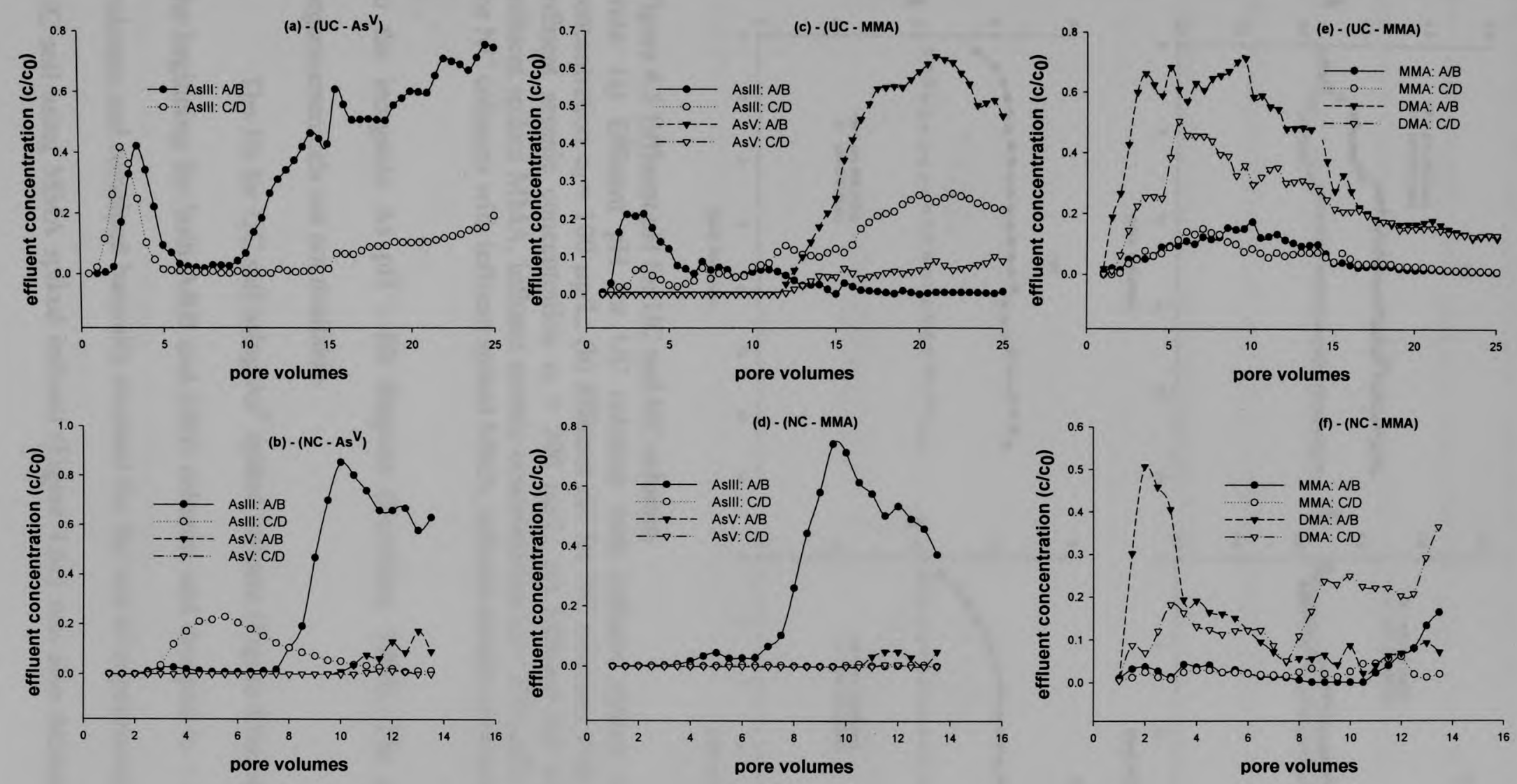

Figure 4.4 Effluent arsenic speciation analysis for UC and NC columns

Note: (a) influent spiked $\mathrm{As}^{\mathrm{V}}, \mathrm{c}_{0}=100 \mu \mathrm{g} / \mathrm{L}$, UC column; (b) influent spiked $\mathrm{As} \mathrm{v}^{\mathrm{V}}, \mathrm{c}_{0}=200 \mu \mathrm{g} / \mathrm{L}, \mathrm{NC}$ column; (c) influent spiked MMA, $c_{0}=100 \mu \mathrm{g} / \mathrm{L}$, UC column, inorganic arsenic species in effluent; (d) influent spiked MMA, $\mathrm{c}_{0}=200 \mu \mathrm{g} / \mathrm{L}, \mathrm{NC}$ column, inorganic arsenic species in effluent; (e) influent spiked MMA, $c_{0}=100 \mu \mathrm{g} / \mathrm{L}$, UC column, organic arsenic species in effluent; (f) influent spiked MMA, $\mathrm{c}_{0}=200 \mu \mathrm{g} / \mathrm{L}, \mathrm{NC}$ column, organic arsenic species in effluent. 


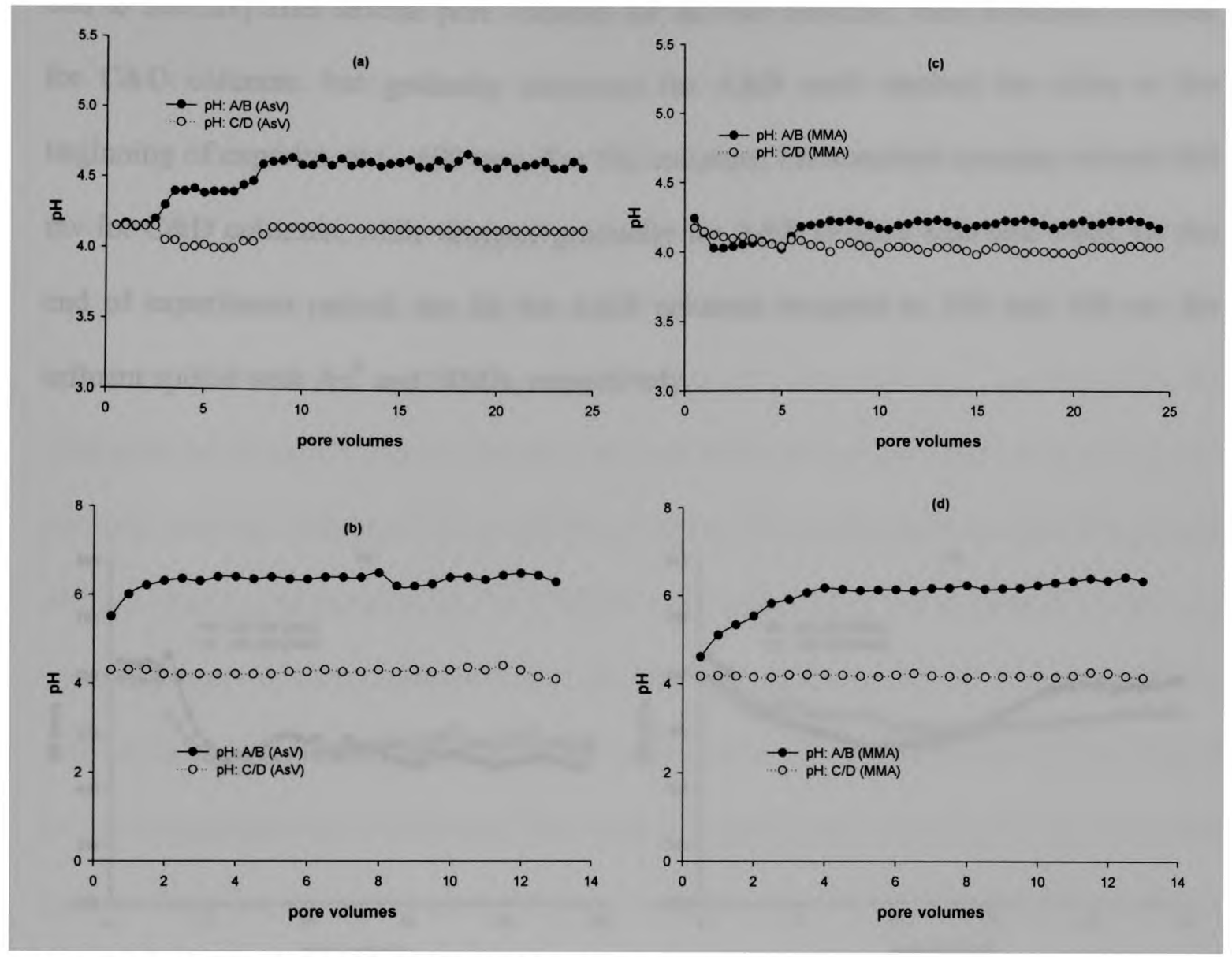

Figure 4.5 Effluent $\mathrm{pH}$ for UC and NC columns

Note: (a) Effluent $\mathrm{pH}$ for UC columns with influent spiked $A s^{\mathrm{V}}$, influent arsenic concentration $\mathrm{c}_{0}=100 \mu \mathrm{g} / \mathrm{L}$; (b) Effluent $\mathrm{pH}$ for $\mathrm{NC}$ columns with influent spiked $\mathrm{As}^{\mathrm{V}}$, influent arsenic concentration $\mathrm{c}_{0}=200 \mu \mathrm{g} / \mathrm{L}$; (c) Effluent $\mathrm{pH}$ for UC columns with influent spiked MMA, influent arsenic concentration $\mathrm{c}_{0}=100 \mu \mathrm{g} / \mathrm{L}$; and (d) Effluent $\mathrm{pH}$ for $\mathrm{NC}$ columns with influent spiked MMA, influent arsenic concentration $\mathrm{c}_{0}=200 \mu \mathrm{g} / \mathrm{L}$.

to the inorganic As $\mathrm{pH}$ - Eh diagram (Brookins, 1986). The $\mathrm{pH}-\mathrm{Eh}$ diagrams for organoarsenicals are not available.

The Eh for UC soil using $\mathrm{As}^{\mathrm{V}}$ spiked influent (Figure 4.6a) was around $600 \mathrm{mv}$ at the beginning for both $\mathrm{A} \& \mathrm{~B}$ and $\mathrm{C} \& \mathrm{D}$ columns and dropped to $\sim 450 \mathrm{mv}$ after 5 pore volumes and remained basically constant for the rest of experimental period. The Eh for UC soil using MMA spiked influent (Figure 4.6c) was also decreased $\sim 100 \mathrm{mv}$ (from 
600 to $500 \mathrm{mv}$ ) after several pore volumes for all four columns, then remained constant for $\mathrm{C} \& \mathrm{D}$ columns, but gradually increased for $\mathrm{A} \& \mathrm{~B}$ until reached the value at the beginning of experiment ( $600 \mathrm{mv})$. For NC columns, Eh remained constant around 600 mv for C\&D columns, while dropped gradually for A\&B (Figure 4.6b and 4.6d). By the end of experiment period, the Eh for $\mathrm{A} \& \mathrm{~B}$ columns dropped to 200 and $100 \mathrm{mv}$ for influent spiked with $\mathrm{As}^{\mathrm{V}}$ and MMA, respectively.
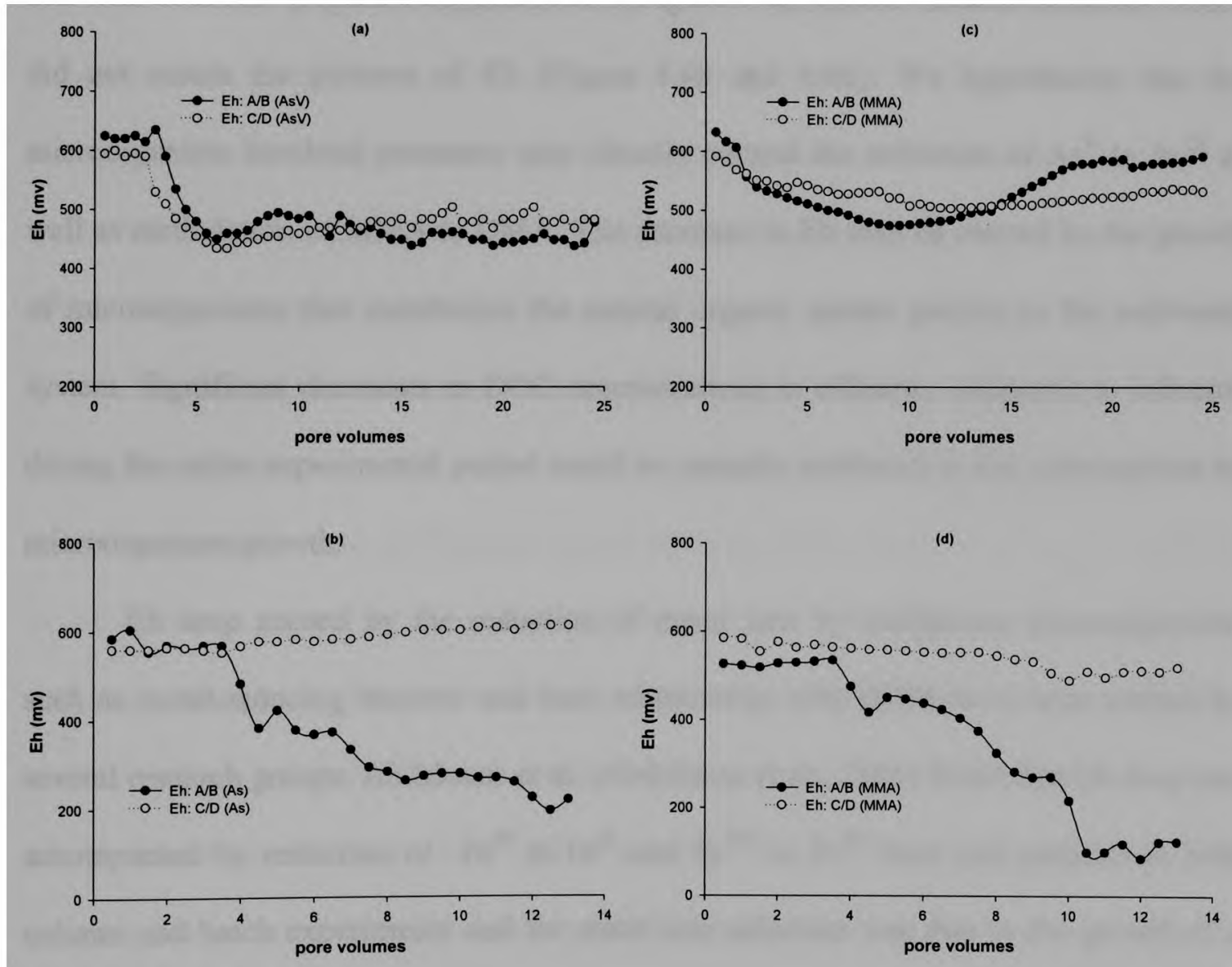

Figure 4.6 Eh for UC and NC columns

Note: (a) Eh for UC columns with influent spiked $\mathrm{As}^{\mathrm{V}}, \mathrm{c}_{0}=100 \mu \mathrm{g} / \mathrm{L}$; (b) Eh for NC columns with influent spiked $\mathrm{As}^{\mathrm{V}}, \mathrm{c}_{0}=200 \mu \mathrm{g} / \mathrm{L}$; (c) Eh for UC columns with influent spiked MMA, $\mathrm{c}_{0}=100 \mu \mathrm{g} / \mathrm{L}$; and (d) Eh for NC columns with influent spiked MMA, $\mathrm{c}_{0}=$ $200 \mu \mathrm{g} / \mathrm{L}$. 
Drops in Eh did not seem to the direct factor that caused the transformation from $A s^{\mathrm{V}}$ to $A s^{\mathrm{III}}$ in this study. This can be supported by the fact that significant amount of $A s^{\text {III }}$ was formed in the experiments using UC soil where Eh was remained either constant (As ${ }^{\mathrm{V}}$ spiked) or slightly dropped (MMA spiked). As ${ }^{\mathrm{III}}$ appeared at the beginning of experiment where Eh changes were not observed (Figure 4.4a and 4.4c and Figure 4.6a and 4.6c). This conclusion is also supported by the fact that $\mathrm{As}^{\mathrm{III}}$ increased to the maximum at 10 pore volumes and then declined with time in the experiments using NC soil with both $\mathrm{As}^{\mathrm{V}}$ (Figure 4.4b) and MMA (Figure 4.4d) spiked influent solutions, which did not match the patterns of Eh (Figure $4.6 \mathrm{~b}$ and $4.6 \mathrm{~d}$ ). We hypothesize that the microorganism involved processes may directly control the reduction of $\mathrm{As}^{\mathrm{V}}$ to $\mathrm{As}{ }^{\mathrm{III}}$ as well as methylation of MMA to DMA. The decrease in Eh may be caused by the growth of microorganisms that metabolize the natural organic matter present in the soil/water system. Significant decreases in DOC concentrations in effluents compared to influents during the entire experimental period could be partially attributed to the consumption by microorganism growth.

Eh drop caused by the reduction of metal ions by indigenous microorganisms such as metal-reducing bacteria and their relationship with DOM have been studied by several research groups. Abdelouas et al. (Abdelouas et al., 2005) found that Eh drop was accompanied by reduction of $\mathrm{Fe}^{\mathrm{III}}$ to $\mathrm{Fe}^{\mathrm{II}}$ and $\mathrm{Tc}^{\mathrm{VII}}$ to $\mathrm{Tc}^{\mathrm{IV}}$ from soil particles in both column and batch experiments and the metal ion reduction was due to the growth of a consortium of anaerobic bacteria (e.g., Fe-reducing bacteria). The stimulation of the growth of indigenous sulfate-reducing bacteria in soil/ $\mathrm{H}_{2} \mathrm{O}$ systems led to even lower Eh. The study conducted by Siddique et al. (Siddique et al., 2006) characterized Se-reducing 
bacterial populations in Lost Hills evaporation pond sediment and observed their response to $\mathrm{Se}^{\mathrm{VI}}$ and organic carbon amendments and found that organic carbon amendments promote bacteria growth and resulted a decrease in redox potential (Eh). DOM, on the other hand, may change As microbial bioavailability via interaction with As. The higher Eh drop for NC columns comparing to UC columns may also due to more microbial activity. Almost completed spiked As species conversion was observed for both UC and NC columns (Figure 4.4).

Microorganisms that express As resistance genes are able to withstand high concentrations of $\mathrm{As}^{\mathrm{V}}$ through the intracellular reduction of $\mathrm{As}^{\mathrm{V}}$ and the subsequent excretion of $A s^{I I I}$ into the surrounding media. It is thought that this pathway may function in aerobic as well as anaerobic environments (Macy et al., 2000; Newman, 1998) and may contribute to apparent no equilibrium conditions where $\mathrm{As}{ }^{\mathrm{III}}$ has been often observed in oxic surface waters (Cullen and Reimer, 1989; Sohrin et al., 1997). Although it is likely that bacteria in soil, especially at As-contaminated sites, possess arsenic detoxification pathways, the literature about the effect of aerobic $\mathrm{As}^{\mathrm{V}}$ - reducing bacteria on As behavior in soils is very limited (Macur et al., 2001). Biomethylation of As is frequently suggested to act as a detoxification method for microbes. Species transformations occurred between surface waters and adjacent soils and groundwater after monosodium methylarsonate (MSMA) organoarsenical was used to control weeds in cotton fields and as defoliation agents applied prior to cotton harvesting (Bednar et al., 2002). Field studies for As transport and species transformation associated with MSMA application on golf course green also revealed microorganism-mediated processes were likely involved in arsenic transformation (Di Carlo and Fuentes, 2000; Feng et al., 2005). 
This study showed that As species conversion in soil columns can be associated with microbial activities especially high concentration of DMA was observed in column effluent after MMA implication to soil columns. The fast methylation of MMA further verified that microorganisms actively involved As species transformation in soil columns. Environmental implications The laboratory column experiments indicated that the dissolved substances derived from natural soils can facilitate As transport through the media. The presence of peat as soil amendment increases significantly the mobility of As in UC and NC, two soils that widely used in Florida Golf courses. Therefore, adding organic matter to soils, a common practice in soil amendment could pose potential problems for As contaminated sites.

After application of MSMA in the field, this organoarsenical will undergo a rapid transformation under environmental conditions, generating new As species. Theses species include inorganic $\mathrm{As}^{\mathrm{V}}$, inorganic $\mathrm{As}{ }^{\mathrm{III}}$, and DMA. Decomposition, reduction, and methylation reactions likely occur under aerobic conditions in the presence of microorganisms. The microbial transformation processes seem to play a very important role in the cycling of As. The toxicity, reactivity and mobility of As will be altered due to the species transformation. Because the toxicity of most organoarsenicals (in pentavalence) is less than that of the inorganic As species, the introduction of these compounds into the environment might seem benign. However, this study revealed the rapid transformation MMA to other As species, some of them are more toxic than MMA. Transport of As species is strongly affected by soil characteristics, particularly by organic matter amendment. A precise estimation of the risk of applying organoarsenicals in the 
soil requires a full understanding of the As species present in the media and the factors controlling transport and transformation of these species. 
CHAPTER 5

General Summary and Future Research Directions 


\subsection{Summary}

It is the general view that the As release in As contaminated soil is strongly related with soil $\mathrm{Fe} / \mathrm{Al}$ oxides content. This is true when concentration of organic matter is low in the soils. Our research findings indicate that dissolved $\mathrm{As}^{\mathrm{V}}$ and MMA are rapidly adsorbed by soil surfaces and soil $\mathrm{Fe} / \mathrm{Al}$ oxides could play an important role in controlling dissolved As distribution in aquifer and soil. However, the organic matter amendments in the soil will effectively reduced soil As adsorption capability. In general, the organic matter amended soils exhibited an increase in mobility of As relative to non amended soils. The presence of organic matter in soil will substantially increase As mobility either by competing soil As adsorption sites or by interacting with As species and forming complexed arsenic species, and subsequently reducing As adsorption on soil.

DOM derived from organic matter such as peat could promote the release of $\mathrm{Fe}$ and $\mathrm{Al}$ oxides, which in turn would alter the adsorption of As on the oxide surfaces and hence affect the fate and transport of As even though As may not be directly associated with the released $\mathrm{Fe}$ and $\mathrm{Al}$ containing colloids. The DOM with certain $\mathrm{MW}$ would bind/associate with As present in the soil solutions. Based on the results of equilibrium membrane dialysis, As was most likely bound to DOM with MW less than 3,500 Da. Arsenic association with these small substances greatly effects As adsorption to soil substrate and As microbial bioavailability, and enhances facilitated-transport of As in the environments. Therefore, care should be exercised for organic matter amendments in Ascontaminated soils. DOM could create the competitive soil-water interfacial environment for As adsorption. It is likely that the dissolved/surface-bound organic matter become competitive ligands for As, possibly resulting in the enhanced mobility of As. 
Colloid-facilitated transport processes could possibly contribute to the rapid transport of As in subsurface environment. This work has shown that a very small fraction of As was associated with colloidal materials (MWCO higher than 3500 Da by definition) in the solutions of all soils studied. Facilitated arsenic transport by soil dissolved substances, DOM in particular, was clearly observed. Arsenic species transformation was rapid and extensive under the column conditions and had a significant impact on arsenic transport for both $\mathrm{As}^{\mathrm{V}}$ and $\mathrm{MMA}^{\mathrm{V}}$. In addition, the association of arsenic species to soil-derived substances influenced arsenic transport and bioavailability, subsequently affected microorganism-involved arsenic transformation. These column studies complemented a range of other experiments conducted in the field as well as laboratory batch studies. These studies yielded additional insight into processes and mechanisms affecting the geochemical cycling of arsenic in the environment, and provided quantitative estimates of key parameters (e.g., extent and rate of adsorption, association reaction, microbe involved species transformation etc.) for risk assessment at arsenic contaminated soil sites.

5.2 Future research directions

The future research work for arsenic transport and transformation in soil should aim to strength on research capacities in two main directions by focusing more on microbe related issues. The first direction is about the mechanism of DOM effect on As adsorption, both As-DOM association mechanism and DOM soil adsorption mechanism are important for As mobility in soil/water system. Second, the research work should focus on the evaluation of the impact of microbe involved arsenic species transformation on arsenic mobility and bioavailability. Arsenic is a reduction/oxidation sensitive element, 
which can exist in multi-oxidation states $(5,3,0$, and -3$)$. A picture is emerging in which nearly every redox-active metal examined is propelled through its stable forms primarily by microbial activity (Bailey, 2002; Picardal and Cooper, 2005; Raab and Feldmann, 2003). This astonishing fact results from the role of microorganisms as masters of energy recovery, where no environment seems too hostile for them to catalyze and exploit an energy-yielding redox reaction. Thermodynamic calculations show that the reduction of arsenate to arsenite yields sufficient energy to sustain microbial growth, and in 1994 Ahmann (Ahmann et al., 1994b) discovered the first arsenic-respiring microbe. Actually, microbes are capable of many reactions that result in changes in speciation of arsenic. $A s^{I I I}$ can be oxidized to $A s^{\mathrm{V}}$, or $A s^{\mathrm{V}}$ can be reduced to $\mathrm{As}{ }^{\mathrm{III}}$. These inorganic forms can also be biomethylated by certain microbes to gaseous arsines or to methylated species monomethyl arsonic acid (MMA) and dimethyl arsinic acid (DMA), while the other microbes can demethylate organic forms to inorganic species (Afkar et al., 2003; Mukhopadhyay et al., 2002; Rosen, 2002; Sohrin et al., 1997). In heavy metal contaminated environments microorganisms have been forced to develop metal-ion homeostasis factors and metal-resistance determinants to uptake, chelation and extrusion of metals (Robinson et al., 2001; Silver, 1996). Metal ions cannot be degraded or modified like toxic organic compounds. There are six possible mechanisms for a metal resistance system: exclusion by permeability barrier; intra- and extra-cellular sequestration; active efflux pumps; enzymatic reduction; and reduction in the sensitivity of cellular targets to metal ions involving metallothioneins, P-type ATPases, cation/proton antiporters and redox enzymes (Bruins et al., 2000; Nies, 1999; Rensing et al., 1999). One or more of these resistance mechanisms allows microorganisms to 
function in metal contaminated environments. The oxyanions of arsenic enter bacterial cells via transporters for other compounds. For example, in bacteria, $\mathrm{As}^{\mathrm{V}}$ is taken up by phosphate transport systems, such as the ATP-coupled Pst pump(Rensing et al., 1999). Arsenic resistance is generally mediated by the $\operatorname{ars} R B C$ genes, three genes usually found in most bacteria, they have evolved mechanisms for arsenic resistance and enzymes that oxidize $A s^{I I I}$ to $A s^{V}$ or reduce $A s^{V}$ to $A s^{I I I}$ (Mukhopadhyay et al., 2002) and caused arsenic species transformation.

Another important direction of research activity will be related with the study of the relationships among such issues as microorganism involved arsenic species transformation, bioavailability of arsenic, the effects of soil properties and arsenic contamination on microbe responses (Fig. 5.1). Besides the different arsenic species, bioavailability of arsenic depends on environmental factors such as $\mathrm{pH}$, redox potential, mineralogy and organic matter content. Soil composition and properties related arsenic bioavailability will be an important aspect of research work. The degree of contaminant bioavailability is determined by the reactivity of contaminant with the biological interface, external factors such as the partitioning behavior or binding strength of the contaminant depending on soil physicochemical parameters have very important effects. Dissolved or weakly adsorbed contaminants are expected to be more bioavailable compared to more structurally complex mineral or dissolved organic matter (DOM)-bound and chelated forms of contaminants. Arsenic mobility and bioavailability in natural systems is controlled primarily by adsorption onto metal oxide surfaces, involving surface complexation reactions in which oxygen moiety of arsenate or arsenite displaces an hydroxyl group on the metal oxide surface to generate an inner-sphere complex (Livesey 
and Huang, 1981; Manning et al., 1998). The common oxides of iron, aluminum, and manganese appear to be the most important sorbents of arsenic in natural systems. NOM, a prevalent constituent of natural waters, is highly reactive toward both arsenic metals and soil surfaces and is thus a clear candidate to influence arsenic bioavailability (Redman et al., 2002). The toxicological effects of heavy metal ions and metalloids depend on their chemical form and bioavailability. Numerous field studies have demonstrated the adverse effect of different heavy metals on soil microbial communities. In both short-term and long-term exposure to heavy metals, the microbial community structure is altered as assessed from soil total phospholipid fatty acid (PLFA) profiles. Several studies have also found that metals decrease soil microbial biomass and viable population size (plate counts). Microbial adaptation is an important response to the presence of soil contaminants and may result in the compensation of an adverse effect by the increased activity of the remaining micro-biota. However, microbial responses to soil contamination may vary, at least in part, due to variations in metal bioavailability among different soils.

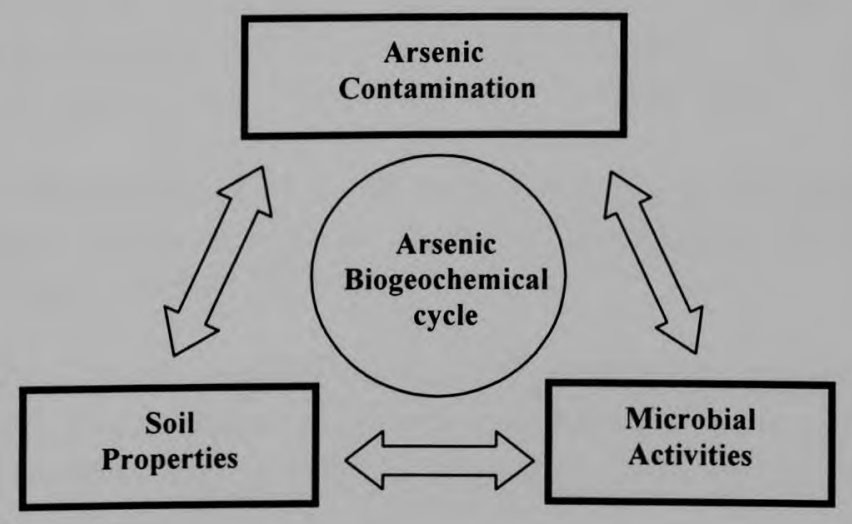

Figure 5.1 Scheme of an approach showing arsenic biogeochemical cycle in soil systems 
Overall, microorganism-involved species transformation of arsenic is of great importance for studying biogeochemical fate of arsenic. However, very limited research work has been done on the effects of microbial activity on transport and transformations of arsenic in soil systems. Microbial community structure and diversity are strongly related to soil physicochemical properties and arsenic contamination level. Microorganism activities also affect metal contaminants arsenic species conversion. The relationships among soil physiochemical properties (e.g. clay content, dissolved organic matter, $\mathrm{pH}$ ), soil microbial community activities and arsenic contamination are very important to help us understand the mechanism involved in the transport and transformation of arsenic, which in turn, will make the risk assessment more accurate and even provide biological methods to remediate arsenic-contaminated environments. 


\section{REFERENCES}

Abdelouas, A., B. Grambow, M. Fattahi, Y. Andres, and E. Leclerc-Cessac, 2005, Microbial reduction of $99 \mathrm{Tc}$ in organic matter-rich soils: Science of the Total Environment, v. 336, p. 255-268.

Abernathy, C. O., Y.-P. Liu, D. Longfellow, H. V. Aposhian, B. Beck, B. Fowler, R. Goyer, R. Menzer, T. Rossman, C. Thompson, and M. Waalkes, 1999, Arsenic: health effects, mechanisms of actions, and research issues: Environmental Health Perspectives, v. 107, p. 593-597.

Adriano, D. C., 1986, Trace Elements in the Terrestrial Environment, 533 pp p.

Afkar, E., J. Lisak, C. Saltikov, P. Basu, R. S. Oremland, and J. F. Stolz, 2003, The respiratory arsenate reductase from Bacillus selenitireducens strain MLS10: FEMS Microbiology Letters, v. 226, p. 107-112.

Ahmann, D., A. L. Roberts, L. R. Krumholz, and F. M. Morel, 1994a, Microbe grows by reducing arsenic: Nature, v. 371, p. 750.

Ahmann, D., A. L. Roberts, L. R. Krumholz, and F. M. M. Morel, 1994b, Microbe grows by reducing arsenic: Nature (London), v. 371, p. 750.

Akkari, K. H., R. E. Frans, and T. L. Lavy, 1986, Factors affecting degradation of MSMA in soil: Weed Science, v. 34, p. 781-7.

Al-Busaidi, A., P. Cookson, and T. Yamamoto, 2005, Methods of $\mathrm{pH}$ determination in calcareous soils: use of electrolytes and suspension effect: Australian Journal of Soil Research, v. 43, p. 541-545.

Alberic, P., E. Viollier, D. Jezequel, C. Grosbois, and G. Michard, 2000, Interactions between trace elements and dissolved organic matter in the stagnant anoxic deep layer of a meromictic lake: Limnology and Oceanography, v. 45, p. 1088-1096.

Amy, G. L., C. W. Bryant, Jr., and M. Belyani, 1987, Molecular weight distributions of soluble organic matter in various secondary and tertiary effluents: Water Science and Technology, v. 19, p. 529-38.

Anawar, H. M., J. Akai, K. Komaki, H. Terao, T. Yoshioka, T. Ishizuka, S. Safiullah, and K. Kato, 2003, Geochemical occurrence of arsenic in groundwater of Bangladesh: sources and mobilization processes: Journal of Geochemical Exploration, v. 77, p. 109-131. 
Antelo, J., M. Avena, S. Fiol, R. Lopez, and F. Arce, 2005, Effects of pH and ionic strength on the adsorption of phosphate and arsenate at the goethite-water interface: Journal of Colloid and Interface Science, v. 285, p. 476-486.

Appleton, J. D., R. Fuge, G. J. H. McCall, and Editors, 1996, Environmental Geochemistry and Health, with Special Reference to Developing Countries. [In: Geol. Soc. Spec. Publ., 1996; 113], 264 pp p.

Arai, Y., and D. L. Sparks, 2002, Residence time effects on arsenate surface speciation at the aluminum oxide-water interface: Soil Science, v. 167, p. 303-314.

Artinger, R., B. Kienzler, W. Schussler, and J. I. Kim, 1998, Effects of humic substances on the 241 Am migration in a sandy aquifer: column experiments with Gorleben groundwater/sediment systems: Journal of Contaminant Hydrology, v. 35, p. 261275 .

Bailey, G. W., 2002, Metal and major-ion redox chemistry of the hypoxic and anoxic zones. An overview, Ecosystems Research Division, National Exposure Research Laboratory,U.S. Environmental Protection Agency,Athens,GA,USA., p. 219-272.

Barrachina, A. C., F. B. Carbonell, and M. M. Beneyto, 1996, Kinetics of arsenite sorption and desorption in Spanish soils: Communications in Soil Science and Plant Analysis, v. 27, p. 3101-3117.

Bednar, A. J., J. R. Garbarino, J. F. Ranville, and T. R. Wildeman, 2002, Presence of Organoarsenicals Used in Cotton Production in Agricultural Water and Soil of the Southern United States: Journal of Agricultural and Food Chemistry, v. 50, p. $7340-7344$.

Benjamin, M. M., and J. O. Leckie, 1981, Multiple-site adsorption of cadmium, copper, zinc, and lead on amorphous iron oxyhydroxide: Journal of Colloid and Interface Science, v. 79, p. 209-21.

Bhumbla, D. K., and R. F. Keefer, 1994, Arsenic mobilization and bioavailability in soils: Advances in Environmental Science and Technology, v. 26, p. 51-82.

Bigelow, C. A., 2000, Sand-based rootzone physical, chemical, and microbial properties as influenced by inorganic soil amendments and sphagnum peat moss. Ph.D dissertation, North Carolina State University, $160 \mathrm{pp}$ p.

Black, W. A. P., W. J. Cornhill, and F. N. Woodward, 1954, Preliminary investigation on the chemical composition of sphagnum moss and peat: Intern Peat Symposium, Dublin, p. 15 pp. 
Bloom, P. R., 1981a, Metal-organic matter interactions in soil: ASA Special Publication, v. 40, p. $129-50$.

Bloom, P. R., 1981b, Phosphorus adsorption by an aluminum-peat complex: Soil Science Society of America Journal, v. 45, p. 267-72.

Bohn, H. L., 1976, Arsenic Eh-pH diagram and comparisons to the soil chemistry of phosphorus: Soil Science, v. 121, p. 125-7.

Bowell, R. J., 1994, Sorption of arsenic by iron oxides and oxyhydroxides in soils: Applied Geochemistry, v. 9, p. 279-86.

Bowen, H. J. M., 1979, Environmental Chemistry of the Elements, 333 pp p.

Brookins, D. G., 1986, Geochemical behavior of antimony, arsenic, cadmium and thallium: Eh-pH diagrams for 25 DegC, 1-bar pressure: Chemical Geology, v. 54, p. 271-8.

Brookins, D. G., 1988, Eh-pH Diagrams for Geochemistry.

Brown, G. E., Jr., A. S. Templeton, T. P. Trainor, A. M. Spormann, T.-H. Yoon, and K. Benzerara, 2004, Synchrotron-based studies of microbe-metal ion-mineral interactions: Water-Rock Interaction, Proceedings of the International Symposium on Water-Rock Interaction, 11 th, Saratoga Springs, NY, United States, June 27July 2, 2004, v. 2, p. 1069-1077.

Bruins, M. R., S. Kapil, and F. W. Oehme, 2000, Microbial resistance to metals in the environment: Ecotoxicology and Environmental Safety, v. 45, p. 198-207.

Buschmann, J., and L. Sigg, 2004, Antimony(III) Binding to Humic Substances: Influence of $\mathrm{pH}$ and Type of Humic Acid: Environmental Science and Technology, v. 38, p. 4535-4541.

Cai, Y., 1999, Size distribution measurements of dissolved organic carbon in natural waters using ultrafiltration technique: Water Research, v. 33, p. 3056-3060.

Cai, Y., J. C. Cabrera, M. Georgiadis, and K. Jayachandran, 2002, Assessment of arsenic mobility in the soils of some golf courses in South Florida: Science of the Total Environment, v. 291, p. 123-134.

Cano-Aguilera, I., N. Haque, G. M. Morrison, A. F. Aguilera-Alvarado, M. Gutierrez, J. L. Gardea-Torresdey, and G. de la Rosa, 2005, Use of hydride generation-atomic absorption spectrometry to determine the effects of hard ions, iron salts and humic substances on arsenic sorption to sorghum biomass: Microchemical Journal, v. 81, p. $57-60$. 
Carter, C. W., and I. H. Suffet, 1982, Binding of DDT to dissolved humic materials: Environmental Science and Technology, v. 16, p. 735-40.

Chakraborti, D., G. K. Basu, B. K. Biswas, U. K. Chowdhury, M. M. Rahman, K. Paul, T. R. Chowdhury, C. R. Chanda, D. Lodh, and S. L. Ray, 2001, Characterization of arsenic-bearing sediments in the gangetic delta of West Bengal, India: Arsenic Exposure and Health Effects IV, Proceedings of the International Conference on Arsenic Exposure and Health Effects, 4th, San Diego, CA, United States, June 1822,2000, p. $27-52$.

Chen, J.-H., D. R. Czajka, L. W. Lion, M. L. Shuler, and W. C. Ghiorse, 1995, Trace metal mobilization in soil by bacterial polymers: Environmental Health Perspectives Supplements, v. 103, p. 53-8.

Chen, M., L. Q. Ma, S. H. Daroub, G. H. Snyder, J. L. Cisar, and C. Y., 2003, Use and fate of arsenic herbicide in Florida golf courses. ASA/CSSA/SSSA Annual Meetings Abstracts: 2003 ASA-CSSA-SSSA Annual Meetings, Abstract: CDROM, S-11-chen952427-Oral.pdf, Denver, CO.

Chen, M., Ma, L. Q., Daroub, S.H., Snyder, G.H., Cisar, J. L., and Cai. Y., 2003, Use and fate of arsenic herbicide in Florida golf courses. ASA/CSSA/SSSA Annual Meetings Abstracts: CD-ROM, S-11-chen952427-Oral.pdf, Denver, CO.

Chen, S.-L., S. R. Dzeng, M.-H. Yang, K.-H. Chiu, G.-M. Shieh, and C. M. Wai, 1994, Arsenic Species in Groundwaters of the Blackfoot Disease Area, Taiwan: Environmental Science and Technology, v. 28, p. 877-81.

Chen, Z., Y. Cai, H. Solo-Gabriele, G. H. Snyder, and J. L. Cisar, 2006, Interactions of Arsenic and the Dissolved Substances Derived from Turf Soils: Environmental science \& technology, v. In press.

Chian, E. S. K., 1977, Stability of organic matter in landfill leachates: Water Research, v. 11, p. 225-32.

Chian, E. S. K., and F. B. DeWalle, 1977, Characterization of soluble organic matter in leachate: Environmental Science and Technology, v. 11, p. 158-63.

Chiou, C. T., R. L. Malcolm, T. I. Brinton, and D. E. Kile, 1986, Water solubility enhancement of some organic pollutants and pesticides by dissolved humic and fulvic acids: Environmental Science and Technology, v. 20, p. 502-8.

Chowdhury, U. K., M. M. Rahman, G. Samanta, B. K. Biswas, G. K. Basu, C. R. Chanda, K. C. Saha, D. Lodh, S. Roy, Q. Quamruzzaman, and D. Chakraborti, 2003, Groundwater arsenic contamination in West Bengal-India and Bangladesh: case 
study on bioavailability of geogenic arsenic: Bioavailability, Toxicity and Risk Relationships in Ecosystems, p. 291-329.

Code of federal regulation, C., revised July 1992, U.S. GPO: Washington, DC, 1992.

Corapcioglu, M. Y., and S. Jiang, 1993, Colloid-facilitated groundwater contaminant transport: Water Resources Research, v. 29, p. 2215-26.

Cox, C. D., and M. M. Ghosh, 1994, Surface complexation of methylated arsenates by hydrous oxides: Water Research, v. 28, p. 1181-8.

Cullen, W. R., and K. J. Reimer, 1989, Arsenic speciation in the environment: Chemical Reviews (Washington, DC, United States), v. 89, p. 713-64.

Das, D., G. Samanta, B. K. Mandal, T. R. Chowdhury, C. R. Chanda, P. P. Chowdhury, G. K. Basu, and D. Chakraborti, 1996, Arsenic in groundwater in six districts of West Bengal, India: Environmental Geochemistry and Health, v. 18, p. 5-15.

Davis, S. A., and M. Misra, 1997, Transport model for the adsorption of oxyanions of selenium (IV) and arsenic (V) from water onto lanthanum- and aluminum-based oxides: Journal of Colloid and Interface Science, v. 188, p. 340-350.

De Brouwere, K., E. Smolders, and R. Merckx, 2004, Soil properties affecting solidliquid distribution of $\mathrm{As}(\mathrm{V})$ in soils: European Journal of Soil Science, v. 55, p. 165-173.

de Jonge, L. W., C. Kjaergaard, and P. Moldrup, 2004, Colloids and colloid-facilitated transport of contaminants in soils: an introduction: Vadose Zone Journal, v. 3, p. 321-325.

de Wit, J. C. M., W. H. van Riemsdijk, and L. K. Koopal, 1993, Proton binding to humic substances. 1. Electrostatic effects: Environmental Science and Technology, v. 27, p. 2005-14.

Deuel, L. E., and A. R. Swoboda, 1972, Arsenic solubility in a reduced environment: Soil Science Society of America Proceedings, v. 36, p. 276-8.

Di Carlo, G. W., 1999, Sorption Measurements and Behavior of Monosodium Methanoarsenate and Arsenic(5+) in Aqueous Suspensions of Florida Soil Fractions, Florida International University, Miami, FL.

Di Carlo, G. W., and H. R. Fuentes, 2000, Potential transport of the herbicides MSMA and arsenate $(+5)$ from golf courses to groundwater in southeastern Florida: WEFTEC 2000, Annual Conference \& Exposition on Water Quality and 
Wastewater Treatment, 73rd, Anaheim, CA, United States, Oct. 14-18, 2000, p. 2938-2965.

Dickens, R., and A. E. Hiltbold, 1967, Movement and persistence of methanearsonates in soil: Weeds, v. 15, p. 299-304.

Dixon, H. B. F., 1997, The biochemical action of arsonic acids especially as phosphate analogs: Advances in Inorganic Chemistry, v. 44, p. 191-227.

Dobran, S., and G. J. Zagury, 2006, Arsenic speciation and mobilization in CCAcontaminated soils: Influence of organic matter content: Science of the Total Environment, v. 364, p. 239-250.

Dunnivant, F. M., P. M. Jardine, D. L. Taylor, and J. F. McCarthy, 1992, Cotransport of cadmium and hexachlorobiphenyl by dissolved organic carbon through columns containing aquifer material: Environmental Science and Technology, v. 26, p. 360-8.

Dzombak, D. A., Morel, F. M. M., 1990: Surface Complexation Modeling. Hydrous Ferric Oxide. John Wiley and Sons, New York, p. 393.

El Khatib, E. A., and A. M. Balba, 2004, Arsenate chemistry in soils of arid ecosystems: Alexandria Science Exchange, v. 25, p. 229-261.

Elkhatib, E. A., O. L. Bennett, and R. J. Wright, 1984, Arsenite sorption and desorption in soils: Soil Science Society of America Journal, v. 48, p. 1025-30.

EPA, U. S. A., 2001: National Primary Drinking Water Regulations, Arsenic and Clarifications and New Source Contaminants Monitoring, Final Rule, Federal Register Part VIII, v. 66, p. 6979-7066.

Fattorini, D., C. M. Alonso-Hernandez, M. Diaz-Asencio, A. Munoz-Caravaca, F. G. Pannacciulli, M. Tangherlini, and F. Regoli, 2004, Chemical speciation of arsenic in different marine organisms: Importance in monitoring studies: Marine Environmental Research, v. 58, p. 845-850.

Feng, M., J. E. Schrlau, R. Snyder, G. H. Snyder, M. Chen, J. L. Cisar, and Y. Cai, 2005, Arsenic Transport and Transformation Associated with MSMA Application on a Golf Course Green: Journal of Agricultural and Food Chemistry, v. 53, p. 35563562 .

Fischer, W. R., and F. Buttchereit, 2002, Sorption of dissolved organic matter on soil particles and its dependence on their surface-charge properties: Refractory Organic Substances in the Environment, p. 383-393. 
Fodor, P., 2001, Arsenic speciation in the environment: Trace Element Speciation for Environment, Food and Health, p. 196-210.

Fowler, B. A., 1977, Toxicology of environmental arsenic: Advances in Modern Toxicology, v. 2, p. 79-122.

Francesconi, K. A., and J. S. Edmonds, 1997, Arsenic and marine organisms: Advances in Inorganic Chemistry, v. 44, p. 147-189.

Francesconi Kevin, A., and D. Kuehnelt, 2004, Determination of arsenic species: a critical review of methods and applications, 2000-2003: Analyst, v. 129, p. 37395.

Fuller, C. C., J. A. Davis, and G. A. Waychunas, 1993, Surface chemistry of ferrihydrite: Part 2. Kinetics of arsenate adsorption and coprecipitation: Geochimica et Cosmochimica Acta, v. 57, p. 2271-82.

Garcia-Vargas, G. G., and M. E. Cebrian, 1996, Health effects of arsenic: Toxicology of Metals, p. 423-438.

Geiszinger, A., W. Goessler, and W. Kosmus, 2002, Organoarsenic compounds in plants and soil on top of an ore vein: Applied Organometallic Chemistry, v. 16, p. 245249.

Gerth, J., 2005, Effects of crystal modification on the binding of trace metals and arsenate by goethite: Journal of Soils and Sediments, v. 5, p. 30-36.

Ghosh, A., A. E. Saez, and W. Ela, 2006, Effect of pH, competitive anions and NOM on the leaching of arsenic from solid residuals: Science of the Total Environment, v. 363, p. $46-59$.

Goldberg, S., 2002, Competitive adsorption of arsenate and arsenite on oxides and clay minerals: Soil Science Society of America Journal, v. 66, p. 413-421.

Goldberg, S., and R. A. Glaubig, 1988, Anion sorption on a calcareous, montmorillonitic soil - arsenic: Soil Science Society of America Journal, v. 52, p. 1297-300.

Gong, C., and R. J. Donahoe, 1997, An experimental study of heavy metal attenuation and mobility in sandy loam soils: Applied Geochemistry, v. 12, p. 243-254.

Gourdon, R., C. Comel, P. Vermande, and J. Veron, 1989, Fractionation of the organic matter of a landfill leachate before and after aerobic or anaerobic biological treatment: Water Research, v. 23, p. 167-73. 
Grafe, M., M. J. Eick, and P. R. Grossl, 2001, Adsorption of arsenate (V) and arsenite (III) on goethite in the presence and absence of dissolved organic carbon: Soil Science Society of America Journal, v. 65, p. 1680-1687.

Griffin, R. A., R. R. Frost, A. K. Au, G. D. Robinson, and N. F. Shimp, 1977, Attenuation of pollutants in municipal landfill leachate by clay minerals. Part 2. Heavy-metal adsorption: Environmental Geology Notes (Illinois State Geological Survey), v. 79, p. 47 pp.

Grolimund, D., and M. Borkovec, 2005, Colloid-facilitated transport of strongly sorbing contaminants in natural porous media: mathematical modeling and laboratory column experiments: Environmental Science and Technology, v. 39, p. 63786386.

Grolimund, D., M. Borkovec, K. Barmettler, and H. Sticher, 1996, Colloid-Facilitated Transport of Strongly Sorbing Contaminants in Natural Porous Media: A Laboratory Column Study: Environmental Science and Technology, v. 30, p. 3118-3123.

Gu, B., J. Schmitt, Z. Chen, L. Liang, and J. F. McCarthy, 1995, Adsorption and desorption of different organic matter fractions on iron oxide: Geochimica et Cosmochimica Acta, v. 59, p. 219-229.

Gupta, G. S., G. Prasad, K. K. Panday, and V. N. Singh, 1988, Removal of chrome dye from aqueous solutions by fly ash: Water, Air, and Soil Pollution, v. 37, p. 13-24.

Gupta, S. K., and K. Y. Chen, 1978, Arsenic removal by adsorption: Journal - Water Pollution Control Federation, v. 50, p. 493-506.

Haberhauer, G., B. Temmel, and H. Gerzabek Martin, 2002, Influence of dissolved humic substances on the leaching of MCPA in a soil column experiment: Chemosphere, v. 46, p. $495-9$.

Haitzer, M., G. R. Aiken, and J. N. Ryan, 2002, Binding of Mercury(II) to Dissolved Organic Matter: The Role of the Mercury-to-DOM Concentration Ratio: Environmental Science and Technology, v. 36, p. 3564-3570.

Han, N., and L. Thompson Michael, 2003, Impact of dissolved organic matter on copper mobility in aquifer material: Journal of environmental quality, v. 32, p. 1829-36.

Han, N., and M. L. Thompson, 1999, Copper-binding ability of dissolved organic matter derived from anaerobically digested biosolids: Journal of Environmental Quality, v. 28 , p. $939-944$. 
Han, N., and M. L. Thompson, 2003, Impact of dissolved organic matter on copper mobility in aquifer material: Journal of Environmental Quality, v. 32, p. 18291836.

Harmsen, J., 1983, Identification of organic compounds in leachate from a waste tip: Water Research, v. 17, p. 699-705.

Harrington, J. M., J. P. Middaugh, D. L. Morse, and J. Housworth, 1978, A survey of a population exposed to high concentrations of arsenic in well water in Fairbanks, Alaska: American journal of epidemiology, v. 108, p. 377-85.

Hartley, W., R. Edwards, and W. Lepp Nicholas, 2004, Arsenic and heavy metal mobility in iron oxide-amended contaminated soils as evaluated by short- and long-term leaching tests: Environmental pollution (Barking, Essex: 1987), v. 131, p. 495504.

Hess, R. E., and R. W. Blanchar, 1976, Arsenic stability in contaminated soils: Soil Science Society of America Journal, v. 40, p. 847-52.

Hsia, T.-H., S.-L. Lo, C.-F. Lin, and D.-Y. Lee, 1994, Characterization of arsenate adsorption on hydrous iron oxide using chemical and physical methods: Colloids and Surfaces, A: Physicochemical and Engineering Aspects, v. 85, p. 1-7.

Huang, Y., 1994, Arsenic distribution in soils: Advances in Environmental Science and Technology, v. 26, p. 17-49.

Hutson, D. H., T. R. Roberts, and Editors, 1990, Progress in Pesticide biochemistry and Toxicology, Vol. 7: Environmental Fate of Pesticides, $286 \mathrm{pp}$ p.

Inskeep, W. P., T. R. McDermott, and S. Fendorf, 2002, Arsenic (V)/(III) cycling in soils and natural waters: Chemical and microbiological processes: Environmental Chemistry of Arsenic, p. 183-215.

Irizarry, R., J. Moore, and Y. Cai, 2001, Atomic fluorescence determination of selenium using hydride generation technique: International Journal of Environmental Analytical Chemistry, v. 79, p. 97-109.

Jackson, B. P., and W. P. Miller, 1999, Soluble Arsenic and Selenium Species in Fly Ash/Organic Waste-Amended Soils Using Ion Chromatography-Inductively Coupled Plasma Mass Spectrometry: Environmental Science and Technology, v. 33 , p. 270-275.

Jackson, B. P., J. F. Ranville, P. M. Bertsch, and A. G. Sowder, 2005, Characterization of Colloidal and Humic-Bound $\mathrm{Ni}$ and $\mathrm{U}$ in the \"Dissolved $\backslash$ " Fraction of 
Contaminated Sediment Extracts: Environmental Science and Technology, v. 39, p. $2478-2485$.

Jackson, C. R., E. F. Jackson, S. L. Dugas, K. Gamble, and S. E. Williams, 2003, Microbial transformations of arsenite and arsenate in natural environments: Recent Research Developments in Microbiology, v. 7, p. 103-118.

Jacobs, L. W., J. K. Syers, and D. R. Keeney, 1970, Arsenic sorption by soils: Soil Science Society of America Proceedings, v. 34, p. 750-4.

Janet, P., 2005, Common arsenical pesticide under scrutiny, Environmental Science \& Technology Online News.

Jansen, B., J. Mulder, and J. M. Verstraten, 2003, Organic complexation of Al and Fe in acidic soil solutions. Comparison of diffusive gradients in thin films analyses with Models V and VI predictions: Analytica Chimica Acta, v. 498, p. 105-117.

Jiang, W., S. Zhang, X.-q. Shan, M. Feng, Y.-G. Zhu, and R. G. McLaren, 2005a, Adsorption of arsenate on soils. Part 1: Laboratory batch experiments using 16 Chinese soils with different physiochemical properties: Environmental Pollution (Amsterdam, Netherlands), v. 138, p. 278-284.

Jiang, W., S. Zhang, X.-q. Shan, M. Feng, Y.-G. Zhu, and R. G. McLaren, 2005b, Adsorption of arsenate on soils. Part 2: Modeling the relationship between adsorption capacity and soil physiochemical properties using 16 Chinese soils: Environmental Pollution (Amsterdam, Netherlands), v. 138, p. 285-289.

Johnson, D. L., 1972, Bacterial reduction of arsenate in sea water: Nature, v. 240, p. 44-5.

Johnson, W. P., and G. L. Amy, 1995, Facilitated Transport and Enhanced Desorption of Polycyclic Aromatic Hydrocarbons by Natural Organic Matter in Aquifer Sediments: Environmental Science and Technology, v. 29, p. 807-17.

Juhasz, A. L., R. Naidu, Y. G. Zhu, L. S. Wang, J. Y. Jiang, and Z. H. Cao, 2003, Toxicity issues associated with geogenic arsenic in the groundwater-soil-planthuman continuum: Bulletin of Environmental Contamination and Toxicology, v. 71, p. $1100-1107$.

Kalbitz, K., and R. Wennrich, 1998, Mobilization of heavy metals and arsenic in polluted wetland soils and its dependence on dissolved organic matter: Science of the Total Environment, v. 209, p. 27-39.

Karim, M. M., Y. Komori, and M. Alam, 1997, Subsurface arsenic occurrence and depth of contamination in Bangladesh: Kankyo Kagaku, v. 7, p. 783-792. 
Kaurichev, I. S., M. V. Bazilinskaya, and L. A. Zabolotnova, 1974, Effect of watersoluble organic substances on the availability of iron, aluminum, and silicon of some minerals and rock: Izvestiya Timiryazevskoi Sel'skokhozyaistvennoi Akademii, p. 105-13.

Khan, M. M. H., F. Sakauchi, T. Sonoda, M. Washio, and M. Mori, 2003, Magnitude of arsenic toxicity in tube-well drinking water in Bangladesh and its adverse effects on human health including cancer: evidence from a review of the literature: Asian Pacific journal of cancer prevention: APJCP, v. 4, p. 7-14.

Ko, I., J.-Y. Kim, and K.-W. Kim, 2004, Arsenic speciation and sorption kinetics in the As-hematite-humic acid system: Colloids and Surfaces, A: Physicochemical and Engineering Aspects, v. 234, p. 43-50.

Kocar Benjamin, D., A. Garrott Robert, and P. Inskeep William, 2004, Elk exposure to arsenic in geothermal watersheds of Yellowstone National Park, USA: Environmental toxicology and chemistry / SETAC, v. 23, p. 982-9.

Kretzschmar, R., D. Hesterberg, and H. Sticher, 1997, Effects of adsorbed humic acid on surface charge and flocculation of kaolinite: Soil Science Society of America Journal, v. 61, p. 101-108.

Kretzschmar, R., and H. Sticher, 1997, Transport of Humic-Coated Iron Oxide Colloids in a Sandy Soil: Influence of $\mathrm{Ca} 2+$ and Trace Metals: Environmental Science and Technology, v. 31, p. 3497-3504.

Laegdsmand, M., L. W. de Jonge, and P. Moldrup, 2005, Leaching of colloids and dissolved organic matter from columns packed with natural soil aggregates: Soil Science, v. 170, p. 13-27.

Lafferty, B. J., and R. H. Loeppert, 2005, Methyl Arsenic Adsorption and Desorption Behavior on Iron Oxides: Environmental Science and Technology, v. 39, p. 21202127.

Langmuir, D., 1997, Aqueous Environmental Geochemistry, 600 pp p.

Langmuir, I., 1918, The adsorption of gases on plane surfaces of glass, mica and platinum: Journal of the American Chemical Society, v. 40, p. 1361-1402.

Langner, H. W., C. R. Jackson, T. R. McDermott, and W. P. Inskeep, 2001, Rapid oxidation of arsenite in a hot spring ecosystem, Yellowstone National Park: Environmental science \& technology, v. 35, p. 3302-9. 
Le, X. C., W. R. Cullen, and K. J. Reimer, 1994, Human urinary arsenic excretion after one-time ingestion of seaweed, crab, and shrimp: Clinical chemistry, v. 40, p. $617-24$.

Le, X. C., X. Lu, and X.-F. Li, 2004, Arsenic speciation: Analytical Chemistry, v. 76, p. 26A-33A.

Leermakers, M., W. Baeyens, M. De Gieter, B. Smedts, C. Meert, H. C. De Bisschop, R. Morabito, and P. Quevauviller, 2006, Toxic arsenic compounds in environmental samples: Speciation and validation: TrAC, Trends in Analytical Chemistry, v. 25, p. 1-10.

Lenoble, V., O. Bouras, V. Deluchat, B. Serpaud, and J.-C. Bollinger, 2002, Arsenic adsorption onto pillared clays and iron oxides: Journal of colloid and interface science, v. 255 , p. 52-8.

Lin, H.-T., M. C. Wang, and G.-C. Li, 2004, Complexation of arsenate with humic substance in water extract of compost: Chemosphere, v. 56, p. 1105-1112.

Lin, S., W. R. Cullen, and D. J. Thomas, 1999, Methylarsenicals and Arsinothiols Are Potent Inhibitors of Mouse Liver Thioredoxin Reductase: Chemical Research in Toxicology, v. 12, p. 924-930.

Lin, T. F., and J. K. Wu, 2001, Adsorption of arsenite and arsenate within activated alumina grains: equilibrium and kinetics: Water research, v. 35, p. 2049-57.

Livesey, N. T., and P. M. Huang, 1980, Adsorption of arsenate by soils and its relation to selected chemical properties and anions: Soils and Fertilizers in Taiwan, p. 13-23.

Livesey, N. T., and P. M. Huang, 1981, Adsorption of arsenate by soils and its relation to selected chemical properties and anions: Soil Science, v. 131, p. 88-94.

Logan, B. E., and G. A. Wagenseller, 2000, Molecular size distributions of dissolved organic matter in wastewater transformed by treatment in a full-scale trickling filter: Water Environment Research, v. 72, p. 277-281.

Lombi, E., W. W. Wenzel, and R. S. Sletten, 1999, Arsenic adsorption by soils and ironoxide-coated sand. Kinetics and reversibility: Journal of Plant Nutrition and Soil Science, v. 162, p. 451-456.

Lund, U., and A. Fobian, 1991, Pollution of two soils by arsenic, chromium and copper, Denmark: Geoderma, v. 49, p. 83-103.

Ma, L. Q., F. Tan, and W. G. Harris, 1997, Concentrations and distributions of eleven metals in Florida soils: Journal of Environmental Quality, v. 26, p. 769-775. 
Macur, R. E., J. T. Wheeler, T. R. McDermott, and W. P. Inskeep, 2001, Microbial populations associated with the reduction and enhanced mobilization of arsenic in mine tailings: Environmental science \& technology, v. 35, p. 3676-82.

Macy, J. M., J. M. Santini, B. V. Pauling, A. H. O'Neill, and L. I. Sly, 2000, Two new arsenate/sulfate-reducing bacteria: mechanisms of arsenate reduction: Archives of Microbiology, v. 173, p. 49-57.

Magee, B. R., L. W. Lion, and A. T. Lemley, 1991, Transport of dissolved organic macromolecules and their effect on the transport of phenanthrene in porous media: Environmental Science and Technology, v. 25, p. 323-31.

Majone, M., M. Petrangeli, P. Papini, and E. Rolle, 1998, Influence of metal speciation in landfill leachates on kaolinite sorption: Water Research, v. 32, p. 882-890.

Mandal, B. K., and K. T. Suzuki, 2002, Arsenic round the world: a review: Talanta, v. 58, p. 201-235.

Manning, B. A., S. E. Fendorf, and S. Goldberg, 1998, Surface Structures and Stability of Arsenic(III) on Goethite: Spectroscopic Evidence for Inner-Sphere Complexes: Environmental Science and Technology, v. 32, p. 2383-2388.

Manning, B. A., and S. Goldberg, 1996a, Modeling arsenate competitive adsorption on kaolinite, montmorillonite and illite: Clays and Clay Minerals, v. 44, p. 609-623.

Manning, B. A., and S. Goldberg, 1996b, Modeling competitive adsorption of arsenate with phosphate and molybdate on oxide minerals: Soil Science Society of America Journal, v. 60, p. 121-31.

Manning, B. A., and S. Goldberg, 1997, Adsorption and Stability of Arsenic(III) at the Clay Mineral-Water Interface: Environmental Science and Technology, v. 31, p. 2005-2011.

Manning, D. A. C., 1998, Reactive transport in porous media edited by P. C. Lichtner, C. I. Steefel and E. H. Oelkers: Applied Geochemistry, v. 13, 917 p.

Masscheleyn, P. H., R. D. Delaune, and W. H. Patrick, Jr., 1991a, Arsenic and selenium chemistry as affected by sediment redox potential and $\mathrm{pH}$ : Journal of Environmental Quality, v. 20, p. 522-7.

Masscheleyn, P. H., R. D. Delaune, and W. H. Patrick, Jr., 1991b, Effect of redox potential and $\mathrm{pH}$ on arsenic speciation and solubility in a contaminated soil: Environmental Science and Technology, v. 25, p. 1414-19. 
McArthur, J. M., D. M. Banerjee, K. A. Hudson-Edwards, R. Mishra, R. Purohit, P. Ravenscroft, A. Cronin, R. J. Howarth, A. Chatterjee, T. Talukder, D. Lowry, S. Houghton, and D. K. Chadha, 2004, Natural organic matter in sedimentary basins and its relation to arsenic in anoxic ground water: the example of West Bengal and its worldwide implications: Applied Geochemistry, v. 19, p. 1255-1293.

McCarthy, J. F., B. Gu, L. Liang, J. Mas-Pla, T. M. Williams, and T. C. J. Yeh, 1996, Field tracer tests on the mobility of natural organic matter in a sandy aquifer: Water Resources Research, v. 32, p. 1223-1238.

McCarthy, J. F., and J. M. Zachara, 1989, Subsurface transport of contaminants: Environmental Science and Technology, v. 23, p. 496-502.

McLean, J. S., J. U. Lee, and T. J. Beveridge, 2002, Interactions of bacteria and environmental metals, fine-grained mineral development, and bioremediation strategies: IUPAC Series on Analytical and Physical Chemistry of Environmental Systems, v. 8, p. 227-261.

McSheehy, S., J. Szpunar, R. Morabito, and P. Quevauviller, 2003, The speciation of arsenic in biological tissues and the certification of reference materials for quality control: TrAC, Trends in Analytical Chemistry, v. 22, p. 191-209.

Mehta, O. P., and R. C. Khandelwal, 1980, Tracer study of adsorption isotherms: adsorption of sulfate ions on zinc, aluminum, copper and stainless steel surfaces: Indian Journal of Chemistry, Section A: Inorganic, Physical, Theoretical \& Analytical, v. 19A, p. 367-9.

Melamed, R., J. J. Jurinak, and L. M. Dudley, 1995, Effect of adsorbed phosphate on transport of arsenate through an Oxisol: Soil Science Society of America Journal, v. 59 , p. $1289-94$.

Michel, P., 1987, Arsenic in the marine environment: a bibliographic review: Revue des Travaux de l'Institut des Peches Maritimes, v. 49, p. 175-85.

Miretzky, P., M. C. Bisinoti, and W. F. Jardim, 2005, Sorption of mercury (II) in Amazon soils from column studies: Chemosphere, v. 60, p. 1583-1589.

Mok, W. M., and C. M. Wai, 1994, Mobilization of arsenic in contaminated river waters: Advances in Environmental Science and Technology, v. 26, p. 99-117.

Monks, C. D., M. G. Patterson, J. W. Wilcut, and D. P. Delaney, 1999, Effect of pyrithiobac, MSMA, and DSMA on cotton (Gossypium hirsutum L.) growth and weed control: Weed Technology, v. 13, p. 6-11. 
Mukhopadhyay, D., and S. K. Sanyal, 2004, Complexation and release isotherm of arsenic in arsenic-humic/fulvic equilibrium study: Australian Journal of Soil Research, v. 42, p. 815-824.

Mukhopadhyay, R., B. P. Rosen, L. T. Phung, and S. Silver, 2002, Microbial arsenic: from geocycles to genes and enzymes: FEMS Microbiology Reviews, v. 26, p. 311-325.

Murphy, R. J., J. J. Lenhart, and B. D. Honeyman, 1999, The sorption of thorium(IV) and uranium(VI) to hematite in the presence of natural organic matter: Colloids and Surfaces, A: Physicochemical and Engineering Aspects, v. 157, p. 47-62.

Newman, D. K., Ahmann, D., Morel F.M.M., 1998, A brief review of dissimilatory arsenate reduction.: Geomicrobiology Journal, v. 15, p. 255-268.

Nies, D. H., 1999, Microbial heavy metal resistance: Applied Microbiology and Biotechnology, v. 51, p. 730-750.

Oeman, C., and P. A. Hynning, 1993, Identification of organic compounds in municipal landfill leachates: Environmental Pollution (Oxford, United Kingdom), v. 80, p. 265-71.

Onken, B. M., and L. R. Hossner, 1996, Determination of arsenic species in soil solution under flooded conditions: Soil Science Society of America Journal, v. 60, p. 1385-1392.

Oremland, R. S., T. R. Kulp, J. S. Blum, S. E. Hoeft, S. Baesman, L. G. Miller, and J. F. Stolz, 2005, A Microbial Arsenic Cycle in a Salt-Saturated, Extreme Environment: Science (Washington, DC, United States), v. 308, p. 1305-1308.

Oremland, R. S., and J. F. Stolz, 2003, The Ecology of Arsenic: Science (Washington, DC, United States), v. 300, p. 939-944.

Oremland, R. S., J. F. Stolz, and J. T. Hollibaugh, 2004, The microbial arsenic cycle in Mono Lake, California: FEMS Microbiology Ecology, v. 48, p. 15-27.

Oscarson, D. W., P. M. Huang, U. T. Hammer, and W. K. Liaw, 1983, Oxidation and sorption of arsenite by manganese dioxide as influenced by surface coatings of iron and aluminum oxides and calcium carbonate: Water, Air, and Soil Pollution, v. 20 , p. $233-44$.

Ouvrard, S., M.-O. Simonnot, P. de Donato, and M. Sardin, 2002, Diffusion-Controlled Adsorption of Arsenate on a Natural Manganese Oxide: Industrial \& Engineering Chemistry Research, v. 41, p. 6194-6199. 
Patrick, W. H., Jr., and R. E. Henderson, 1981, A method for controlling redox potential in packed soil cores: Soil Science Society of America Journal, v. 45, p. 35-8.

Petrick, J. S., B. Jagadish, E. A. Mash, and H. V. Aposhian, 2001, Monomethylarsonous Acid (MMAIII) and Arsenite: LD50 in Hamsters and In Vitro Inhibition of Pyruvate Dehydrogenase: Chemical Research in Toxicology, v. 14, p. 651-656.

Picardal, F., and D. C. Cooper, 2005, Microbially mediated changes in the mobility of contaminant metals in soils and sediments: Heavy Metal Contamination of Soil, p. 43-88.

Pierce, M. L., and C. B. Moore, 1982, Adsorption of arsenite and arsenate on amorphous iron hydroxide: Water Research, v. 16, p. 1247-53.

Pigna, M., and A. Violante, 2003, Arsenate uptake in soil and minerals of variable requirements in the presence of polycarboxylic organic acids and phosphate: Agrochimica, v. 47, p. 103-111.

Planer-Friedrich, B., 2004, Volatile arsenic in aquatic environments: Freiberger Forschungshefte C, v. C503, p. i-xv,1-242.

Pokrovsky, O. S., and J. Schott, 2002, Iron colloids/organic matter associated transport of major and trace elements in small boreal rivers and their estuaries (NW Russia): Chemical Geology, v. 190, p. 141-179.

Pongratz, R., 1998, Arsenic speciation in environmental samples of contaminated soil: Science of the Total Environment, v. 224, p. 133-141.

Prasad, G., 1994, Removal of arsenic(V) from aqueous systems by adsorption onto some geological materials: Advances in Environmental Science and Technology, v. 26, p. 133-54.

Puls, R. W., C. J. Paul, and D. A. Clark, 1993, Surface chemical effects on colloid stability and transport through natural porous media: Colloids and Surfaces, A: Physicochemical and Engineering Aspects, v. 73, p. 287-300.

Raab, A., and J. Feldmann, 2003, Microbial transformation of metals and metalloids: Science Progress (St. Albans, United Kingdom), v. 86, p. 179-202.

Raven, K. P., A. Jain, and R. H. Loeppert, 1998, Arsenite and Arsenate Adsorption on Ferrihydrite: Kinetics, Equilibrium, and Adsorption Envelopes: Environmental Science and Technology, v. 32, p. 344-349. 
Reddad, Z., C. Gerente, Y. Andres, M.-C. Ralet, J.-F. Thibault, and P. Le Cloirec, 2002, $\mathrm{Ni}(\mathrm{II})$ and $\mathrm{Cu}(\mathrm{II})$ binding properties of native and modified sugar beet pulp: Carbohydrate Polymers, v. 49, p. 23-31.

Redman, A. D., D. L. Macalady, and D. Ahmann, 2002, Natural Organic Matter Affects Arsenic Speciation and Sorption onto Hematite: Environmental Science and Technology, v. 36, p. 2889-2896.

Rensing, C., M. Ghosh, and B. P. Rosen, 1999, Families of soft-metal-ion-transporting ATPases: Journal of Bacteriology, v. 181, p. 5891-5897.

Robinson, N. J., S. K. Whitehall, and J. S. Cavet, 2001, Microbial metallothioneins: Advances in microbial physiology, v. 44, p. 183-213.

Rosen, B. P., 2002, Biochemistry of arsenic detoxification: FEBS Letters, v. 529, p. 8692.

Saada, A., D. Breeze, C. Crouzet, S. Cornu, and P. Baranger, 2003, Adsorption of arsenic(V) on kaolinite and on kaolinite-humic acid complexes. Role of humic acid nitrogen groups: Chemosphere, v. 51, p. 757-763.

Sadiq, M., 1997, Arsenic chemistry in soils: an overview of thermodynamic predictions and field observations: Water, Air, and Soil Pollution, v. 93, p. 117-136.

Sakata, M., 1987, Relationship between adsorption of arsenic(III) and boron by soil and soil properties: Environmental Science and Technology, v. 21, p. 1126-30.

Samanta, G., T. R. Chowdhury, B. K. Mandal, B. K. Biswas, U. K. Chowdhury, G. K. Basu, C. R. Chanda, D. Lodh, and D. Chakraborti, 1999, Flow Injection Hydride Generation Atomic Absorption Spectrometry for Determination of Arsenic in Water and Biological Samples from Arsenic-Affected Districts of West Bengal, India, and Bangladesh: Microchemical Journal, v. 62, p. 174-191.

Sawhney, B. L., and R. P. Kozloski, 1984, Organic pollutants in leachates from landfill sites: Journal of Environmental Quality, v. 13, p. 349-52.

Schindler, P. W., and W. Stumm, 1987, The surface chemistry of oxides, hydroxides, and oxide minerals: Aquat. Surf. Chem., p. 83-110.

Schmitt, D., F. Saravia, F. H. Frimmel, and W. Schuessler, 2003, NOM-facilitated transport of metal ions in aquifers: importance of complex-dissociation kinetics and colloid formation: Water Research, v. 37, p. 3541-3550. 
Schuessler, W., R. Artinger, B. Kienzler, and J.-I. Kim, 2000, Conceptual Modeling of the Humic Colloid-Borne Americium(III) Migration by a Kinetic Approach: Environmental Science and Technology, v. 34, p. 2608-2611.

Shafer, M. M., S. R. Hoffmann, J. T. Overdier, and D. E. Armstrong, 2004, Physical and Kinetic Speciation of Copper and Zinc in Three Geochemically Contrasting Marine Estuaries: Environmental Science and Technology, v. 38, p. 3810-3819.

Shibata, Y., and M. Morita, 2000, Chemical forms of arsenic in the environment - with special emphasis in the marine environment: Biomedical Research on Trace Elements, v. 11, p. 1-24.

Siddique, T., Y. Zhang, B. C. Okeke, and W. T. Frankenberger, 2006, Characterization of sediment bacteria involved in selenium reduction: Bioresource Technology, v. 97, p. 1041-1049.

Silver, S., 1996, Bacterial resistances to toxic metal ions--a review: Gene, v. 179, p. 9-19.

Slaveykova, V. I., and K. J. Wilkinson, 2005, Predicting the Bioavailability of Metals and Metal Complexes: Critical Review of the Biotic Ligand Model: Environmental Chemistry, v. 2, p. 9-24.

Smedley, P. L., and D. G. Kinniburgh, 2002, A review of the source, behaviour and distribution of arsenic in natural waters: Applied Geochemistry, v. 17, p. 517-568.

Smith, E., R. Naidu, and A. M. Alston, 1999, Chemistry of arsenic in soils: I. Sorption of arsenate and arsenite by four Australian soils: Journal of Environmental Quality, v. 28 , p. $1719-1726$.

Snyder, R. H., 2003, Investigation of Coated Sands and Peat for Use in Putting Green Construction: Ph.D Dissertation thesis, University of Florida, Gainesville, Florida.

Sohrin, Y., M. Matsui, M. Kawashima, M. Hojo, and H. Hasegawa, 1997, Arsenic Biogeochemistry Affected by Eutrophication in Lake Biwa, Japan: Environmental Science and Technology, v. 31, p. 2712-2720.

Sposito, G., 1984, The Surface Chemistry of Soils, 304 pp p.

Stollenwerk, K. G., 2003, Geochemical processes controlling transport of arsenic in groundwater: a review of adsorption: Arsenic in Ground Water, p. 67-100.

Stuben, D., Z. Berner, D. Chandrasekharam, and J. Karmakar, 2003, Arsenic enrichment in groundwater of West Bengal, India: geochemical evidence for mobilization of As under reducing conditions: Applied Geochemistry, v. 18, p. 1417-1434. 
Stumm, W., John Wiley \& Sons: New York 1992, Chemistry of the solid-water interface: Processes at the mineral-water and particle-water interface in natural systems.: Chemistry of the solid-water interface: Processes at the mineral-water and particle-water interface in natural systems.

Styblo, M., L. M. Del Razo, L. Vega, D. R. Germolec, E. L. LeCluyse, G. A. Hamilton, W. Reed, C. Wang, W. R. Cullen, and D. J. Thomas, 2000, Comparative toxicity of trivalent and pentavalent inorganic and methylated arsenicals in rat and human cells: Archives of Toxicology, v. 74, p. 289-299.

Svendsen, L. M., A. Rebsdorf, and P. Nornberg, 1993, Comparison of methods for analysis of organic and inorganic phosphorus in river sediment: Water Research, v. 27 , p. $77-83$.

Swartz, C. H., and P. M. Gschwend, 1998, Mechanisms Controlling Release of Colloids to Groundwater in a Southeastern Coastal Plain Aquifer Sand: Environmental Science and Technology, v. 32, p. 1779-1785.

Takahashi, Y., Y. Minai, S. Ambe, Y. Makide, and F. Ambe, 1999, Comparison of adsorption behavior of multiple inorganic ions on kaolinite and silica in the presence of humic acid using the multitracer technique: Geochimica et Cosmochimica Acta, v. 63, p. 815-836.

Takamatsu, T., H. Aoki, and T. Yoshida, 1982, Determination of arsenate, arsenite, monomethylarsonate, and dimethylarsinate in soil polluted with arsenic: Soil Science, v. 133, p. 239-46.

Tamaki, S., and W. T. Frankenberger, Jr., 1992, Environmental biochemistry of arsenic: Reviews of Environmental Contamination and Toxicology, v. 124, p. 79-110.

Tchounwou, P. B., J. A. Centeno, and A. K. Patlolla, 2004, Arsenic toxicity, mutagenesis, and carcinogenesis - a health risk assessment and management approach: Molecular and Cellular Biochemistry, v. 255, p. 47-55.

Thanabalasingam, P., and W. F. Pickering, 1986, Arsenic sorption by humic acids: Environmental Pollution, Series B: Chemical and Physical, v. 12, p. 233-46.

Thelin, G. P., and L. P. Gianessi, 2000, Method for estimating pesticide use for county areas of the conterminous United states, U.S. Geological Survey Open-File Report 00-250, U.S. Geological Survey, chief of pesticide national synthesis: Sacramento, CA.

Thurman, E. M., 1985, Organic Geochemistry of Natural Waters, 512 pp p. 
Thurman, E. M., L. R. Zimmerman, E. A. Scribner, and R. H. Coupe, 1998, Occurrence of cotton pesticides in surface water of the Mississippi embayment.: U.S. Geological SurVey Fact Sheet; U.S. GPO: Washington, DC, 1998; FS-022-98.

Tlustos, P., W. Goessler, J. Szakova, and J. Balik, 2002, Arsenic compounds in leaves and roots of radish grown in soil treated by arsenite, arsenate and dimethylarsinic acid: Applied Organometallic Chemistry, v. 16, p. 216-220.

Toes, A. C. M., B. A. Maas, J. S. Geelhoed, J. G. Kuenen, and G. Muyzer, 2004, Interactions between microorganisms and heavy metals: European Symposium on Environmental Biotechnology, ESEB 2004, Proceedings, Oostende, Belgium, Apr. 25-28, 2004, p. 55-59.

Tossell, J. A., 1997, Theoretical studies on arsenic oxide and hydroxide species in minerals and in aqueous solution: Geochimica et Cosmochimica Acta, v. 61, p. 1613-1623.

Truitt, R. E., and J. H. Weber, 1981, Determination of complexing capacity of fulvic acid for copper(II) and cadmium(II) by dialysis titration: Analytical Chemistry, v. 53, p. 337-42.

Tseng, W. P., H. M. Chu, S. W. How, J. M. Fong, C. S. Lin, and S. Yeh, 1968, Prevalence of skin cancer in an endemic area of chronic arsenicism in Taiwan: Journal of the National Cancer Institute, v. 40, p. 453-63.

Turpeinen, R., M. Pantsar-Kallio, M. Haggblom, and T. Kairesalo, 1999, Influence of microbes on the mobilization, toxicity and biomethylation of arsenic in soil: Science of the Total Environment, v. 236, p. 173-180.

Turpeinen, R., M. Pantsar-Kallio, and T. Kairesalo, 2002, Role of microbes in controlling the speciation of arsenic and production of arsines in contaminated soils: Science of the total environment, v. 285, p. 133-45.

USGS, 1992, U.S. Geological Survey National Water Quality Assessment Program.

Velthorst, E. J., 1993, Manual for chemical water analysis, Department of Soil Science and Geology, Agricultural University, Wageningen, The Netherlands.: Manual for chemical water analysis, Department of Soil Science and Geology, Agricultural University, Wageningen, The Netherlands.

Vink, B. W., 1996, Stability relations of antimony and arsenic compounds in the light of revised and extended Eh-pH diagrams: Chemical Geology, v. 130, p. 21-30. 
Violante, A., M. Pigna, M. Ricciardella, and L. Gianfreda, 2002, Adsorption of phosphate on variable charge minerals and soils as affected by organic and inorganic ligands: Developments in Soil Science, v. 28A, p. 279-295.

Viraraghavan, T., Y. C. Jin, and P. M. Tonita, 1992, Arsenic in water supplies: International Journal of Environmental Studies, v. 41, p. 159-67.

Vorenhout, M., H. G. Van Der Geest, D. Van Marum, K. Wattel, and H. J. P. Eijsackers, 2004, Automated and continuous redox potential measurements in soil: Journal of Environmental Quality, v. 33, p. 1562-1567.

Wakui, Y., T. Ebina, H. Matsunaga, and T. M. Suzuki, 2002, Solvent extraction of arsenic(V) with dispersed ultrafine magnetite particles: Analytical Sciences, v. 18, p. 793-798.

Wakui, Y., E. Persulessy Anna, T. Ikeda, T. Ebina, Y. Onodera, and M. Suzuki Toshishige, 2005, Separation and enrichment of arsenic(V) with composite resin beads containing magnetite crystals: Analytical sciences: international journal of the Japan Society for Analytical Chemistry, v. 21, p. 433-5.

Wang, J. S., and C. M. Wai, 2004, Arsenic in drinking water - a global environmental problem: Journal of Chemical Education, v. 81, p. 207-213.

Wanibuchi, H., E. I. Salim, A. Kinoshita, J. Shen, M. Wei, K. Morimura, K. Yoshida, K. Kuroda, G. Endo, and S. Fukushima, 2004, Understanding arsenic carcinogenicity by the use of animal models: Toxicology and Applied Pharmacology, v. 198, p. 366-376.

Warwick, P., E. Inam, and N. Evans, 2005, Arsenic's Interaction with Humic Acid: Environmental Chemistry, v. 2, p. 119-124.

Waslenchuk, D. G., 1979, The geochemical controls on arsenic concentrations in southeastern United States rivers: Chemical Geology, v. 24, p. 315-25.

Waslenchuk, D. G., and H. L. Windom, 1978, Factors controlling the estuarine chemistry of arsenic: Estuarine and Coastal Marine Science, v. 7, p. 455-64.

Watanabe, C., K. Miyazaki, R. Ohtsuka, and T. Inaoka, 2001, Arsenic contamination of groundwater: a Bangladesh survey: RIKEN Review, v. 35, p. 19-22.

Wauchope, R. D., and L. L. McDowell, 1984, Adsorption of phosphate, arsenate, methanearsonate, and cacodylate by lake and stream sediments: comparisons with soils: Journal of Environmental Quality, v. 13, p. 499-504. 
Webb, J. L., 1966, Enzyme and Metabolic Inhibitors, Vol. 2: Malonate, Analogs, Dehydroacetate, Sulfhydryl Reagents, o-Iodosobenzoate, Mercurials; Vol. 3: Iodoacetate, Maleate, N-ethylmaleimide, Alloxan, Quinones, Arsenicals, 1237 pp; $1028 \mathrm{pp}$ p.

Welch, A. H., D. B. Westjohn, D. R. Helsel, and R. B. Wanty, 2000, Arsenic in ground water of the United States: occurrence and geochemistry: Ground Water, v. 38, p. 589-604.

Wiegand, G. E., 1999, Preliminary report: Environmental quality monitoring for pesticides and arsenic at five municipal golf courses in Miami-Dade County: Preliminary report: Environmental quality monitoring for pesticides and arsenic at five municipal golf courses in Miami-Dade County. Prepared by The Florida Department of Agriculture and Consumer Services (FDACS) and the Dade County Environmental Resources Management (DERM).

Wiese, A. F., and E. B. Hudspeth, Jr., 1968, Effects of DSMA [disodium methanearsonate] and MSMA [monosodium acid methanearsonate] on cotton yield and arsenic content of cottonseed, Southwestern Great Plains Res. Center,Texas Agr. Exp. Sta.,Bushland,TX,USA., p. 4 pp.

Wilkie, J. A., and J. G. Hering, 1996, Adsorption of arsenic onto hydrous ferric oxide: effects of adsorbate/adsorbent ratios and co-occurring solutes: Colloids and Surfaces, A: Physicochemical and Engineering Aspects, v. 107, p. 97-110.

Williams, C. F., J. Letey, and W. J. Farmer, 2002, Molecular weight of dissolved organic matter-napropamide complex transported through soil columns: Journal of Environmental Quality, v. 31, p. 619-627.

Williams, C. F., J. Letey, and W. J. Farmer, 2006, Estimating the potential for facilitated transport of napropamide by dissolved organic matter: Soil Science Society of America Journal, v. 70, p. 24-30.

Woolson, E. A., N. Aharonson, and R. Iadevaia, 1982, Application of the highperformance liquid chromatography-flameless atomic absorption method to the study of alkyl arsenical herbicide metabolism in soil: Journal of Agricultural and Food Chemistry, v. 30, p. 580-4.

Xu, H., B. Allard, and A. Grimvall, 1988, Influence of $\mathrm{pH}$ and organic substance on the adsorption of arsenic(V) on geologic materials: Water, Air, and Soil Pollution, v. 40, p. 293-305.

Xu, H., B. Allard, and A. Grimvall, 1991, Effects of acidification and natural organic materials on the mobility of arsenic in the environment: Water, Air, and Soil Pollution, v. 57-58, p. 269-78. 
Yariv, S., and H. Cross, 1979, Geochemistry of Colloid Systems for Earth Scientists, 450 pp p.

Yokota, H., K. Tanabe, M. Sezaki, Y. Yano, K. Hamabe, K. Yabuuchi, and H. Tokunaga, 2002, Arsenic contamination in groundwater of Samta, Bangladesh: Water Science and Technology, v. 46, p. 375-380.

Yokoyama, T., Y. Takahashi, and T. Tarutani, 1993, Simultaneous determination of arsenic and arsenious acids in geothermal water: Chemical Geology, v. 103, p. 103-111.

Zhang, H., and H. M. Selim, 2005, Kinetics of Arsenate Adsorption-Desorption in Soils: Environmental Science and Technology, v. 39, p. 6101-6108.

Zhou, L. X., and J. W. C. Wong, 2003, Behavior of heavy metals in soil: effect of dissolved organic matter: Geochemical and Hydrological Reactivity of Heavy Metals in Soils, p. 245-269.

Zobrist, J., P. R. Dowdle, J. A. Davis, and R. S. Oremland, 2000, Mobilization of Arsenite by Dissimilatory Reduction of Adsorbed Arsenate: Environ. Sci. Technol., v. 34, p. 4747-4753. 


\section{APPENDIX}

\section{Supplemental Information for Chapter 4}

a) Conceptual model of kinetically controlled availability model, modified from Schuessler et al's KICAM (Schuessler et al., 2000)

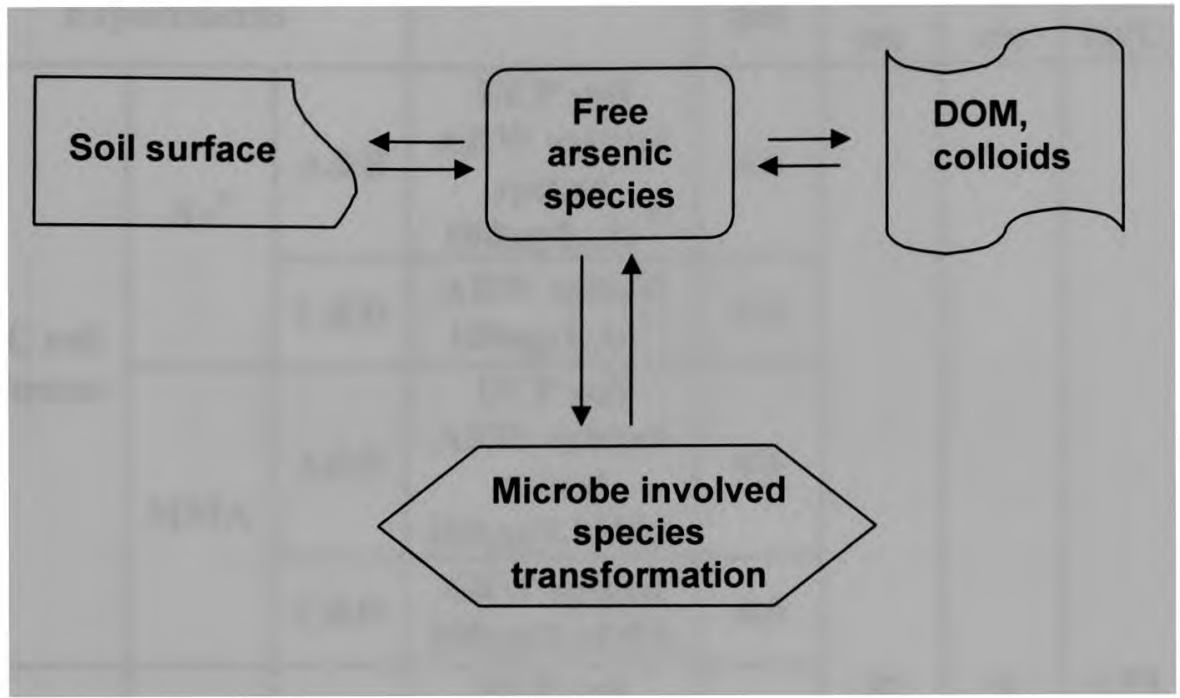


b) Column transport experimental design

\begin{tabular}{|c|c|c|c|c|c|c|c|c|c|}
\hline \multicolumn{10}{|c|}{$\begin{array}{l}\text { Transport Experiments: Column Properties, Flow Conditions, and Composition of } \\
\text { the Feed Solution }\end{array}$} \\
\hline & & & \multicolumn{2}{|c|}{ Influent composition } & \multicolumn{5}{|c|}{ Column parameters } \\
\hline \multicolumn{3}{|c|}{ Experiments } & & pH & $\begin{array}{l}\mathbf{L}, \\
\mathbf{c m}\end{array}$ & $\begin{array}{l}\mathbf{D}, \\
\mathbf{c m}\end{array}$ & $\begin{array}{c}\rho, \\
\mathrm{kg} / \mathrm{L}\end{array}$ & pv, & $\begin{array}{c}V_{p} \\
(\mathbf{c m} / \mathbf{h r})\end{array}$ \\
\hline \multirow{4}{*}{$\begin{array}{l}\text { UC soil } \\
\text { columns }\end{array}$} & \multirow[t]{2}{*}{$\mathrm{As}^{\mathrm{V}}$} & A\&B & $\begin{array}{c}\text { UCP soil } \\
\text { ARW extract } \\
\text { spiked } \\
100 \mu \mathrm{g} / \mathrm{L} \mathrm{As} \\
\end{array}$ & 4.6 & & & & & \\
\hline & & C\&D & $\begin{array}{l}\text { ARW spiked } \\
100 \mu \mathrm{g} / \mathrm{LAs} v\end{array}$ & 4.0 & & & & & \\
\hline & \multirow[t]{2}{*}{ MMA } & A\&B & $\begin{array}{c}\text { UCP soil } \\
\text { ARW extract } \\
\text { spiked } \\
100 \mu \mathrm{g} / \mathrm{LMMA} \\
\end{array}$ & 4.6 & & & & & \\
\hline & & C\&D & $\begin{array}{c}\text { ARW spiked } \\
100 \mu \mathrm{g} / \mathrm{LMMA}\end{array}$ & 4.0 & & & & & \\
\hline \multirow{4}{*}{$\begin{array}{l}\text { NC soil } \\
\text { columns }\end{array}$} & \multirow[t]{2}{*}{$\mathrm{As}^{\mathrm{V}}$} & A\&B & $\begin{array}{c}\text { NCP soil } \\
\text { ARW extract } \\
\text { spiked } \\
200 \mu \mathrm{g} / \mathrm{LAs} \mathrm{V} \\
\end{array}$ & 6.0 & 31 & 5 & 1.72 & 180 & 0.625 \\
\hline & & C\&D & $\begin{array}{l}\text { ARW spiked } \\
200 \mu \mathrm{g} / \mathrm{L} \mathrm{As} \mathrm{v}^{\mathrm{v}}\end{array}$ & 4.1 & & & & & \\
\hline & \multirow[t]{2}{*}{ MMA } & $A \& B$ & $\begin{array}{c}\text { NCP soil } \\
\text { ARW extract } \\
\text { spiked } \\
200 \mu \mathrm{g} / \mathrm{L} \\
\text { MMA } \\
\end{array}$ & 6.0 & & & & & \\
\hline & & C\&D & $\begin{array}{c}\text { ARW spiked } \\
200 \mu \mathrm{g} / \mathrm{LMMA}\end{array}$ & 4.1 & & & & & \\
\hline
\end{tabular}

${ }^{\mathrm{a}} \mathrm{L}$ ) length, D) diameter, $\mathrm{p}$ ) mass of soil per pore volume, $\mathrm{pv}$ ) pore volume, $\mathrm{Vp}$ ) pore water velocity 
c) Arsenic concentration (nitric acid digestion results) on different section of column soil at the end of column experiments
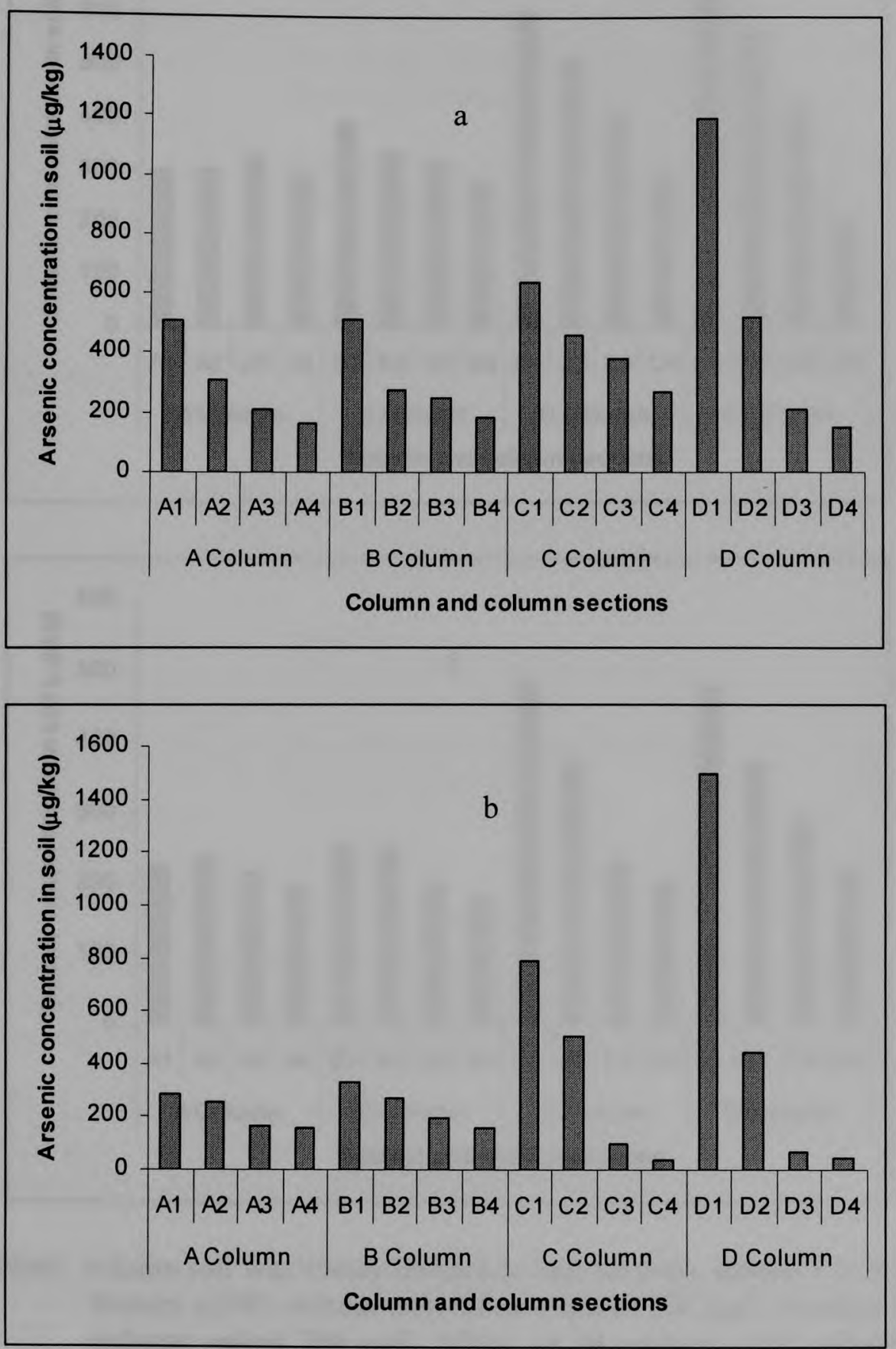

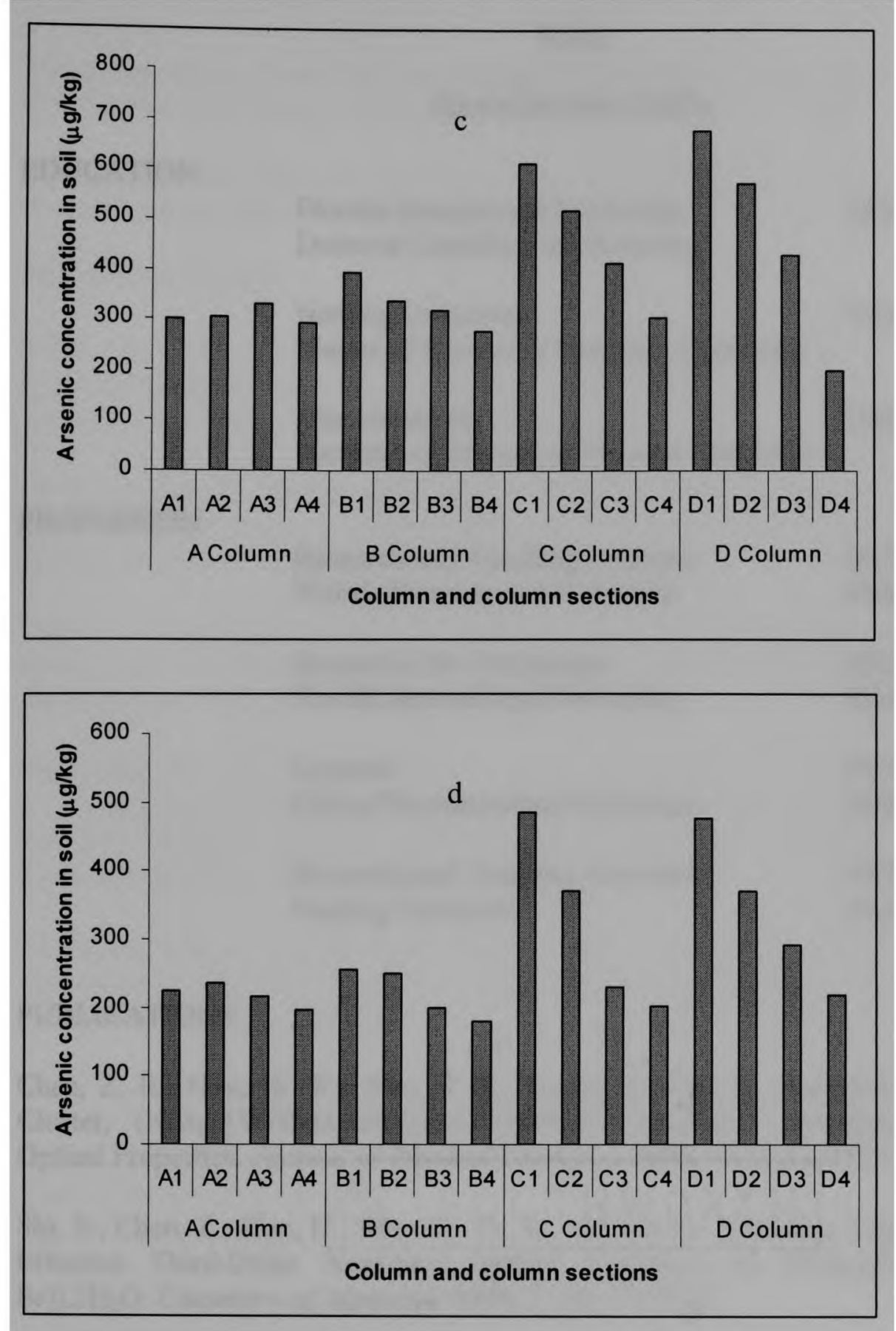

Note: column soil was evenly divided to four sections, named 1 to 4 from column top to bottom. a) NC column with influent spiked $200 \mu \mathrm{g} / \mathrm{L}$ arsenate, b) NC column with influent spiked $200 \mu \mathrm{g} / \mathrm{L}$ MMA, c) UC column with influent spiked $100 \mu \mathrm{g} / \mathrm{L}$ arsenate and d) UC column with influent spiked $100 \mu \mathrm{g} / \mathrm{L} \mathrm{MMA.}$ 


\section{VITA}

\section{ZHANGRONG CHEN}

EDUCATION

Florida International University

Doctoral Candidate in Chemistry

Nanjing University

Master of Science in Inorganic Chemistry

Jilin University

Bachelor of Science in Physical Chemistry

Miami, FL

July 2006

Nanjing, China July 1994

Changchun, China July 1991

PROFESSION

Research and Teaching Assistant

Florida International University

Research Lab Technician

Florida International University

Lecturer

China Pharmaceutical University

Research and Teaching Assistant Nanjing University
06/2002 - Present

Miami, FL

03/2001-04/2002

Miami, FL

09/1994-10/2000

Nanjing, P.R. China

09/1992-01/1993

Nanjing, P.R. China

\section{PUBLICATIONS}

Chen, Z. R.; Hou, H. W.; Xin, X. Q.; Yu, K. B.; Shi, S., A Half-Open Cage-Shaped Cluster, $\left(\mathrm{NEt}_{4}\right)_{3}\left[\mathrm{WOS}_{3}(\mathrm{CuBr})_{3}(\mathrm{~m} 2-\mathrm{Br})\right] \cdot 2 \mathrm{H}_{2} \mathrm{O}$ : Synthesis, Structure, and Nonlinear Optical Properties. Journal of Physical Chemistry 1995, 99, (21), 8717-21.

Shi, S.; Chen, Z.; Hou, H.; Xin, X.; Yu, K., Solid-State Synthesis, Crystal Structure, and Effective Third-Order Nonlinear Optical Properties of $\left(\mathrm{NEt}_{4}\right)_{3}\left[\mathrm{MoOS}_{3} \mathrm{Cu}_{3} \mathrm{Br}_{3}(\mathrm{~m} 2-\right.$ $\mathrm{Br})] .2 \mathrm{H}_{2} \mathrm{O}$. Chemistry of Materials 1995, 7, (8), 1519-24.

Chen, Z.; Xu, K.; Wu, H., Cheng, Y., The Flocculation of Chitosan on Water Extract of Scutellaria Baicalensis. Journal of China Pharmaceutical University 1999, 30, (3), 227 230.

Chen, Z., Y. Cai, H. Solo-Gabriele, G. H. Snyder, and J. L. Cisar, 2006, Interactions of Arsenic and the Dissolved Substances Derived from Turf Soils: Environmental Science \& Technology, v. In press. 
Zhangrong Chen, Yong Cai, and George Snyder, Arsenic Transport and Speciation in Golf Course Soils Using Column Experiment. To be submitted 2006.

Zhangrong Chen, Alejandro Jaramijjo, Yong Cai, and George Snyder, Partitioning of Arsenic Species in Soils Used in Golf Course. To be submitted 2006.

\section{PRESENTATIONS}

Chen, Z.; Cai, Y., Organic acids and amino acids in Brake fern, an arsenic hyperaccumulator. Abstracts of Papers, 223rd ACS National Meeting, Orlando, FL, United States, April 7-11, 2002 2002, ANYL-019.

Chen, Z.; Cai, Y., Binding of arsenic to dissolved colloidal materials derived from golf course soils. Abstracts of Papers, 226th ACS National Meeting, New York, NY, United States, September 7-11, 2003 2003, GEOC-091.

Chen, Z.; Jaramillo, A.; Cai, Y.; Snyder, G. H., Partitioning of arsenic species in soils used in golf courses. Abstracts of Papers, 229th ACS National Meeting, San Diego, CA, United States, March 13-17, 2005 2005, ENVR-057.

Hernandez, D.; Liu, G.; Schrlau, J. E.; Chen, Z.; Guanira, K.; Cai, Y.; Allen, M.; Moos, L., Arsenic leachability from coal fly ash. Preprints of Extended Abstracts presented at the ACS National Meeting, American Chemical Society, Division of Environmental Chemistry 2005, 45, (1), 456-460.

Zhangrong Chen, Yong Cai, and George Snyder, Assessment of Arsenic Transport and Speciation in Golf Course Soils Using Column Experiments. SETAC North American $26^{\text {th }}$ Annual Meeting, Baltimore, Maryland, United States, November 13-17, 2005.

Yong Cai, Zhangrong Chen, and George Snyder, Arsenic Transport and Transformation in Golf Course Soils Associated with MSMA Application - from Field to Laboratory Studies. SETAC North American $26^{\text {th }}$ Annual Meeting, Baltimore, Maryland, United States, November13-17, 2005. 